\title{
REGULATION OF $\beta 1$ INTEGRIN TRAFFIC AND ARF6 GTPASE BY AMP-ACTIVATED PROTEIN KINASE
}

by

Rehman Ata, BSc Ryerson University 2014

\author{
A thesis \\ presented to Ryerson University \\ in partial fulfillment of the \\ requirements for the degree of \\ Master of Science \\ in the Program of \\ Molecular Science
}

Toronto, Ontario, Canada, 2016

(C) Rehman Ata 2016 


\section{AUTHOR'S DECLARATION FOR ELECTRONIC SUBMISSION OF A THESIS}

I hereby declare that I am the sole author of this thesis. This is a true copy of the thesis, including any required final revisions, as accepted by my examiners.

I authorize Ryerson University to lend this thesis to other institutions or individuals for the purpose of scholarly research.

I further authorize Ryerson University to reproduce this thesis by photocopying or by other means, in total or in part, at the request of other institutions or individuals for the purpose of scholarly research.

I understand that my thesis may be made electronically available to the public. 


\title{
Abstract \\ Regulation of $\beta 1$ Integrin Traffic and Arf6 GTPase by AMP-activated Protein Kinase
}

\author{
Rehman Ata \\ Master of Science, Molecular Science, Ryerson University 2016
}

Integrins are cell surface receptors that physically bridge the extracellular matrix to the cytoskeleton and responsible for adhesion, migration, and signaling. Integrin function is intimately controlled by their membrane traffic. For example, integrins are dynamically internalized from the cell posterior and recycled to the cell anterior during cell migration. Misregulation of integrins is intimately linked with cancer progression, including metastasis and cell proliferation and survival. We have recently uncovered that integrin membrane traffic is controlled by AMP-activated protein kinase (AMPK), an energy stress sensing kinase within cells at becomes activated upon energy stress such as by an increase in cell AMP:ATP ratio. I confirmed that AMPK activation resulted in a reduction of cell surface $\beta 1$-integrin. Using assays that selectively measure integrin exocytosis and endocytosis, I found that AMPK activation regulates $\beta 1$-integrin recycling and possibly endocytosis. I demonstrated that AMPK regulates Arf6 localization, a key protein which regulates $\beta 1$-integrin membrane traffic. I confirmed that Arf6 and clathrin are involved in reciprocal regulation, thus highlighting the possible pathway for $\beta 1$-integrin regulation by AMPK. 


\section{Acknowledgements}

I would like to thank Dr. Costin N. Antonescu for his excellence as a mentor and a professor. Without his guidance and support throughout this arduous degree, this journey would have been much more difficult. It has been an honour taking up the mantle of AMPK research from my predecessor, and I look forward to passing on the project to capable hands.

I would also like to thank my supervisory committee members Dr. Andras Kapus and Dr. Sarah Sabatinos, for they continually offered their support and challenged me throughout this degree.

It is with utmost sincerity that I would like to thank my colleagues and friends in Molecular Science who have supported me throughout the last two years. I simply would not have been able to accomplish this without their patience, guidance and heart. You all are truly special for sticking by me - you know who you are.

I would not be standing here, had the two bravest individuals I know, decided not to make the incredible sacrifice of leaving their friends and family behind, and immigrating to Canada in 1998. To my parents, Atta Ullah and Nyla Ata, I am forever in debt for your selflessness, bravery and heart.

Lastly, I would like to thank my best friend and brother, Marco Cirone. Without your support and presence, I'm not sure where I would be. I am truly fortunate to be able to surround myself with incredible people. 


\section{Table of Contents}

ABSTRACT III

\begin{tabular}{ll} 
ACKNOWLEDGEMENTS & IV \\
\hline
\end{tabular}

\begin{tabular}{lc} 
LIST OF TABLES & VII \\
\hline
\end{tabular}

\begin{tabular}{lc} 
LIST OF FIGURES & VIII \\
\hline
\end{tabular}

LIST OF ABBREVIATIONS IX IX

\begin{tabular}{lc} 
INTRODUCTION & 1 \\
\hline
\end{tabular}

EXECUTIVE SUMMARY OF INTRODUCTION

1 Cell homeostasis and Cell Stress $\quad 3$

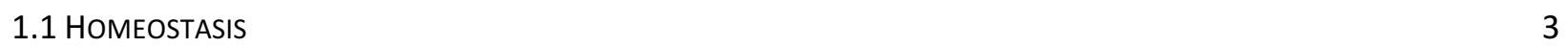

1.2 ATP SYNTHESIS $\quad 4$

1.3 METABOLIC STRESS $\quad 8$

2 AMP-Activated Protein KINASE $\quad 9$

2.1 AMPK REGULATION $\quad 10$

$\begin{array}{ll}2.2 \text { SUBSTRATES \& TARGETS OF AMPK } & 13\end{array}$

2.3 PHYSIOLOGICAL SIGNIFICANCE OF AMPK

3 MEMBRANE TRAFFIC $\quad 20$

3.1 CLATHRIN MEDIATED ENDOCYTOSIS $\quad 20$

3.2 CLATHRIN COAT VESICLE FORMATION

3.3 SMALL GTPASES: RAB \& ARF $\quad 25$

3.4 ROUTES OF INTERNALIZATION AND RECYCLING USING ARF AND RAB GTPASES

4 INTEGRINS $\mathbf{2 9}$

4.1 STRUCTURE AND FUNCTION

4.2 INTEGRIN TRAFFICKING

4.3 CELL MigRATION

5 CONTROL OF CELL MIGRATION DURING METABOLIC STRESS

5.1 AMPK \& CONTROL OF $\beta 1$-INTEGRIN 36

RATIONALE \& HYPOTHESIS $\quad 39$

MATERIALS \& METHODS

RPE CELL CULTURE AND PHARMACOLOGICAL TREATMENTS

CDNA TRANSFECTION

SIRNA TRANSFECTION

TOTAL AND CELL SURFACE IMMUNOFLUORESCENCE ASSAY 43

ENDOCYTOSIS ASSAY

ANTIBODY RECYCLING ASSAY

WIDEFIELD EPIFLUORESCENCE IMAGING 45

CELl SURFACE AND TOtAL STAINING ABUNDANCE QUANTIFICATION

Cell Migration Assay

CELL VIABILITY ASSAY 
RESULTS PART I: AMPK REGULATES $\beta$ 1-INTEGRIN ON THE CELL SURFACE \& CELL MIGRATION

AMPK IS REQUIRED FOR $\beta 1$-INTEGRIN CELL SURFACE REDUCTION

AMPK ACTIVATION BY A-769662 HINDERS MIGRATION OF RPE-WT CELLS

LONG TERM AMPK ACTIVATION BY A-769662 DOES NOT AFFECT CELL VIABILITY

RESULTS PART II: AMPK ACTIVATION CONTROLS SPECIFIC STAGES OF $\boldsymbol{\beta} 1$-INTEGRIN MEMBRANE TRAFFIC

ACUTE AMPK ACTIVATION DOES NOT APPRECIABLY ALTER THE RATE OF $\beta 1$-INTEGRIN ENDOCYTOSIS

RESULTS PART III: REGULATION OF ARF6 GTPASE BY AMPK

DISCUSSION

REGULATION OF $\boldsymbol{\beta} 1$-INTEGRIN BY AMP-ACTIVATED PROTEIN KINASE (AMPK)

AMPK REGULATION OF $\beta$ 1-INTEGRIN ENDOCYTOSIS

AMPK REGULATES $\beta 1$-INTEGRIN RECYCLING BUT NOT TRANSFERRIN RECEPTOR RECYCLING 86

AMPK REGULATION OF ARF6 TO CONTROL $\beta 1$-INTEGRIN TRAFFICKING 88

AMPK AND ARFS REGULATION OF CCPS AND ENDOCYTOSIS 93

\begin{tabular}{ll} 
CONCLUSION & 97 \\
\hline
\end{tabular}

\begin{tabular}{l} 
REFERENCES \\
\hline
\end{tabular} 


\section{List of tables}

Table 1 - ArfGAPs removed from the cell surface upon treatment with A-769662.............66 


\section{List of figures}

Figure 1 - Glycolysis, Krebs cycle \& Oxidative phosphorylation...............................................5

Figure 2 - AMPK allosteric regulation by AMP ADP \& ATP binding ........................................12

Figure 3 - Membrane traffic of $\beta 1$-integrins by Arf \& Rabs...................................................28

Figure 4 - Cell migration requires integrin trafficking........................................................

Figure $\mathbf{5}$ - Inhibition of AMPK by siRNA gene silencing prevents the reduction in cell surface $\beta 1$-integrin elicited by A-769662 treatment..............................................................54

Figure 6 - Activation or inhibition of AMPK does not lead to $\beta 1$-integrin degradation.......55

Figure 7 - A-769662 treatment does not affect cell area......................................................56

Figure 8 - Treatment with A-769662 reduces cell migration..................................................57

Figure 9 - Treatment with AMPK activators does not alter cell viability...............................59

Figure 10 - Acute AMPK activation (15 min) does not affect $\beta 1$-integrin endocytosis........64

Figure 11 - $\beta 1$-integrin recycling is hindered by AMPK activation........................................65

Figure 12 - Transferrin receptor recycling is unaffected by AMPK activation.......................66

Figure 13 - AMPK activation by A-769662 regulates Arf6-GTP binding.................................72

Figure 14 - QS11 treatment reduces the abundance of cell surface $\beta 1$-integrin...................73

Figure 15 - QS11 treatment hinders $\beta 1$-integrin endocytosis...............................................74

Figure 16 - AMPK activation by A-769662 treatment decreases GFP-Arf6-WT recruitment

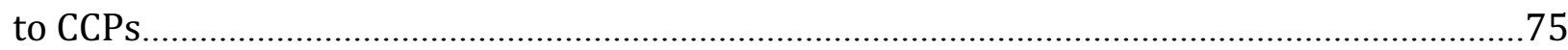

Figure 17 - AMPK activation does not affect GFP-Arf6-GTP-locked mutant recruitment to

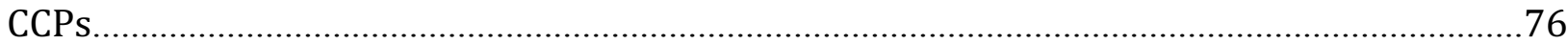

Figure 18 - Arf6 regulates clathrin assembly in clathrin coated pits...................................79

Figure 19 - Proposed model for AMPK and Arf6 on $\beta 1$-integrin regulation...........................96 


\section{List of abbreviations}

ACC - Acetyl-CoA carboxylase

ADP - Adenosine diphosphate

AgRP - Agouti-related protein-expressing neuron

AICAR - 5-Aminoimidazole-4-carboxamide ribonucleotide; AICA ribonucleotide; Acadesine

AMP - Adenosine monophosphate

AMPK - AMP-activated protein kinase

ANOVA - Analysis of variance

ANTH - AP180 amino-terminal homology

AP-2 - Adaptor complex 2

Arf - ADP-ribosylation factor

Arp 2/3 - Actin related protein 2/3

ATP - Adenosine triphosphate

BSA - Bovine Serum Albumin

CaMKK - $\mathrm{Ca}^{2+} /$ calmodulin-dependent kinase kinase

CBM - Carbohydrate binding domain

CBS - Cystathionine beta synthase

CCP - Clathrin coated pit

CCV - Clathrin coated vesicle

CD36 - Fatty acid translocase

CHC - Clathrin heavy chain

CLC - Clathrin light chain

CLIC3 - Chloride intracellular channel protein 3

CME - Clathrin mediated endocytosis

CPT1 - Carnitine palmitoyltransferase 1

CTD - C-terminal domain

DTT - Dithiothreitol

ECM - Extracellular matrix

eEF2 - Eukaryotic elongation factor 2 kinase

EGF - Epidermal growth factor 
EGFR - Epidermal growth factor receptor

ENTH - Epsin N-terminal homology

EPS15 - EGFR pathway substrate 15

ETC - Electron transport chain

FCHo - FCH domain only protein

FAD/FADH $H_{2}$ - Flavin adenine dinucleotide

FAT4 - FAT tumour suppressor homolog 4

FAK - Focal adhesion kinase

FBS - Fetal bovine serum

G-clathrin - Gyrating clathrin

GAP - GTPase activating protein

GEF - Guanyl exchange factor

GDI - GDP-dissociation inhibitors

GFS - GDI displacement factors

GDP - Guanosine diphosphate

GFP - Green fluorescent protein

GHSR - Growth hormone secretagogue receptor type 1

GLUT-1 - Glucose transporter 1

GLUT-4 - Glucose transporter 4

GTP - Guanosine triphosphate

HSC70 - Heat shock cognate 90

IMAC - Immobilixed metal ion chromatography

LKB1 - Liver kinase B1

LSB - Laemmli Sample Buffer

MHC - Major Histocompatibility Complex

M025 - Mouse protein 25

MS - Mass spectrometry

mTOR - Mammalian target of rapamycin

NA - Numerical Aperture

$\mathrm{NAD}^{+} / \mathrm{NADH}$ - Nicotinamide adenine dinucleotide

NPY - Neuropeptide Y 
NT - Non-targetting

PBS - Phosphate buffered saline

Pdlim5 - PDZ and LIM domain 5

PFA - Paraformaldehyde

PI - Propidium iodide

PI4P - Phosphatidylinositol-(4)-bisphosphate

PI(4,5)P2 - Phosphatidylinositol-(4,5)-bisphosphate

PIP5K - Phosphatidylinositol-4-phosphate-5-kinase xii

PKA - Protein kinase A

PM - Plasma membrane

POMC - pro-opiomelanocortin-expressing neurons

PNRC - Perinuclear recycling compartments

PSF - Point-spread function

Q - Ubiquinone

$\mathrm{QH}_{2}$ - Ubiquinol

RFP - Red fluorescent protein

RPE - Retinal pigment epithelial cells

SDS - Sodium dodecyl sulfate

SDS PAGE - SDS Polyacrylamide gel electrophoresis

SH3 - Src homology 3

siRNA - Silencing RNA

SNX9 - Sorting nexin 9

STRAD - STE20-related kinase adaptor protein

TBC1D1 - TBC1 domain family member 1

TBC1D4 - TBC1 domain family member 4

TfR - Transferrin receptor

TIRFM - Total internal reflection fluorescence microscopy

TXNIP - Thioredoxin-interacting protein

WT - Wildtype

VALAP - Vaseline, Lanolin, Parafin wax 


\section{Introduction}

\section{Executive Summary of introduction}

In this study, I will discuss cellular stress and its implications for whole cell physiology. A major type of physiologically significant cellular stress is energetic stress, in which there is a significant decrease in ATP concentration. ATP is generated by glycolysis and oxidative phosphorylation, but can also be synthesized by oxidation of fatty acids. For a cell to regulate levels of ATP, it requires an ATP sensor. In all eukaryotic cells, this is AMPactivated protein kinase (AMPK). AMPK is activated when cells are experiencing energetic (or other types of) stress, to rectify the energetic stress and establish homeostasis. It performs this by limiting processes which are energy consuming (anabolic) and increasing pathways involved in energy creation (catabolic). A significant, but not well understood, role of AMPK in limiting anabolic and increasing catabolic processes, is the regulation of the cell surface proteome. In short, our understanding of how cell metabolism and metabolic signaling affects membrane traffic is currently quite limited. A few notable examples of the AMPK regulation of membrane traffic are the increase of GLUT transporters on the cell surface, and the decrease of $\mathrm{Na}^{+} / \mathrm{K}^{+}$ATPase upon AMPK activation. A major regulator of cell surface membrane traffic is clathrin-mediated endocytosis, and the small GTPases ADPribosylation factors (Arfs) and Rabs. These regulate the membrane traffic of a variety of proteins, such as transferrin receptors (TfR) and integrins. Interestingly, integrins were shown to be regulated by metabolism (specifically, AMPK activation) through an unknown pathway (Ross et al., 2015). Integrins are involved in cell adhesion, migration, signaling but can also be involved in tumourigenesis when misregulated. How AMPK regulates integrins is not known and is explored in this study. 
The proteins found on the cell surface (collectively termed the cell surface proteome) are involved in numerous processes such as nutrient transport, signaling, and cell adhesion. Availability of these proteins at the cell surface controls their function, as many of these proteins have a primary function that they are no longer able to perform if internalized into the cell. For example, nutrient transporters require access to substrates in the extracellular milieu, and adhesion molecules require access to extracellular matrix (ECM) contact sites (Shaw et al. 2004; Caswell et al. 2009).

The cell surface proteome is a dynamically regulated compartment, which allows it to be regulated by a variety of cellular processes and cues during changing cellular conditions. For example, remodelling the cell surface proteome is required during mammalian erythropoiesis - the production of red blood cells (Wraith \& Chesterton 1982). During mammalian erythropoiesis, erythroblasts (immature red blood cells containing a nucleus) give rise to reticulocytes (immature red blood cells lacking a nucleus), which leave the bone marrow and mature into circulating erythrocytes (Wraith \& Chesterton 1982). Leaving the bone marrow and entering circulation is paired with two major plasma membrane events for erythrocytes: 1) forming the disc shape via changes in the cytoskeleton and 2) loss of erythroblast-specific proteins from the cell surface. The loss of erythroblast proteins occurs through endocytic events between the reticulocyte and circulating erythrocyte stage (Wraith \& Chesterton 1982). This flexibility of the cell surface proteome has many other functions during development (Artavanis-tsakonas et al. 1999; Yan et al. 2010). Importantly, the plasticity of the plasma membrane with regards to protein content and regulation is very important in adult organisms, as this phenomenon 
allows cells to survive a variety of differing metabolic and environmental conditions such as ischemia, hypoxia and energy stress. Understanding how the cell surface proteome is dynamically regulated by cellular cues, such as metabolism and energy stress is a fundamentally important question in biology.

\section{Cell Homeostasis and Cell Stress}

\subsection{Homeostasis}

Within every cell, a balance of ATP $\leftrightarrow$ ADP + Pi exists. This reaction exists in a state that is far away from equilibrium, as the cell maintains a high concentration of ATP to ADP at 10:1 (Hardie et al. 2012). Favouring of ATP in equilibrium is necessary to maintain cell homeostasis and drive energy-requiring processes. In all eukaryotic cells, adenylate kinase is highly expressed, which catalyses the reversible reaction 2ADP $\leftrightarrow$ ATP + AMP close to equilibrium (separate from the ATP $\leftrightarrow$ ADP + Pi reaction) (Hardie et al. 2012). If the concentration of ADP rises (meaning ATP levels are decreasing) the adenylate kinase reaction shifts away from equilibrium and now favours the production of ATP + AMP at a 1:1 ratio (Hardie et al. 2012). The rate of ATP production through this reaction is not able to offset the energy deficiency in cells. Therefore, when a cell begins to lose energy, AMP and ADP concentrations rise, signaling metabolic stress. 


\subsection{ATP synthesis}

\subsubsection{Glycolysis}

ATP generation starts with the consumption of glucose by glycolysis to generate ATP and NADH (Li et al. 2015). Briefly, in the energy investment stage, glucose is converted to fructose-1,6-bisphosphate while consuming 2 ATP molecules in the process. In the next few reactions, dubbed the energy harvesting stage, 2 molecules of NADH and 4 molecules ATP are generated (Li et al. 2015). This gives a net gain of 2 molecules of ATP, NADH and pyruvate for glycolysis. This production of ATP from glucose as a result of glycolysis is limited, and cells must either have a massive rate of transport of glucose from the extracellular milieu, or must use additional metabolic pathways to further metabolize pyruvate (Li et al. 2015). Most healthy cells in adult organisms do the latter, where the bulk of ATP comes from Acetyl-CoA metabolism in the mitochondria, through the action of the Kreb's cycle and oxidative phosphorylation (Akram 2014). Pyruvate is oxidized to AcetylCoA, generating another molecule of NADH. Acetyl-CoA then enters the Kreb's cycle, in which acetyl-CoA undergoes 8 different reactions to ultimately generate 3 molecules of NADH, 1 molecule of $\mathrm{FADH}_{2}$ and 1 molecule of ATP per cycle (Fig 1A) (Akram 2014). In total, the Krebs cycle generates $6 \mathrm{NADH}, 2 \mathrm{FADH}_{2}$, and $2 \mathrm{ATP}$ - as 2 acetyl-CoA molecules enters the Krebs cycle per glucose (Akram 2014). From here, the NADH and $\mathrm{FADH}_{2}$ made from glycolysis (2 NADH), the conversion of pyruvate to acetyl-CoA (2 NADH) and the Krebs cycle (6 $\mathrm{NADH}$ and $2 \mathrm{FADH}_{2}$ ) are used in the electron transport chain (ETC) (Sazanov 2015). 


\section{Fig 1. Glycolysis, Krebs cycle \& Oxidative phosphorylation}

Glycolysis reactions take place in the cytoplasm and it produce 2 molecules of pyruvate, 2 $\mathrm{NADH}$ and 2 ATP. The pyruvate then enters the mitochondria where it is converted to acetyl-CoA and undergoes the 8 step Krebs cycle. This produces 3 NADH, $2 \mathrm{FADH}_{2}$ and 1 ATP per molecule of pyruvate. NADH and $\mathrm{FADH}_{2}$ then enter the Electron Transport Chain. The ETC consists of 5 membrane protein complexes: Complex I, II, III, IV, and ATPase synthase. Two transport proteins ubiquinone (Q) and cytochrome $\mathrm{c}$ are also involved. The ETC carries the electrons from NADH and FADH2 throughout the complexes to pair proton movement across the inner mitochondrial membrane to establish a proton gradient. This gradient is used by ATPase synthase to create ATP at the end of the chain. Oxygen is also required for the ETC (thus the name, oxidative phosphorylation), as it acts as the final electron acceptor on complex IV. When oxygen is not sufficient in a cell, the ETC shuts down as it can no longer carry electrons throughout the ETC.
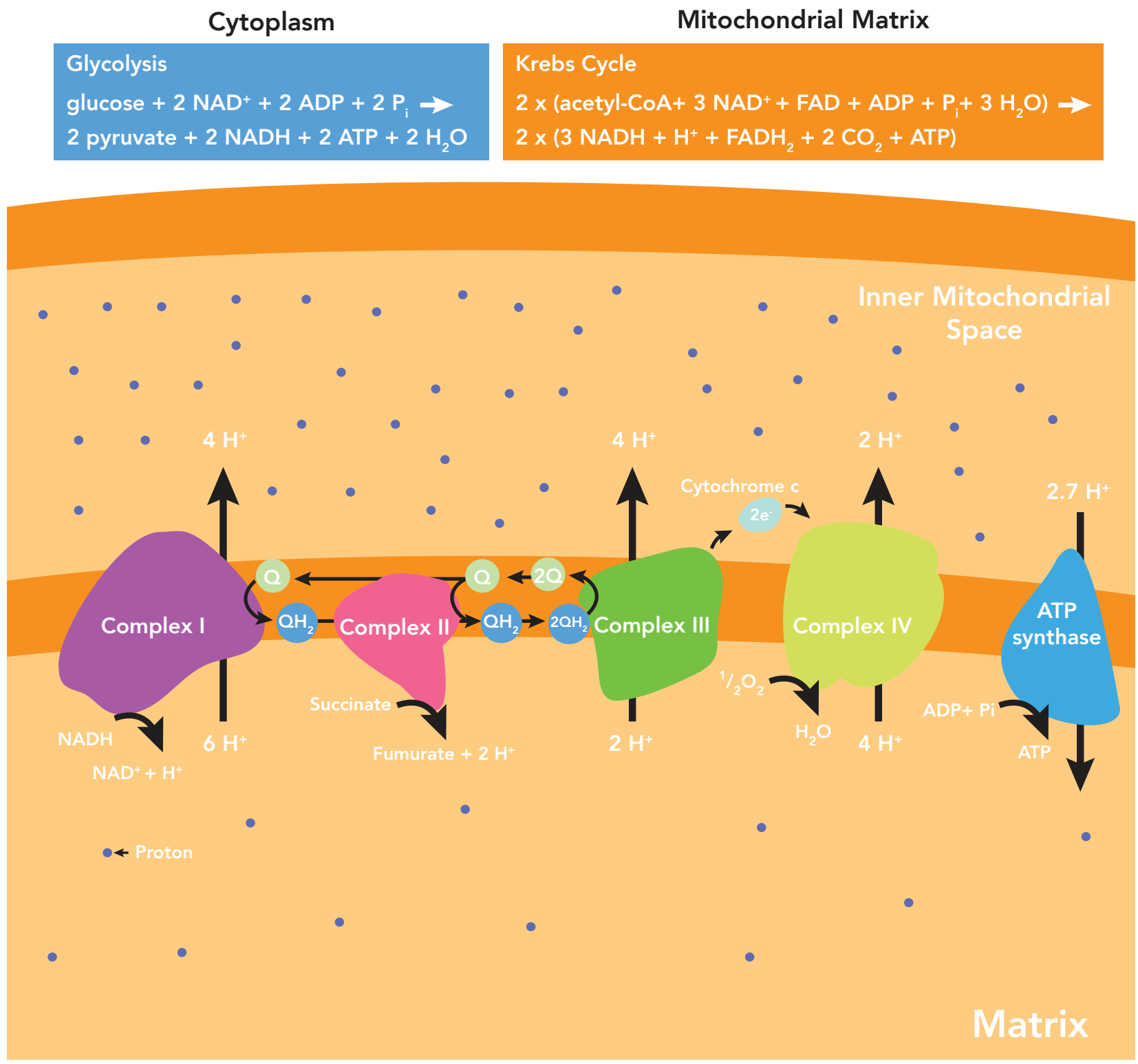


\subsubsection{Oxidative phosphorylation}

The ETC (Fig 1B) is composed of a series of protein complexes embedded in the mitochondrial inner membrane that make up oxidative phosphorylation (Sazanov 2015). Electrons are captured from donor molecules and are transferred through these complexes. Coupled with this transfer is the pumping protons from the matrix to the intermembrane space, generating a proton gradient that subsequently drives ATP production (Sazanov 2015). The complexes in the ETC are as follows: NADH dehydrogenase (complex I), succinate dehydrogenase (complex II), cytochrome-bC ${ }_{1}$ (complex III), cytochrome c oxidase (complex IV), and ATP synthase (Sazanov 2015). ATP synthase is responsible for generating ATP at the end of the ETC. In addition to these complexes, two mobile carriers are involved: ubiquinone (Q) and cytochrome c (Sazanov 2015). Q is responsible for carrying electrons from complex I to complex III and floats within the membrane. Cytochrome $\mathrm{c}$ is a mobile protein in the intermembrane space and transports electrons from complex III to complex IV (Sazanov 2015). At the start of the ETC, NADH is oxidized and its electrons are passed inside Complex I, to reduce $\mathrm{Q}$ to ubiquinol $\left(\mathrm{QH}_{2}\right)$. At the same time, 4 protons are pumped via complex I to the intermembrane space. $\mathrm{QH}_{2}$ is used by complex III to reduce cytochrome $\mathrm{c}$ in the intermembrane space (Sazanov 2015). As complex III reduces cytochrome c, 4 more protons are pumped across the intermembrane space. Complex IV uses cytochrome c (2e-) to reduce molecular oxygen $\left(\mathrm{O}_{2}\right)$ to $\mathrm{H}_{2} \mathrm{O}$, while pumping out 2 protons into the intermembrane space. Oxygen is known as the final electron acceptor - if oxygen is not available, the ETC shuts to a halt as electrons are not able to be freed up from complex IV (Sazanov 2015). As such, hypoxia exerts metabolic stress as a result of reduced ATP production by the ETC. Each NADH molecule pumps 10 
protons across to the intermembrane space, and this creates a proton gradient. The potential energy in this gradient is used by ATP synthase to create ATP using ADP and inorganic phosphate (Sazanov 2015).

In the Krebs cycle, the conversion of succinate to fumarate uses the enzyme succinate dehydrogenase to reduce $\mathrm{FAD}$ to $\mathrm{FADH}_{2}$. As mentioned above, succinate dehydrogenase is complex II, and holds the electrons in $\mathrm{FADH}_{2}$ - transfer of these electrons are also used to pump protons across the inner membrane. Complex II reduces $\mathrm{Q}$ to $\mathrm{QH}_{2}$, which travels to complex III to reduce cytochrome c (2e-). Cytochrome c (2e-) reduction is coupled with 4 protons pumped across complex III. Cytochrome c (2e-) then travels to complex IV where oxygen is reduced to $\mathrm{H}_{2} \mathrm{O}$ and 2 more protons are pumped across the membrane. Each $\mathrm{FADH}_{2}$ molecule pumps 6 protons into the intermembrane space. 2.7 protons are needed to create 1 molecule of ATP. At the end of oxidative phosphorylation, total ATP produced from 1 glucose molecule is 30-32 ATP (Sazanov 2015).

When oxidative phosphorylation is not enough, fatty acids can also be shuttled into ATP production. This is called fatty acid oxidation ( $\beta$-oxidation). The overall purpose of fatty acid oxidation is to break down long carbon chains into 2 carbon subunits groups and oxidizing them in the process (Houten \& Wanders 2010). The electrons from oxidation are used to reduce NAD+ and FAD - these are capable of producing ATP in the ETC. The 2 carbon subunits are also converted to acetyl-CoA, which can enter the Krebs cycle to create more ATP. From a single 16-carbon fatty acid chain, 107 ATP can be generated which is significantly higher than what 1 molecule of glucose generates (Houten \& Wanders 2010). 
The net consequence of these catabolic pathways is to converge on ATP production, in order to fuel the large range of chemical reactions in the rest of the cell that are otherwise energetically unfavourable.

\subsection{Metabolic Stress}

The vast majority of cell culture models grow cells under optimal conditions to ensure rapid and consistent growth. Optimal in this case refers to nutrient and serum availability. This is unlikely to correspond to the physiological situation for most cells, which experience ongoing metabolic challenges, arising from changes in blood flow, nutrient availability and oxidative damage. This is evident with the behaviour of Mammalian target of rapamycin (mTOR), the serine/threonine kinase that regulates cell growth, cell proliferation, and protein synthesis among others. mTOR becomes inactivated in many diverse types of cells 3-4 hours post feeding, as the amino acid levels drop (Kim 2009; Demetriades et al. 2014). Although glucose concentration remain relatively stable, they also at times fluctuate, particularly as large spikes 1 hour after a meal (Giugliano et al. 2008). These are the physiologically relevant conditions that cells encounter with regard to cell metabolism supply and stress, which can differ substantially from the conditions typically used in most current cell culture growth models.

There are a variety of physiological metabolic cell stressors, such as hypoxia (lack of oxygen), ischemia (low blood flow), and other mechanisms that lead to metabolic stress (not enough energy) (Hardie et al. 2012). Metabolic stress occurs when there is a lack of ATP available for cells to maintain its homeostatic functions, which causes a reduction in 
the ATP:AMP or ATP:ADP ratio in cells. Without cellular response mechanisms to metabolic stress, this can lead to reductions in ATP sufficient to impair key cellular processes required for survival, such as transcription, translation and DNA replication (Uni 1981; Conaway \& Conaway 1988; Harms et al. 2014). To allow cells to maintain homeostasis and to survive short-term metabolic challenges and stressors, cells undergo calculated changes in its signaling and processes, shifting priority away from macromolecule biosynthesis and other energy-consuming processes (broadly, anabolism) to energy synthesis and autophagy (broadly, catabolism).

\section{AMP-activated Protein Kinase}

It is evident then that a cell energy sensor must monitor and react to increasing concentrations of the ratio of AMP and ADP in order to maintain cellular homeostasis. When a cell is put under conditions of metabolic stress, a decrease in the ATP:AMP ratio results in activation of AMP-activated protein kinase (AMPK), a key protein that initiates signalling pathways that lead to energy conservation, increased energy production and intake. AMPK is the principal energy sensor in most eukaryotic cells (Hardie et al. 2012). This is evinced by many approaches, including studies with mice in which AMPK or its activating kinase liver kinase B1 (LKB1) are genetically knocked out. In these animals the ATP:AMP ratio is significantly lower during stress inducing conditions in muscle cells (contraction) and cardiac muscle (ischemia) (Sakamoto et al. 2005; Sakamoto et al. 2006), demonstrating that AMPK signaling is required for cells to detect metabolic stress, and subsequently to engage in processes to restore ATP:AMP ratio, thus maintaining cellular 
homeostasis. How does AMPK sense ATP:AMP rations and subsequently, how does AMPK control cell physiological processes to maintain homeostasis?

\subsection{AMPK Regulation}

AMPK is a heterotrimer that is activated by direct binding of AMP or ADP. The heterotrimer is composed of an $\alpha$ (catalytic), $\beta$ and $\gamma$ (regulatory) subunit. Genes encoding AMPK subunits are found in all eukaryotes (Hardie et al. 2012). The $\alpha$ and the $\beta$ subunits can exists in two isoforms: $\alpha 1$ or $\alpha 2$ and $\beta 1$ or $\beta 2$. The gamma subunit has three isoforms: $\gamma 1, \gamma 2$ and $\gamma 3$. The $\alpha 2$ isoforms are predominantly found in skeletal and cardiac tissue, whereas hepatic tissue consists of equal distribution of $\alpha 1$ and $\alpha 2$ (Pinter et al. 2013; Viollet et al. 2006). Also, AMPK complexes containing $\alpha 2$ and $\gamma 2$ are stimulated to a greater extent than those with $\alpha 1$ and $\gamma 1$ and AMPK containing $\gamma 3$ are the least sensitive to AMP (Salt et al. 1998; F Cheung et al. 2000; Oakhill et al. 2011; Scott et al. 2004). Hence, while AMPK has a general role in sensing metabolic stress, specific aspects of AMPK function are distinctly regulated in different tissues based on the isoforms expressed.

AMP, ADP, and ATP directly bind to the $\gamma$ subunit to allosterically activate or deactivate AMPK (Hardie et al. 2012), by changing the conformation of AMPK. The $\alpha$ subunit contains a Ser/Thr kinase domain at the amino terminus; the kinase activity in this domain is activated when the conserved Threonine-172 (T172) residue - located in the activation loop - is phosphorylated (Hardie et al. 2012; Suter et al. 2006). T172

phosphorylation is mediated by upstream kinases: LKB1-STRAD-MO25 complex (Hawley et al. 2003; Woods et al. 2003; Shaw et al. 2004) and the Calcium/Calmodulin activated 
protein kinase kinases (CAMKK $\beta$ ) (Hurley et al. 2005; Woods et al. 2005; Hawley et al. 2005). LKB1-STRAD-MO25 is a heterotrimeric complex composed of the protein liver kinase B1 (LKB1), along with its accessory subunits STE20-related kinase adaptor protein (STRAD) and mouse protein 25 (MO25). The AMPK $\beta$ subunit contains a carbohydrate binding domain (CBM), which allows mammalian AMPK to bind glycogen particles; however, the physiological significance of AMPK binding to glycogen is still yet unknown. The $\beta$ subunit C-terminal domain (CTD) binds both the $\alpha$-CTD and the $\gamma$-subunit, forming the core of AMPK protein.

LKB1-STRAD-MO25 phosphorylation of T172 on AMPK is initiated by binding of AMP to the $\gamma$ subunit, which promotes phosphorylation and inhibits dephosphorylation (Davies et al. 1995; Hawley et al. 1995). The $\gamma$ subunit contains 4 regulatory binding sites for AMP, ADP, and ATP (under the conditions within the cell, site 2 is predominantly empty and site 4 is predominantly bound with an AMP molecule) (Fig 2) (Hardie et al. 2012). The binding sites are composed of two Bateman domains, which are formed by two tandem repeats of CBS repeats (four CBS repeats total) (Xiao et al. 2011). The CBS repeats associate together to form a central cleft able to bind adenosine derivatives. AMP binding on site 1 causes allosteric activation of AMPK, while binding of AMP or ADP to site 3 allows for T172 phosphorylation (Xiao et al. 2011). When AMP or ADP binds site 3, a region of the $\alpha$ subunit, termed the $\alpha$-hook interacts with the $\gamma$ subunit (Xiao et al. 2011). This interaction stabilizes the active conformation of AMPK by not allowing phosphatase access to T172, thereby protecting it from dephosphorylation (Xiao et al. 2011). The activation loop is protected by the CTD of the $\alpha$ and $\beta$ subunits in the active conformation. When ATP is 


\section{AMPK}

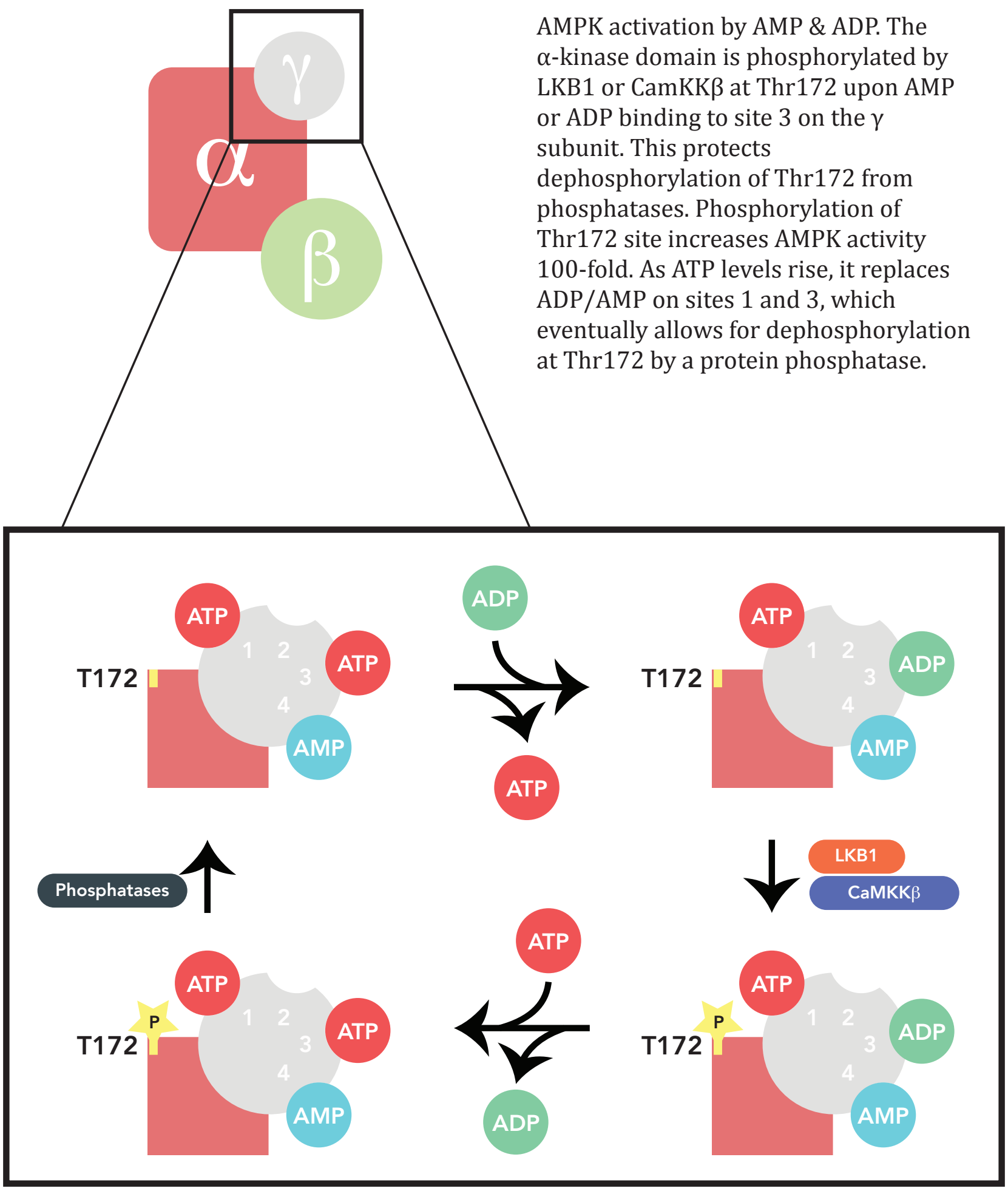

Fig 2. AMPK allosteric regulation by AMP ADP \& ATP binding

AMPK activation by AMP \& ADP. The $\alpha$-kinase domain is phosphorylated by LKB1 or CamKK $\beta$ at Thr172 upon AMP or ADP binding to site 3 on the $\gamma$ dephosphorylation of Thr172 from phosphatases. Phosphorylation of Thr 172 site increases AMPK activity 100 -fold. As ATP levels rise, it replaces ADP/AMP on sites 1 and 3, which eventually allows for dephosphorylation 
bound to site 3 , the $\alpha$-hook interaction is not favourable due to a steric clash, and T172 is left unprotected and susceptible to dephosphorylation (Xiao et al. 2011). As energy levels decrease in a cell, the net result of AMP binding and protection from phosphatases is T172 phosphorylation, which in turn results in a 100-fold increase in AMPK activity (Fig 2) (Xiao et al. 2011).

\subsection{Substrates \& Targets of AMPK}

\subsubsection{Role of AMPK in Glucose uptake}

Once activated, AMPK acts on a host of different targets, either directly or indirectly, and phosphorylation of these substrates functions to limit energy expenditure and increase energy production. A classic mechanism affected by AMPK is glucose uptake via glucose transporter 4 (GLUT4) in skeletal muscle cells. During muscle contraction, AMPK is activated as a result of a substantial drop in ATP:AMP ratio, which results from the energetic requirements of muscle contraction. AMPK activation in skeletal muscle cells allows enhancement of catabolism of glucose to ATP (Shearer et al. 2004). This increased catabolism of glucose in exercising skeletal muscle cells occurs as a result of the translocation of vesicles containing the GLUT4 transporter to the plasma membrane (Chen et al. 2008; Pehmoller et al. 2009). For GLUT4 carrying vesicles to fuse with the plasma membrane, G proteins from the Rab family must be in the GTP-bound state (Sakamoto \& Holman 2008). However, in the absence of muscle stimuli, these specific Rab proteins are predominantly in the GDP-bound state (and therefore inactive); this is ensured by the high activity of the Rab GAPs TBC1 domain family member 4 (TBC1D4) and TBC1D1 (Chen et al. 
2008; Pehmoller et al. 2009). In a contracting muscle, AMPK activation leads to the phosphorylation of TBC1D1, which allows for TBC1D1 to bind with 14-3-3 proteins and ultimately dissociate from the GLUT4 vesicles (Chen et al. 2008; Pehmoller et al. 2009). This event allows for conversion of Rab to its active GTP-bound form, enabling the GLUT4 carrying vesicles to fuse to the plasma membrane and release GLUT4 transporters.

Similarly, AMPK participates in modulating glucose uptake by glucose transporter 1 (GLUT1) uptake as well. GLUT1 is the glucose transporter responsible for glucose transport into a wide range of tissues throughout the body (Wu et al. 2013). Under conditions of energetic sufficiency, Thioredoxin-interacting protein (TXNIP) binds to GLUT1 to mediate GLUT1 internalization by clathrin mediated endocytosis, thus limiting the glucose transport activity of GLUT1. TXNIP exhibits high levels of expression when cells are cultured in high glucose levels. By a separate mechanism, TXNIP also impairs expression of GLUT1 mRNA, thereby functioning as a negative feedback loop. AMPK activation by energy stress phosphorylates TXNIP, resulting in rapid TXNIP degradation (Wu et al. 2013). The degradation of TNXIP both increases the amount of GLUT1 mRNA and impairs GLUT1 endocytosis, thus enhancing the content of GLUT1 at the cell surface, thus increasing the uptake of glucose molecules (Wu et al. 2013). Once the energy stress has been relieved, TXNIP begins once again to negatively regulate GLUT1 (Wu et al. 2013). AMPK thus controls the membrane traffic of GLUT4 and GLUT1 by different mechanisms. AMPK also controls the internalization of the tight junction protein occludin, the $\mathrm{Na}^{+} \mathrm{K}^{+}$-ATPase pump, and fatty acid translocase (CD36) (Antonescu et al. 2014). The mechanisms for the regulation of the membrane traffic of these membrane proteins differs than what has been 
described for GLUT1 and GLUT4, or in some cases are currently not known (Zheng \& Cantley 2007; Samovski et al. 2012; Gusarova et al. 2009; Antonescu et al. 2014). Hence, a number of separate studies have found that AMPK controls the cell surface membrane traffic of multiple proteins, which raises the question of the extent to which AMPK may more broadly control the cell surface proteome (Ross et al. 2015).

\subsubsection{Regulation of lipid metabolism}

During period of fasting or low carbohydrate nutrient availability, fatty acid metabolism is an important aspect of maintaining whole body energy metabolism (Kiens 2006). The regulation of fatty acid metabolism occurs through transcriptional control of specific genes by AMPK. Fatty acid uptake has been shown to be higher in cells in which AMPK is activated, suggesting AMPK also has a role in regulating fatty acid uptake (Shearer et al. 2004; Shearer et al. 2005; Steinberg et al. 2004; Luiken et al. 2003). The mechanism is thought to occur by AMPK increasing translocation of fatty acid translocase (CD36) to the plasma membrane, although there is still some debate to this idea (Bonen et al. 1999). After fatty acid uptake, they can either be shuttled straight to oxidation, or kept as storage to meet the metabolic demands of cells later on. Going forward with the oxidation pathway begins with Acetyl-CoA carboxylase (ACC). ACC is an enzyme that exists in two isoforms: ACC1 and ACC2. ACC2 but not ACC1 contains a 146 amino acid stretch on its $\mathrm{NH}_{2}$-terminal which localizes it to the mitochondria (Abu-Elheiga et al. 2000). ACC catalyzes the carboxylation of acetyl-CoA to malonyl-CoA, which is either incorporated into fatty acids via fatty acid synthase during synthesis or acts to allosterically inhibit carnitine palmitoyltransferase 1 (CPT1). CPT1 is found on the outer mitochondrial membrane and 
inhibits translocation of fatty acids to the mitochondria, where fatty oxidation occurs (Bianchi et al. 1990; Munday 2002). ACC2 localization to mitochondria is thought to be important as malonyl-CoA production occurs in close proximity to CPT1, where it can easily inhibit it. Liver and brain tissue contain equal amounts of ACC1 and ACC2, whereas

skeletal and cardiac muscle contain ACC2 predominantly (Iverson et al. 1990; Abu-Elheiga et al. 1995). Deletion of whole body ACC is embryonically lethal, which demonstrates its importance in development (Abu-Elheiga et al. 2005).

ACC regulation occurs by phosphorylation by AMPK. In ACC1, phosphorylation at S79 by AMPK inhibits it, while the equivalent site on ACC2 is S221 (Abu-elheiga et al. 1997; Corton et al. 1995). In most AMPK studies, phosphorylation of ACC1 and ACC2 at those serine residues is used as the measurement of AMPK activation in vivo. The AMPK ACC interplay is a major signaling pathway which determines whether fatty acids are undergoing synthesis or oxidation, and at a larger scale represents the switch between anabolism and catabolism in cells.

\subsection{Physiological Significance of AMPK}

\subsubsection{Role of AMPK in whole body metabolism}

AMPK attempts to restore homeostasis by inhibiting anabolic processes such as gluconeogenesis, fatty acid synthesis and protein synthesis, while increasing glucose intake and glycolysis (Hardie et al. 2012). One way AMPK regulates protein synthesis is by inhibiting peptide elongation, by acting on eukaryotic elongation factor 2 kinase (eEF2). 
AMPK phosphorylates eEF2 on S398, which in turn inhibits protein elongation (Browne et al. 2004).

Through its actions in the hypothalamus of the brain, AMPK is able to influence whole body metabolism and energy balance. The arcuate nucleus of the hypothalamus is the appetite control centre, wherein increased activity of neuropeptide $Y$ and agoutirelated protein-expressing neurons (NPY/AgRP neurons) increases appetite and subsequent feeding (Aponte et al. 2011). On the opposite spectrum, activity in proopiomelanocortin-expressing neurons (POMC) inhibits appetite (Aponte et al. 2011). Ghrelin is a hormone released from the stomach that promotes feeding when the body is in a fasted state. Ghrelin binds to the growth hormone secretagogue receptor type 1 (GHSR) in presynaptic neurons upstream NPY/AgRP neurons, to activate AMPK (Yang et al. 2011). Its activation begins due to upstream activation of heterotrimeric $\mathrm{G}$ protein $\mathrm{G}_{\mathrm{q}}$ via GHSR, which triggers intracellular $\mathrm{Ca}^{2+}$ release (Yang et al. 2011). The increased intracellular $\mathrm{Ca}^{2+}$ activates AMPK via the CaMKK $\beta$ pathway (Andrews 2011). AMPK activation also induces a positive feedback cycle, where $\mathrm{Ca}^{2+}$ release from ryanodine receptors sustains AMPK activation. Although the downstream targets of AMPK are still unclear, it is evident that its activation results in neurotransmitter release onto the NPY/AgRP neurons. This promotes sustained feeding, which persists even after ghrelin is no longer activating GHSR, due to the positive feedback loop (Andrews 2011). In accordance to this model, feeding stops when leptin is released to POMC neurons that release opioids to inhibit AMPK (Claret et al. 2007; Yang et al. 2011). Hence, AMPK has multiple roles that manifest in whole-body control of human physiology. 


\subsubsection{Role of AMPK in tumourigenesis}

Genetic mutations in the tumour suppressor LKB1, the upstream activator of AMPK, leads to Peutz-Jeghers syndrome, which is characterized by noncancerous growths in the gastrointestinal tract, called hamartomatous polyps (Shaw et al. 2016). The genetic disease also comes with a greater risk of developing other types of cancers. Several studies have shown that AMPK mediates many of the tumour suppressor effects of LKB1. Support of this comes in the form of AMPK activators (e.g. A-769662, metformin, phenformin) which delay the onset of tumourigenesis in vivo (Huang et al. 2008; Evans et al. 2005). One mechanism by which AMPK may control tumor growth comes from the observation that AMPK controls mTORC1 and RNA polymerase transcription factor TIF-1A, both of which are needed for rapid cell proliferation (Gwinn et al. 2008; Inoki et al. 2003; Hoppe et al. 2009). In addition, AMPK activation also causes G1 cell cycle arrest, which occurs by activation of p53 and subsequently p21, the cell cycle inhibitor protein (Jones et al. 2005; Imamura et al. 2001). As such, low glucose conditions result in activation of p53 via phosphorylation on S15 by AMPK. Interestingly, in p53-deficient cells, AMPK activation was not able to arrest cells, showing that p53 is critical for induction of cell cycle arrest via AMPK (Jones et al. 2005). Collectively, these studies indicate that AMPK may negatively regulate the growth of some tumors under some circumstances. However, the functions of AMPK in tumour growth is complex, as AMPK activation in later stages of tumor growth may enhance tumor survival and growth, by protecting these tumors from some of effects of hypoxia and nutrient limitation (Faubert et al. 2015).

In the latter situations of late-stage tumor growth, loss of AMPK might cooperate 
with oncogenes to promote tumourigenesis. One of the ways AMPK loss might promote tumour progression is the propensity for the cell metabolism to switch to aerobic glycolysis, commonly referred to as the Warburg effect. The Warburg effect is phenotype of many tumours, in which there is deliberate shift of ATP generation via oxidative phosphorylation to ATP generation through glycolysis, even under oxidative conditions (Warburg 1956). Although there is much debate as to why tumour cells default to aerobic glycolysis, the latest hypothesis describes that the needs of rapidly proliferating cells go far beyond ATP generation: they require massive amounts of macromolecular building blocks (lipids, amino acids, nucleotides) to incorporate into biomass (Vander Heiden et al. 2009; Newsholme et al. 1985). A cell undergoing division needs a variety of macromolecular building blocks to replicate all of its cellular content for the two daughter cells. Knockout of AMPK in mouse models has demonstrated a Warburg-like metabolic shift (Faubert et al. 2013). Further, loss of LKB1, the AMPK upstream kinase, promoted the Warburg effect in tumours (Faubert et al. 2014). Another consequence of AMPK loss is unregulated mTOR activity (Shaw et al. 2016; Inoki et al. 2003). This can have wide-spreading effects that promote tumour progression, as loss of AMPK with mTOR activation leads to an unchecked cellular metabolism.

Thus, AMPK controls a number of cellular processes that have fundamental roles in normal cell physiology and in certain diseases such as cancer. Some of these functions involve control of cell cycle and metabolic enzymes, but AMPK also has emerging functions in the control of membrane traffic, in particular in the control of cell surface abundance of specific proteins. Understanding the mechanism, extent and significance of control of cell 
surface membrane traffic by AMPK thus represents an important objective to understanding how cell metabolism controls cell physiology.

\section{Membrane traffic}

The plasma membrane harbors proteins involved in processes such as cell signaling, cell adhesion, and membrane trafficking. The proteins and lipids of the plasma membrane are in dynamic exchange with intracellular compartments (endosomes), as a result of constitutive endocytosis and recycling. The vast majority of proteins undergo turnover between the plasma membrane and intracellular compartments with a $t_{1 / 2}$ on the order of minutes or ten's of minutes (Swiatecka-Urban 2013). Hence, the relative rates of endocytosis and recycling effectively control the cell surface content of each specific protein (Antonescu et al. 2014). This typically occurs through clathrin or non clathrin mediated endocytosis. Subsequently, the formation of transport vesicles and their delivery to specific compartments is controlled by two main families of small GTPases: ADPribosylation factors (Arfs) and Rabs.

\subsection{Clathrin mediated endocytosis}

Clathrin mediated endocytosis (CME) is the main internalization mechanism for integral membrane proteins from the cell surface, resulting in the formation of clathrin coated vesicles (CCVs). CME requires recruitment of the protein clathrin, the adaptor protein AP-2 and other proteins and cargo to small regions on the inner leaflet plasma membrane to form clathrin-coated pits (CCPs). Effector proteins, some of which facilitate membrane curvature, contribute to assembly and maturation of CCPs, after which some 
CCPs undergo scission from the plasma membrane by the GTPase dynamin, leading to production of an intracellular CCV left to be trafficked to endosomes. Although there are several proteins found in a CCP, there are five key molecules needed for CCP to transition to CCV: clathrin, AP-2 adaptor protein, phosphatidyl-inositol-4,5-bisphosphate $\left(\mathrm{PI}(4,5) \mathrm{P}_{2}\right)$, cargo proteins, and dynamin (Antonescu et al. 2011).

Clathrin forms a stable trimer made up of a 3 heavy chain, each associated with a light chain, termed a triskelion (Kirchhausen et al. 2014). Purified clathrin self-assembles to form cage-like structures (Kirchhausen et al. 2014). The presence of AP-2 enhances the assembly of clathrin into the cage-like structure of CCPs (Kirchhausen et al. 2014) . CCPs and CCVs vary in size, averaging anywhere from $50-200 \mathrm{~nm}$ in diameter (Steven et al. 1983) and contain 35-40 triskelions. On average, there are 25-30 molecules of AP-2 found in a CCV (Kirchhausen et al. 2014).

AP-2 is the prototypical clathrin adaptor protein, as it is the principle non-clathrin component of purified clathrin coated vesicles (Jackson et al. 2010). AP-2 is a heterotetrameric protein composed of a $100 \mathrm{kDa} \alpha$-subunit, $100 \mathrm{kDa} \beta 2$-subunit, a $50 \mathrm{kDa}$ $\mu 2$-subunit and a $17 \mathrm{kDa} \sigma 2$ subunit. The AP-2 $\mu 2$ subunit interacts directly with cytoplasmic tails of transmembrane receptors through a tyrosine sorting motif (YXX $\phi)$ and the acidic dileucine motif [ED]XXXL[LI] (Traub 2009). AP-2 also binds clathrin via the clathrin box ( $\mathrm{L} \phi \mathrm{X} \phi[\mathrm{DE}]$ ) found on the $\beta 2$ hinge to act as the central hub in the maturing clathrin coated pit (Traub 2009). AP-2 is found in two states: closed and open (Jackson et al. 2010) . In its closed state, the two cargo binding sites are buried; in the open state, at 
least one of the cargo binding sites is accessible and is stabilized by binding to PI(4,5)P2 (Kirchhausen et al. 2014; Jackson et al. 2010). Further, in the closed state, the clathrin box is sequestered within the core of AP-2 (Kelly et al. 2014). AP-2 membrane and cargo binding enhances formation of the open structure from the closed state, which releases the clathrin box to recruit clathrin. Thus, this allows coupling of cargo and membrane recognition by AP-2 to clathrin assembly. However, AP-2 has low affinity for biological membranes and as such, it requires the enriched presence of $\mathrm{PI}(4,5) \mathrm{P}_{2}$ on the plasma membrane to on the plasma membrane (Traub 2009).

$\mathrm{PI}(4,5) \mathrm{P}_{2}$ is found in all eukaryotic organisms and functions and regulates many important cell processes such organization of the cytoskeleton, and vesicular trafficking. $\operatorname{PI}(4,5) \mathrm{P}_{2}$ also regulates CCP initiation, stabilization, and size (Antonescu et al. 2011). It must also be present and enriched on the inner leaflet of the plasma membrane for AP-2 to function as an adaptor in CME (Honing et al. 2005). AP-2 interacts with $\mathrm{PI}(4,5) \mathrm{P}_{2}$ at two basic sites on the $\alpha$ and $\mu 2$ subunits. $\mathrm{PI}(4,5) \mathrm{P}_{2}$ is synthesized by PI 4-kinases phosphorylating PI on the 4 site to produce PI(4)P, followed by PI 5-kinase phosphorylation on the 5 site to produce $\mathrm{PI}(4,5) \mathrm{P}_{2}$ (Toker 1998). It has been demonstrated that $\mathrm{PI}(4,5) \mathrm{P} 2$ synthesis is required for CCP initiation and for CCP maturation (Antonescu et al. 2011) . Further, clathrin stabilization is dependent on the rate of AP-2 and PI(4,5)P2 presence on the plasma membrane (Mcmahon \& Boucrot 2011).

Dynamin proteins are large multidomain GTPases which pinch off the CCVs at the plasma membrane. They function through cycles of oligomerization driven by self- 
assembly and GTP hydrolysis, which drives scission between dynamins GTPase domain and its $\alpha$-helical stalk to create CCV from CCPs (Kirchhausen et al. 2014).

\subsection{Clathrin coat vesicle formation}

Clathrin coat vesicle formation occurs in 5 main steps: nucleation, cargo selection, clathrin coat assembly, vesicle scission, \& uncoating and clathrin component recycling (Mcmahon \& Boucrot 2011).

\subsubsection{Nucleation}

The first step of vesicle formation is the invagination of the plasma membrane. This is called the nucleation module and defines where on the plasma membrane clathrin coat formation will occur. The proteins involved in the nucleation module are AP-2, PI(4,5)P2 and clathrin (Cocucci et al. 2012). Nearly concomitantly with CCP initiation, specific proteins such as FCH domain only (FCHo) proteins, EGFR pathway substrate 15 (EPS15), and intersectins are recruited and facilitate assembly at the early stages of CCPs (Cocucci et al. 2012). In cells in which EPS15 and intersectins are perturbed, the assembly of CCPs is dramatically impaired. Consistent with a role for FCHo in early stages of CCP assembly (prior to CCP invagination), the F-BAR domain of FCHo binds to low curvature areas on membranes and induces membrane curvature. This suggests that membrane curvature occurs at the earliest stages of CCP formation (Mcmahon \& Boucrot 2011).

\subsubsection{Cargo selection}

The nucleation module proteins described above are thought to recruit AP-2, 
alongside other adaptor proteins, to begin cargo selection. AP180 amino-terminal homology (ANTH) is a membrane binding protein and epsin N-terminal homology (ENTH) is a membrane bending protein, both of which are often found alongside AP-2 during this step (Ford et al. 2001; Ford et al. 2002). ANTH and ENTH are thought to be involved in cargo selection as well (Dittman \& Kaplan 2006; Chidambaram et al. 2008). FCHo proteins also contain ligand binding domains which suggests that cargo selection might occur in the nucleation stage as well. If AP-2 recruitment is disrupted, clathrin does not bind the plasma membrane - this highlights the importance of AP-2 in CME (Mcmahon \& Boucrot 2011).

\subsubsection{Clathrin coat assembly}

Clathrin triskelia are recruited from the cytosol to the plasma membrane at sites of adaptor protein enrichment to begin coat assembly. Clathrin assembly stabilizes membrane curvature and relocates membrane bending adaptor proteins to the edge of the vesicle, where they can work more efficiently (Mcmahon \& Boucrot 2011). The clathrin lattice forms a scaffold to which many proteins are recruited via binding the N-terminal proteinprotein interaction platform formed by a 7-bladed beta-propeller domain (ter Haar et al. 2000; ter Haar et al. 1998). Many of the $\sim 50$ cytosolic proteins recruited to CCPs are as a result of binding to the $\mathrm{N}$-terminal domain.

\subsubsection{Vesicle scission}

Dynamin is recruited by proteins containing BAR domains (Mim \& Unger 2012)these proteins have preference to localize at curved membrane location, and likely assist in creation of the vesicle neck. Endophillin, amphiphysin and sorting nexin 9 (SNX9) are 
examples of BAR containing proteins - these proteins all have Src homology 3 (SH3) domains, which bind the pro-rich sites of dynamin. GTP hydrolysis dependent conformational change of dynamin allows for membrane scission (Mcmahon \& Boucrot 2011).

\subsubsection{Uncoating and clathrin component recycling}

Following scission from the plasma membrane, ATPase heat shock cognate 90 (HSC70) and auxilin dissemble clathrin from its lattice structure to its triskelia, allowing the vesicle to travel to and subsequently fuse with its target endosome. Hydrolysis of $\mathrm{PI}(4,5) \mathrm{P} 2$ to phosphatidylinositol-(4)-bisphosphate (PI4P), which is initiated by the

phosphatase synaptojanin, is required for uncoating as well (Cremona et al. 1999). Auxilin binds the terminal domains of clathrin triskelia during the coat assembly and budding stage, and it then recruits HSC70 to a specific motif below the clathrin hub (Rapoport et al. 2008; Xing et al. 2010). That is where uncoating is initiated. Once uncoated, the clathrin molecules are released back into the cytoplasm, where they can participate in additional rounds of vesicle formation.

\subsection{Small GTPases: Rab \& Arf}

Small GTPases are signalling molecules that are oversee membrane protein trafficking. These molecules are able to switch between an active GTP-loaded form, and an inactive GDP-loaded form. Guanine-exchance factors (GEFs) and GTPase-activating proteins (GAPs) control the loading of GTP and GDP to regulate small GTPase activation. Spontaneous release of GDP is very slow and therefore GEFs must catalyze the removal 
GDP for the addition of GTP to active small GTPases (Behnia \& Munro 2005).

\subsubsection{ADP-ribosylation factor proteins (Arfs)}

Arfs are a group of 6 small GTP binding proteins $20 \mathrm{kDa}$ in size responsible for intracellular transport. The Arf protein of interest here is Arf6, the least conserved of the 6 (Chavrier \& Goud 1999). It mediates transport from the plasma membrane and also helps regulate the actin cytoskeleton (Chavrier \& Goud 1999).

Arfs contain an N-terminal amphipathic helix which is bound to a myristoyl group. In its GDP form, the hydrophobic residues of the amphipathic helix are buried inside a hydrophobic pocket on the GTPase (Antonny et al. 1997). The myristoyl group mediates rapid and reversible association with membranes; association with membranes allow GEFs to act on the Arf to activate it. GTP binding induces a conformational change in regions on Arfs (and small GTPases in general) termed switch 1 and switch 2 (Behnia \& Munro 2005). In Arfs however, there is also an "interswitch" region (Pasqualato et al. 2002). Once a GEF removes GDP in place for GTP, it induces a conformational change not only in switch 1 and switch 2 regions, but also the interswitch region (Pasqualato et al. 2002). A conformational change in the interswitch region displaces the $\mathrm{N}$-terminal amphipathic helix from its hydrophobic compartment in the core of the Arf GTPase, and allows for the Arf to associate with the membrane via the hydrophobic residues and the myristoyl group (Behnia \& Munro 2005). This interswitch mechanism allows for coupling of membrane recruitment to GTP binding. Now, the membrane-associated, GTP-bound Arf is ready to recruit its effectors. 


\subsubsection{Rab GTPases}

Rab GTPases function in the movement of peripheral membrane proteins to organelles, overseeing the timing and location of their recruitment. There are approximately 60 different human Rab proteins, and each exhibits specific enrichment within specific membrane compartments, functioning to control specific membrane traffic events (Kanno et al. 2010). To ensure Rabs are present at the correct membranes, they are modified by two prenyl groups on their C-terminals. A prenyl group is a lipid anchor which allows association with membranes, however this is not enough for specificity to subcellular compartments, as many Rabs share the same lipid groups. Evidence points towards GEFs and GAPs providing correct localization and specificity to membranes for Rabs (Blümer et al. 2013). An example of this is the Rab GEF Rabex-5 which specifically targets and localizes Rab5a to endomembranes (Blümer et al. 2013). In the cytosol, Rabs bind to GDP-dissociation inhibitors (GDIs), which mask the prenyl groups, to limit random associations with the plasma membrane. GDI displacement factors (GDFs) which are found embedded in membranes, catalyse the removal of GDIs allowing the prenyl groups to bind with the membrane. With the Rab recruited to the membrane, GEFs remove the GDP for GTP which activates the protein and causes a conformational change in switch 1 and switch 2 regions that allows it to bind effectors (Behnia \& Munro 2005). 


\section{Fig 3. Membrane Traffic of integrins by Arfs and Rabs}

$\beta 1$ integrins recycling occurs through Rab \& Arf proteins. (1) Rab 5 and rab 21 are responsible for initial internalization, which locates them to the APPL early endosome or the EEA 1 early endosome. (2) RASA1 (p120RasGAP) competes for rab21 for the same site and quickly recycles integrin back to the membrane if it binds. (3) Rab25 sorts integrins via activation states - inactive integrins are quickly recycling back to the membrane. (4) Rab4 is also involved in quick integrin recycling, while rab11 is involved in slower recycling. (5) Arf6 activity on integrin depends on the GAPs bound to them: ARAP2 recycles integrins to EEA1 from APPL early endosomes, while ACAP1 recycles integrins from rab11 endosomes.

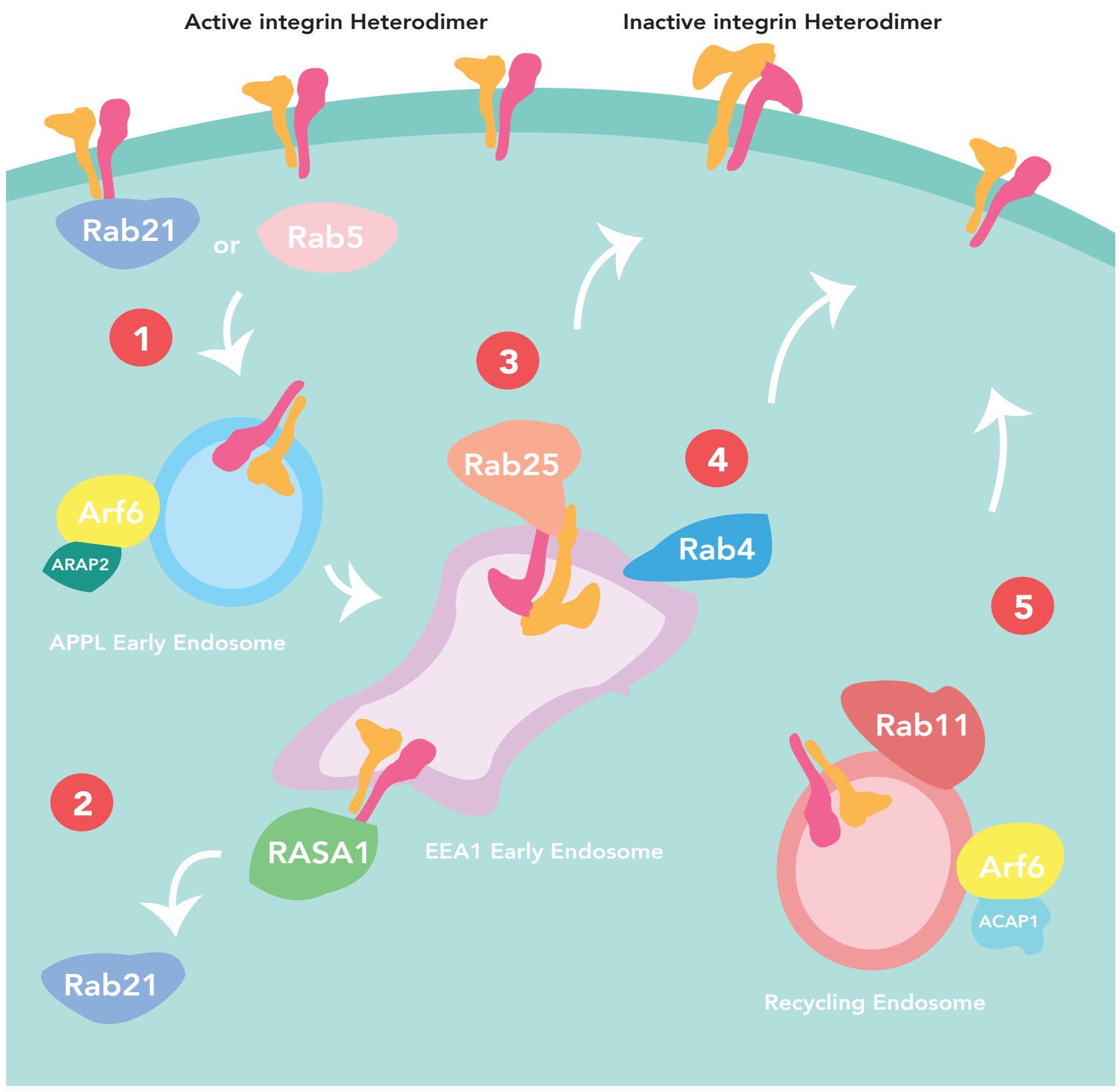




\subsection{Routes of internalization and recycling using Arf and Rab GTPases}

Many different receptors use Arfs and Rabs to mediate their endocytosis and recycling from the plasma membrane. Transferrin receptor (TfR), a constitutively internalizing and recycling integral membrane protein that functions in the cellular uptake of iron, uses both Arf6 and Rab proteins in its recycling mechanisms (Grant \& Donaldson 2009). Epidermal growth factor (EGF) receptor (EGFR), an important receptor tyrosine kinase that internalizes upon binding its hormone ligand (EGF), can undergo endocytic trafficking leading to recycling back to the plasma membrane, a phenomenon requiring Rab proteins, primarily Rab5 and 11 (Ceresa 2006). As will be discussed in detail below, integrin receptors undergo internalization and membrane traffic leading to recycling which involves both Arf6 and many different Rab proteins. Hence, the distinct membrane traffic of various integral membrane proteins such as TfR, EGFR and integrins is controlled by some common Rabs and Arf proteins, as well as unique GTPases; the latter provide nodes controlling membrane traffic that allow unique and distinct regulation of a subset of membrane protein cargo by specific stimuli and conditions, such as those elicited during metabolic stress.

\section{Integrins}

Integrins are a family of transmembrane cell surface proteins that mediate attachment to the ECM (De Franceschi et al. 2015). Integrins are critical regulators of cell migration, and dynamic membrane traffic (endocytosis and recycling) of integrins is required for the movement of cell adhesions to the extracellular matrix and assembly of the actin cytoskeleton during cell migration. 


\subsection{Structure and Function}

Integrins are present on the cell surface as heterodimers consisting of a $\alpha$ and a $\beta$ subunit (Caswell et al. 2009). In mammals, there exist $19 \alpha$-integrins and $8 \beta$-integrin subunits, comprising a total of $25 \alpha \beta$ heterodimers (Caswell et al. 2009). Originally thought to only link the ECM to the actin cytoskeleton, integrins are part of a variety of intracellular signalling pathways, including outside-in signalling that control activation of actin nucleation, polymerization and cross-linking proteins, as well as pro-survival and mitogenic signaling (Caswell et al. 2009); these signals can have cancerous consequences if their appropriate regulation is lost (De Franceschi et al. 2015). Integrins can exist on the cell surface in one of three conformations: inactive and bent with low affinity for ECM ligands, extended and primed with a closed head-piece and therefore low affinity for its ligand, or extended with an open head-piece with high affinity for ECM ligands. The inactive integrin conformation is stabilized by a salt bridge between the $\alpha \beta$ in the cytoplasmic tail regions and helix packing in the transmembrane domain (Partridge et al. 2005). Integrin activation can occur through two mechanisms: inside-out signaling, where binding of proteins to the cytoplasmic tails induces conformational changes in the integrin heterodimer, or outside-in signaling, where binding on the extracellular portion induces activation (Partridge et al. 2005). In both cases, talin binding $\beta 1$ integrin is a common final step of activation. Talin a protein that links the cytoskeleton to the cell membrane, (Shattil et al. 2010).

\subsection{Integrin Trafficking}

The Rab and Arf family have a direct role in integrin membrane traffic regulation. 
Rab21 directly interacts with $\alpha$-tails of the integrin heterodimer, via the WKLGFFKR sequence that is common to many $\alpha$-subunit (Pellinen 2006; Hynes 2002). The $\beta 1$ integrin heterodimer pair is internalized via clathrin and dynamin to Rab5 or Rab21-positive EEA1containing early endosomes (Mai et al. 2011). In the EEA1 endosome, p120RasGAP competes with Rab21 for the same cytoplasmic binding site (De Franceschi et al. 2015). The displacement of Rab21 by p120RasGAP results in the shuttling of $\beta 1$ integrin heterodimers back to the plasma membrane (Mai et al. 2011). Rab25 can interact with $\alpha 5 \beta 1$ integrins through the $\beta 1$ cytoplasmic domain on endosomes, and sort them based on their activation state (De Franceschi et al. 2015). Rab25 is also able to shuttle active $\alpha 5 \beta 1$ to the lysosome, where instead of degradation, they are transported to the plasma membrane at the rear of cancer cells, in a chloride intracellular channel protein 3 (CLIC3)dependent manner (Dozynkiewicz et al. 2012). As of yet, the particular GEFs \& GAPs involved in Rab21 and Rab25 regulation are not yet certain.

The other major family involved in integrin trafficking is the Arf family. Arf6 are involved in clathrin dependent \& independent integrin endocytosis (Sakurai et al. 2011; Yue et al. 2014), and shuttling integrins to the plasma membrane as part of cell migration regulation (Arjonen et al. 2012). Arf6 has also been shown to localize to CCPs and ArfGAPs and Arfs (including possibly Arf6) have been shown to enhance membrane binding of AP-2 and promote formation of CCPs (Hyman et al. 2006; Bai et al. 2011). Arf6 is able to bind GAPs, which further regulate Arf6 activity. For instance, the Arf6 GAPs ARAP2 \& ACAP1 both localize to Arf6-positive endosomal compartments to perform contrasting functions. ARAP2 allows for integrin receptors to move from early APPL endosomes to EEA1- 
containing early endosomes, which shuttles them towards recycling or degradation (Dai et al. 2004). APPL endosomes are Rab5-positive, early endosomes which contain either one or both APPL1 and APPL2 (Erdmann et al. 2007; Miaczynska et al. 2004; Zoncu et al. 2009). APPL endosomes exhibit some, albeit limited colocalization with EEA1-endosomes, and as such are considered a distinct population of early endosomes (Urbanska et al. 2011). In contrast, ACAP1 is involved in rapid $\beta 1$ integrin recycling from Rab11-containing endosomes (Dai et al. 2004). Interestingly, Arf5 has also been implicated in $\beta 1$-integrin trafficking. BRAG2, a GEF, recruits to CCPs via direct interaction with clathrin and AP-2, and interacts with PI(4,5) $\mathrm{P}_{2}$ (Sakurai et al. 2011). BRAG2 then activates Arf5 at the plasma membrane to internalize $\alpha 5 \beta 1$ to early endosomes.

\subsection{Cell Migration}

Cell migration is a process that begins with dynamic polarization and formation of the lamellipodia -protrusions at the leading edge of the cell surface. Here, Rac1 - a small GTPase - activation is needed for the formation of the lamellipodium which leads to cell migration (Ballestrem et al. 2000). Rac1 is an upstream regulator of actin dynamics \& organization, and once it is activated by GEFs, it recruits a complex which activates the actin-related protein 2/3 (Arp 2/3) complex (Koronakis et al. 2011). Arp 2/3 functions as an actin nucleator and to organize the actin filament involved in lamellipodia formation (Yan et al. 2015).

During cell migration, regulated integrin trafficking and actin polymerization drives the formation of protrusions of filopodia and lamellipodia at the leading edge of a cell. Actin 


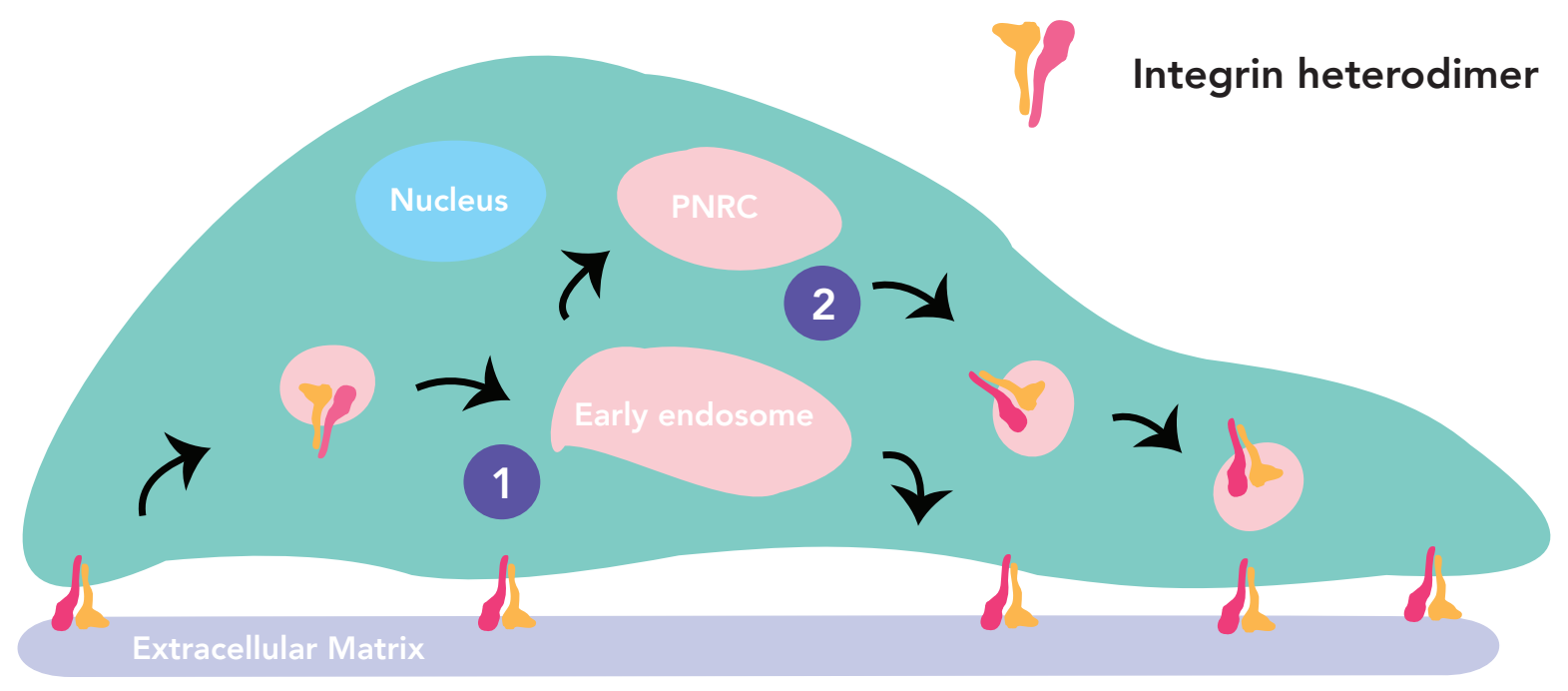

Fig 4. Cell migration requires integrin trafficking

Coordinated integrin membrane traffic is required for cell migration. Integrins are continuously recycled from the cell surface, to internal compartments and back to the plasma membrane for cell migration. Integrins traffics through two main pathways: (1) the short-loop pathway and 2) the long loop pathway. (1) In the short-loop pathway, recycling is dependent on Rab4 and promotes, like its name suggests, rapid integrin recycling back to the membrane. The short-loop pathway converges at the early endosome, and also recycles inactive $\beta 1$-integrin heterodimers. (2) The long-loop pathway locates integrsin to the perinuclear recycling comparment (PNRC), and is Rab11 dependent. It is a longer recyling pathway for integrins, and is the pathway active $\beta 1$-integrin heterodimers take. This recycling ensures a fresh pool of integrins are available at the cell surface to engage the matrix and create new adhesions for traction in cell migration. 
assembly at the plasma membrane allows for traction required for migrating cells, as the actin fibers link the cytoskeleton of the cell to the ECM proteins such as fibronectin via integrin heterodimers. Ligand binding on integrins activates them, that which induces clustering to allow for intracellular linkage proteins to bind to the cytoplasmic tail. The proteins which mediate linkage of integrins to the actin cytoskeleton are talin, vinculin, and $\alpha$-actinin (Huttenlocher \& Horwitz 2011). Various combination of binding of these proteins to the cytoplasmic tails of integrins, and also linkage of integrins to the ECM mediates formation of focal adhesions. Focal adhesions are clusters of integrins found at central and periphery regions of the cell, and are important in providing traction forces required for migration (Huttenlocher \& Horwitz 2011). Focal adhesions also serve as signaling centres that promote cell migration. These involve Rho GTPases, which use the focal adhesions as a docking point to regulate actin polymerization and cell adhesion (Abram \& Lowell 2009; Huveneers \& Danen 2009). Cell adhesion via integrins itself serves as a signal for migration as well, in a form of outside-in signaling. Here, protein kinase A (PKA) activation by integrin adhesion is an early signal in directed cell migration (Lim et al. 2008). $\alpha 5 \beta 1$ integrins are particularly pertinent in cell migration, as they are found in many cells types, but also serve as the receptor for the ECM protein fibronectin which aids in traction (Caswell \& Norman 2008; Jones et al. 2006; Pellinen \& Ivaska 2006).

Cell migration requires the coordinated release of adhesion from the posterior of the migrating cell. The release of integrins is partly due to contractile forces, which severs the connection of integrins with the actin cytoskeleton, leaving the integrin bound to the substratum as integrin footprints (Regen \& Horwitz 1992; Smilenov et al. 1999). The other 
aspect involves coordinated integrin endocytosis at the rear of the cell, however this does not occur in all cell types (Caswell et al. 2009). Some signaling implicated in cell retraction at the trailing edge and cell adhesion detachment is the Rho/ROCK signaling pathway (Webb et al. 2004).

\section{Control of cell migration during metabolic stress}

AMPK activation has been shown to have alleviating roles in a variety of diseases, including atherosclerosis, tumour invasion and metastasis (Steinberg \& Kemp 2009). In all of these diseases, dysregulated cell migration is needed for their development and progression. The prevention of these diseases by AMPK activation may occur due to the cell migration inhibition upon AMPK activation. Given that cell migration involves massive levels of ATP consumption, due to actin dynamics and membrane traffic, the downregulation of this process under conditions of metabolic stress is consistent with the other described roles of AMPK to allow cells to maintain homeostasis and ensure survival under conditions of limited energy availability. Hence, AMPK might be expected to control cell migration, and it is possible that this occurs by several parallel molecular mechanisms.

There are several possible mechanisms by which AMPK may regulate cell migration, which to date have largely focused on the control of the actin and microtubule cytoskeleton involved in cell migration by AMPK. One of these involves a role of AMPK to inhibit cell migration through PDZ and LIM domain 5 (Pdlim5) (Yan et al. 2015). AMPK activation phosphorylates Pdlim5 which associates with Rho GEF 6 (Arhgef6) to displace it from the leading edge of the migrating cell. Displacing Arhgef6 interrupts Rac1 activity, which can no 
longer recruit Arp 2/3 to the lamellipodium. This leads to disruption of the actin network and ultimately inhibits cell migration (Yan et al. 2015).

Furthermore, AMPK phosphorylates CLIP-170 to control the speed of microtubule polymerization and directional cell migration (Nakano et al. 2010). CLIP-170 is a microtubule plus end protein that links endocytic vesicles to microtubules. It binds to newly polymerized distal ends of growing microtubules, while dissociating from older microtubules. Inhibition of AMPK results in slower tubulin polymerization and prolonged CLIP-170 association at older microtubule tips. AMPK inhibition also destabilizes microtubules and perturbs directional cell migration (Nakano et al. 2010).

It is clear that both activation and inhibition of AMPK has the propensity to perturb cell migration, and AMPK regulation of cell migration is not an on-off switch, but likely a very specific and precise regulation. Massively activating AMPK with pharmacological activators such as 5-Aminoimidazole-4-carboxamide ribonucleotide (AICAR) and A-769662 or inhibiting with Compound $\mathrm{C}$ both yield perturbed and inhibited cell migration (Nakano et al. 2010; Ross et al. 2015).

\subsection{AMPK \& control of $\beta 1$-integrin}

As described above, AMPK is an emerging regulator of the membrane traffic of a number of proteins including GLUTs, $\mathrm{Na}^{+} / \mathrm{K}^{+}$-ATPase, and others, suggesting that AMPK may have previously unappreciated, broader roles in regulating the cell surface membrane traffic of a number of additional proteins. To determine how AMPK may broadly control the 
cell surface proteome, the Antonescu lab previously used a streptavidin/biotinylation approach to selectively label proteins on the cell surface (Ross et al. 2015). When coupled with treatment of cells with the AMPK activator A-769662 and mass spectrometry, this approach allowed the identification of proteins that exhibited altered cell surface abundance in AMPK-activated cells. This work revealed that AMPK activation resulted in alteration of cell surface abundance of many proteins. Gene ontology analysis revealed that regulators of cell adhesion and migration are depleted from the cell surface upon activation of AMPK, including $\beta 1$-integrin, $\alpha 4$ integrin, $\alpha 11$-integrin, FAT tumour suppressor homolog 4 (FAT4) and protocadherin-7 (Ross et al. 2015) . Using several additional methods, AMPK indeed reduced the level of cell surface $\beta 1$-integrin, but did not change the total levels of $\beta 1$-integrin (Ross et al. 2015). As such, this previous work identified $\beta 1$-integrin as a protein that undergoes alteration in membrane traffic upon treatment with the AMPK activator A-769662, resulting in reduced cell surface levels of $\beta 1$-integrin (Ross et al. 2015). As $\beta 1$-integrin does not contain a consensus AMPK phosprylation site, direct interaction with AMPK to mediate this regulation is not likely.

However, it is important to consider the possibility of off target effects of most drugs, of which AMPK activators are no exception (Vincent et al. 2014). AMPK activators such as AICAR, 2-deoxy-D-glucose, salicylate, metformin and phenformin display AMPKindependent effects on cell proliferation and metabolism with only A-769662 exerting AMPK-dependent effects (Vincent et al. 2014). Thus, it is with care that results should be interpreted, when only pharmacological activators are used. Based on the previous findings, it is possible that AMPK has a role in regulating $\beta 1$-integrin membrane traffic as a 
paradigm to regulate migration. However, it is not known whether AMPK is involved directly and what the mechanism by which AMPK may regulate integrin membrane traffic. Obtaining a better understanding of whether and how AMPK controls $\beta 1$-integrin membrane traffic is critical in order to understand how cell metabolism and metabolic stress signals broadly control endomembrane traffic and cell migration. 


\section{Rationale \& Hypothesis}

Previous findings in our lab has used a systematic approach to demonstrate coordinated remodeling of the cell surface upon in response to cell stress. This is highlighted in Ross et al. (2015), where proteins depleted from the cell surface upon AMPK activation were identified. $\beta 1$-integrin was of particular interest due to its many integrin binding partners (the most among $\beta$-integrins), as well as the role of integrins in many physiological processes, including angiogenesis and metastasis (Desgrosellier \& Cheresh 2010; De Franceschi et al. 2015; Caswell \& Norman 2006). $\beta 1$-integrin was shown to be reduced from the cell surface upon treatment with the AMPK activator A-769662 (Ross et al. 2015). Importantly, this effect of A-769662 treatment was partly specific for for $\beta 1$ integrin, as this drug had no effect on cell surface transferrin receptor levels, However, whether A-769662 controls $\beta 1$-integrin as a result of activation of AMPK or as a consequence of an off-target effect of the pharmacological activators of AMPK, AICAR and A-769662 remains to be determined. Further, elucidating the mechanism behind the interaction of $\beta 1$-integrin and AMPK will lead to greater understanding of a new pathway, but also improved potential therapeutics for cancer and metastasis.

It is not known how AMPK regulates $\beta 1$-integrin on the cell surface. I hypothesize that AMPK effects at least one component of $\beta 1$-integrin endocytosis and recycling, to cause a massive reduction of $\beta 1$-integrin on the cell surface. Using silencing RNA (siRNA) against AMPK, I determined that the effect of A-769662 on cell surface $\beta 1$-integrin was AMPK specific and not an off target consequence. I examined the mechanism of $\beta 1$-integrin cell 
surface reduction, determining whether AMPK acts to reduce the recycling or endocytosis of $\beta 1$-integrin, thus revealing the mechanism by which AMPK controls cell surface $\beta 1$ integrtin levels. AMPK may also control specific aspects of CME. Further, I found evidence suggesting that AMPK may regulate Arf6 to control membrane traffic. Arf6 GAPs, such as ArfGAP3, were found to be reduced from the cell surface upon AMPK activation (Ross et al. 2015). Analysis of ArfGAP3 revealed that it contains a consensus AMPK phosphorylation site (Table 1). AMPK activation also induces relocalization of Arf6 from the plasma membrane to cytoplasmic compartments in a Arf6 GTPase-dependent manner. Therefore, AMPK regulates $\beta 1$-integrin in response to metabolic stress, potentially by acting on Arf6 or its effectors. 


\section{Materials \& Methods}

A-769662 and QS11 was obtained from Abcam (Cambridge, MA), AICAR was obtained from Cell Signaling Technology (Danvers, MA), Antibodies for immunoblotting were: anti-pACC, anti-AMPK $(\alpha 1 / 2)$, anti-actin and from Cell Signaling Technology (Danvers, MA), and anti- $\beta 1$-integrin (Calbiochem, Billerica, MA). Antibodies used for immunofluorescence assay were: anti- $\beta 1$-integrin from EMD Millipore, (Darmstadt, Germany), and anti-TfR from Santa Cruz Biotechnology (Santa Cruz, CA). GFP-Arf6-WT \& GFP-Arf6-Q67L were generously gifted by Sergio Grinstein (The Hospital for Sick Children, Toronto, ON).

\section{RPE cell culture and pharmacological treatments}

Human non-immortalized Retinal Pigment Epithelial (ARPE-19, henceforth RPE) were obtained from ATCC. RPE cells stably expressing clathrin light chain fused to enhanced RFP (RPE-RFP-CLC, henceforth RPE-RFP) were previously generated (Aguet, Antonescu, Mettlen, Schmid \& Danuser, 2013). All RPE cells were maintained in T75 flasks in DMEM F12 supplemented with 10\% fetal bovine serum (FBS) and 5\% streptomycin/penicillin in a humidified incubator at $37^{\circ} \mathrm{C}$ and $5 \% \mathrm{CO} 2$. For experiments requiring AMPK activation, RPE cells were washed with PBS and incubated in low serum media (0.1\% FBS in DMEM F12) for 1 hour, after which they were treated with $100 \mu \mathrm{M} \mathrm{A-}$ 769662 or 2 mM AICAR as indicated (while remaining in the 0.1\% FBS DMEM F12 media) to activate AMPK. After treatment for 15, 30, 60 minutes or 24 hours, cells were washed and harvested. For experiments requiring ArfGAP inhibition, RPE cells were incubated in low serum media for 30 minutes and treated with $5 \mu \mathrm{M}$ QS11 for 15 minutes for endocytic 
assay, or 30 minutes for cell surface experiments. In some experiments (Fig 6), cells were also treated with $40 \mu \mathrm{M}$ compound $\mathrm{C}$ for 1 hour.

\section{cDNA transfection}

Transfection of RPE cells with GFP-Arf6-WT and GFP-Arf6-Q67L or only eGFP (control) was performed with Lipofectamine 2000 (ThermoFisher, Waltham, MA) as per the manufacturers' instructions. Briefly, RPE and RPE-RFP cells were transfected using $1 \mu \mathrm{g}$ DNA and $3 \mu \mathrm{L}$ Lipofectamine 2000 reagent in a volume of $1 \mathrm{~mL}$ of serum-free media (per well of a 12 well plate) for 4 hours.

\section{siRNA transfection}

RPE cells were transfected with siRNA using custom-synthesized siRNAs using RNAiMAX transfection reagent (Life Technologies, Carlsbad, CA), as per manufacturer's instructions. Briefly, each siRNA was transfected at a concentration of $220 \mathrm{pmol} / \mathrm{L}$ with the transfection reagent in Opti-MEM media (Life Technologies, Carlsbad, CA) for 4 hours, followed by washing and replacement with regular growth media. siRNA transfections were performed twice (72 h and $48 \mathrm{~h}$ ) prior to each experiment. Sequences used were as follows: nontargeting (NT) control: (sense) CGUACUGCUUCGGAUACGGUU, (antisense) CCGUCUCGCAAGCAGUACGUU and AMPK $\alpha 1 / 2$ :

(sense) GCACCUUCGGCAAAGUGAAUU, (antisense) UUCACUUUGCCGAAGGUGCUU (Dharmacon, GE Healthcare, Lafayette, CO). 


\section{Total and cell surface immunofluorescence assay}

To selectively detect cell-surface proteins, intact cells were washed with PBS

(supplemented with $1 \mathrm{mM} \mathrm{CaCl} 2$ and $\mathrm{MgCl}_{2}\left(\mathrm{PBS}^{2+}\right)$ ) and blocked in a solution of $\mathrm{PBS}^{2+}$ with $3 \%$ bovine serum albumin (BSA) for 15 minutes at $4^{\circ} \mathrm{C}$. Cells were then incubated with primary antibody to an exofacial epitope recognizing Transferrin receptor or $\beta 1$-integrin for 1 hour at $4{ }^{\circ} \mathrm{C}$. Coverslips were washed in $\mathrm{PBS}^{2+}$ before fixation with $4 \% \mathrm{PFA}\left(\right.$ in $\mathrm{PBS}^{2+}$ ) for 20 minutes at $4^{\circ} \mathrm{C}$. After quenching with $\mathrm{PBS}^{2+}$ containing $100 \mathrm{mM}$ glycine, cells were washed with $\mathrm{PBS}^{2+}$ and incubated with goat anti-mouse cy3 secondary antibody for 1 hour at room temperature. After several washes, coverslips were mounted in Dako fluorescent mounting media (Dako, Carpinteria, CA).

For total protein detection (i.e. of both cell surface and intracellular proteins), cells were initially fixed in $4 \% \mathrm{PFA}$ for 20 minutes at $4^{\circ} \mathrm{C}$, following by quenching with solution of $100 \mathrm{mM}$ glycine and $0.1 \%$ Triton $\mathrm{X}-100$ in $\mathrm{PBS}^{2+}$ for 10 minutes at room temperature. Cells were then washed in $\mathrm{PBS}^{2+}$ and blocked with 3\% BSA (in $\mathrm{PBS}^{2+}$ ) for 15 minutes at room temperature, followed by addition of primary antibody at room temperature for 1 hour. Cells were washed with PBS followed by addition of goat anti-mouse cy3 secondary antibody for 1 hour. After several washes, coverslips were mounted in Dako fluorescent mounting media (Dako, Carpinteria, CA). 


\section{Endocytosis assay}

Cells were incubated with low serum conditions (0.1\% DMEM F12) for 1 hour at

$37^{\circ} \mathrm{C}$. Following that, the intact cells were blocked with 3\% BSA, and subsequently incubated with anti- $\beta 1$-integrin antibody for 1 hour at $4^{\circ} \mathrm{C}$ to label only cell surface $\beta 1$ integrin. After several washes with $\mathrm{PBS}^{2+}$, cells were incubated at $37^{\circ} \mathrm{C}$ in media with or without $100 \mu \mathrm{M}$ A-769662 for 15 minutes. Time $=0$ coverslips were not subsequently incubated at $37^{\circ} \mathrm{C}$ and left at $4^{\circ} \mathrm{C}$ during the 15 -minute incubation of the experimental conditions. All conditions were then subjected to goat anti-mouse cy3 secondary antibody for 1 hour; for the conditions that underwent rewarming after labeling with primary antibody labeling, this allowed detection of only those antibody- $\beta 1$-integrin complexes remaining at the cell surface (and not those that underwent internalization). Following washes with $\mathrm{PBS}^{2+}$, cells were fixed with 4\% PFA (in $\mathrm{PBS}^{2+}$ ) and quenched with $100 \mathrm{mM}$ glycine solution in $\mathrm{PBS}^{2+}$. After several $\mathrm{PBS}^{2+}$ washes, coverslips were mounted in Dako fluorescent mounting media (Dako, Carpinteria, CA).

For ArfGAP1 inhibition endocytic experiments, protocol was as described above except the following changes: cells were incubated in low serum conditions for 1 hour at $37^{\circ} \mathrm{C}$, followed by 30 -minute treatment with $5 \mu \mathrm{M}$ QS11. After primary antibody labelling, cells were incubated with $5 \mu \mathrm{M}$ QS11 for 15 minutes. 


\section{Antibody recycling assay}

Cells were incubated for 1 hour at low serum conditions. Following that, 0.1\% FBS DMEM F12 media supplemented with anti- $\beta 1$-integrin or anti-TfR antibody (1:400) and $100 \mu \mathrm{M} \mathrm{A}-769662$ or without (control) was added to cells for 15,30 and 60 minutes at $37^{\circ} \mathrm{C}$ to allow for receptor recycling. After incubation for indicated times, cells were placed at $4^{\circ} \mathrm{C}$ and fixed with $4 \% \mathrm{PFA}$ and quenched with $100 \mathrm{mM}$ glycine $+0.1 \%$ Triton X-100 solution in $\mathrm{PBS}^{2+}$. After washing with $\mathrm{PBS}^{2+}$, cells were labelled with goat anti-mouse cy3 secondary antibody for 1 hour. After several washes with $\mathrm{PBS}^{2+}$, coverslips were mounted in Dako fluorescent mounting media (Dako, Carpinteria, CA). $\beta 1$-integrin and TfR total protein labelling was performed as described above. Each timed recycling condition was divided by total receptor to measure recycling rate (timed condition fluorescence/total fluorescence).

\section{Widefield epifluorescence imaging}

Immunofluorescence microscopy presented in Figures 5B, $\mathbf{7}$ and $\mathbf{8}$ was performed using a 63x (NA 1.49) oil objective on a Leica DM5000 B epifluorescence microscope using a DFC350FX camera (Leica Microsystems, Wetzlar, Germany). Images were acquired using Adobe Photoshop (San Jose, CA) and all exposure times and image scaling were equal within an experiment. Wide-field epifluorescence microscopy experiments presented in

Figures 10, 11, 12, 14 and 15 were obtained using a 60× (NA 1.4) oil immersion objective on a Zeiss Axiovert 200M epifluorescence microscope using an ORCA-Flash 4.0 camera (Hamamatsu Corporation, Bridgewater, NJ). 


\section{Cell surface and total staining abundance quantification}

Surface and total $\beta 1$-integrin or TfR in each cell was quantified using ImageJ software (National Institutes of Health, Bethesda, MD). Mean pixel intensity of fluorescence was measured for regions of interest corresponding to cell contour (whole cell) via manually delineation in ImageJ (Fig 7, red traces). Average background fluorescence was determined by measuring pixel intensity of a region of interest outside of the cell area and subtracted from the mean pixel intensity of a region of interest as indicated in Fig $\mathbf{7}$ Cyellow traces). Similar measurements were performed on cells subjected to a similar immunofluorescence method but without incubation with specific primary antibodies. Cell surface secondary antibody labeling in cells not incubated with primary antibody was $\sim 10 \%$ of that of control cells incubated with either anti- $\beta 1$-integrin or-TfR antibodies; the mean no-primary fluorescence intensity value was subtracted from all conditions in each experiment.

Images were 16-bit and typical intensity ranges were between 10-30000 units ensuring pixel intensity saturation did not occur. Measurements of $\beta 1$-integrin cell surface abundance under each set of conditions were subject to one-way analysis of variance (ANOVA) with Newman-Keuls post-test, with $\mathrm{p}<0.05$ as a threshold for significant difference among conditions. Measurements of $\beta 1$-integrin cell surface under two conditions (Control, A-769662 or Control, QS11) and TfR cell surface abundance under two conditions (Control, A-769662) were subject to a Student's t-test, with a p $<0.05$ as a threshold for significant difference among conditions. 


\section{Cell Migration Assay}

RPE cells grown to confluence in a $35 \mathrm{~mm}$ dish with a grid (Sarstedt Canada, Montreal, QC) for cell migration experiments. Plates with confluent cells were wounded by a single passage of a p10 micropipette tip. Cells were then immediately washed and placed in media containing $0.1 \%$ FBS (to minimize cell proliferation), and treated with $100 \mu \mathrm{M} \mathrm{A}$ 769662 or not (control). Images were acquired at 0 and 24 hours following wounding. Images of cells were acquired using a Leica DM IL microscope equipped with a Skylight camera phone microscope mount, using a Samsung Galaxy S4 smartphone digital camera. Images were manually aligned using dish grid. Cell migration was quantified by measuring the area of the wound covered by cells after $24 \mathrm{~h}$ (using manual delineation of cell coverage area using Image J), and expressed as a percent of the initial wound area. At least 20 individual wounded areas were examined for each condition in each experiment.

\section{Cell viability assay}

Cell viability determination by propidium iodide staining in the absence of detergent permeabilization. Following cellular with A-769662 for 24 hours, intact RPE cells were incubated with $500 \mathrm{nM}$ propidium iodide for $15 \mathrm{~min}$ at $4^{\circ} \mathrm{C}$, followed by washing, fixation and mounting in Dako fluorescent mounting media as described above. As a positive control for propidium iodide staining, an additional, parallel experiment was performed by first subjecting cells to fixation (4\% PFA for $30 \mathrm{~min}$ ) and permeabilization (0.1\% TX-100 for $20 \mathrm{~min}$ ) prior to labeling with $500 \mathrm{nM}$ propidium iodide. 


\section{Immunoblotting}

Whole-cell lysates were prepared in Laemmli Sample Buffer (LSB, 0.5M Tris pH 6.8, Glycerol, 10\% SDS, 10\% $\beta$-mercaptoethanol, and 5\% bromophenol blue, all from BioShop, Burlington, ON) supplemented with a protease and phosphatase cocktail (1 mM sodium orthovanadate, $10 \mathrm{nM}$ okadaic acid, and $20 \mathrm{nM}$ Protease inhibitor cocktail (BioShop, Burlington, $0 \mathrm{~N}$ ). Lysates were then heated at $65 \mathrm{C}$ for $15 \mathrm{~min}$ and passed through a 27.5 gage syringe.

Lysates from whole-cell extracts were probed by Western blotting. Samples were subjected to glycine-Tris SDS-PAGE to resolve proteins and followed by transfer to polyvinylidene fluoride membrane (Bio-Rad, Burlington, ON). The membranes were blocked in a solution of TBS-T containing 4\% BSA or 3\% milk for 30 minutes at room temperature with primary antibody for 1 hour. Appropriate secondary antibodies were used to probe the primary antibodies. The measurements of anti- $\beta 1$-integrin were normalized to the loading control signal (actin). Quantification of AMPK $\alpha 1 / \alpha 2$ knockdowns via immunoblotting was performed by normalizing anti-AMPK signal to the loading control (actin), followed by comparison to control (NT) siRNA anti-AMPK signal.

\section{TIRF microscopy and spinning disk confocal microscopy imaging}

Fixed cells on $22 \mathrm{~mm}$ by $22 \mathrm{~mm}$ coverslips were mounted on two double-strips of double-sided tape on a glass slide with PBS supplemented and sealed with VALAP (Antonescu et al., 2011) for TIRF microscopy (TIRFM). TIRFM experiments presented in Fig 16 and 17 were visualized using a 150× (NA 1.45) objective on an Olympus IX81 
instrument (Olympus, Tokyo, Japan) equipped with CellTIRF modules (Olympus Canada, Richmond Hill, Canada) using 491- (50 mW) and 561-nm (50 mW) laser illumination and 520/30 and 624/50 emission filters. Images were recorded using a C9100-13 EM-CCD camera (Hamamatsu). Images were acquired using Volocity (PerkinElmer, Waltham, MA). All exposure times were consistent within an experiment.

Spinning disk confocal microscopy experiments presented in Fig 13 obtained using a Nikon Olympus IX81 equipped with a Yokogawa CSU X1 scanhead and a 100× (NA 1.4) oil objective using a Hamamatsu C9100-13 electron-multiplying charge-coupled device (EMCCD) camera. Excitation light was provided by 488- (100 mV), and emitted light was collected after passage through 525/50.

\section{TIRF microcopy and spinning disk confocal microscopy analysis}

Diffraction limited objects light exhibit a point-spread function (PSF) as a result of diffraction from a small point-emitter of light (Aguet et al. 2013). CCPs are diffraction limited objects. To detect CCPs, a Gaussian model approach was used as per Aguet et al. (2013) to approximate the PSF of the diffraction-limited CCPs. The position of CCPs and intensity of RFP-CLC and of GFP-Arf6 was measured at each CCP (Aguet et al., 2013). For the latter, the amplitude of the Gaussian model for each CCP (in one of many fluorescence channels) is an indication of the fluorescence intensity of clathrin (or other proteins) within CCPs, measured relative to a local background fluorescence, without the need for global image thresh-holding (Aguet et al. 2013) . The fluorescence intensity of a particular protein within CCPs thus reflects the number of such molecules within each structure. 
Measurements of clathrin or other proteins within individual CCPs by this method were used to obtain a cellular average of relative protein recruitment to CCPs under specific conditions. 


\section{Results}

Using siRNA gene silencing in combination with treatment with the AMPK activator A-769662, I uncovered that AMPK activation reduces cell surface $\beta 1$-integrin. This was an important consideration, as pharmacological activators of AMPK exhibit a growing list of off-target and AMPK independent effects which may result in misinterpretation of results based only on A-769662 (Vincent et al. 2014). I established AMPK silencing in RPE cells, to establish that the regulatory control of $\beta 1$-integrin by AMPK is a real phenomenon. I found that total cellular $\beta 1$-integrin levels do not change upon treatment with A-769662, showing that AMPK does not lead to degradation of internalized $\beta 1$-integrin. To study physiological consequences of AMPK regulating $\beta 1$-integrin, I established a scratch wound assay, measuring cell migration. I found that AMPK activation impairs cell migration, consistent with a role for AMPK in controlling $\beta 1$-integrin membrane traffic. I uncovered that AMPK activation results in alteration in the rate of $\beta 1$-integrin recycling, as well as in the properties of clathrin-coated pits, showing that AMPK may control membrane traffic at several distinct stages. Lastly, I uncovered evidence that AMPK regulates Arf6 in a manner that requires Arf6 GTPase activity. 


\section{Results Part I: AMPK regulates $\beta 1$-integrin on the cell surface \& cell migration}

\section{AMPK is required for $\beta 1$-integrin cell surface reduction}

In order to determine if AMPK is required for $\beta 1$-integrin cell surface reduction elicited by A-76962 treatment, I established AMPK silencing in RPE cells. I transfected RPE cells with siRNA targeting AMPK $\alpha 1 / 2$ and non-targeting (NT, control) siRNA. To confirm and measure the level of AMPK $\alpha 1 / 2$ knockdown, I prepared whole-cell lysates and subjected these to immunoblotting with anti-AMPK $\alpha 1 / 2 \&$ anti-actin antibodies (loading control) (Fig. 5A). AMPK $\alpha 1 / 2$ siRNA cells showed a $69.6 \pm 2.6 \%$ reduction in total AMPK $\alpha$-subunit expression, indicating effective silencing of AMPK.

To determine how AMPK silencing impacts the control of cell surface $\beta 1$-integrin upon A-769662 treatment, I then fluorescently labelled cell surface $\beta 1$-integrin in intact control siRNA cells (control and A-769662 treated conditions) and AMPK $\alpha 1 / 2$ silenced cells (control and A-769662 treated conditions). The antibody recognizes an exofacial epitope on $\beta 1$-integrin, and does not bind differently to activate and inactive $\beta 1$-integrin, making this a suitable reporter of total cell surface $\beta 1$-integrin (Jimenez-Soto et al. 2009). NT siRNA cells displayed the same reduction of cell surface $\beta 1$-integrin upon AMPK activation by A-769662 seen previously (Fig 5B,C). However, the AMPK $\alpha 1 / 2$ siRNA cells no longer displayed reduction in cell surface $\beta$ 1-integrin (Fig 5B,C). Both the control and the A-769662 treated conditions of AMPK $\alpha 1 / 2$ deficient cells showed comparable levels of $\beta 1$-integrin to the NT siRNA condition. These results indicate that the reduction of cell 
surface $\beta 1$-integrin by A-769662 require AMPK, suggesting that AMPK does indeed control $\beta 1$-integrin membrane traffic.

To determine whether the reduced levels of $\beta 1$-integrin on the cell surface in AMPK activated cells is due to translocation of cell surface $\beta 1$-integrin to an internal membrane compartment or instead due to $\beta 1$-integrin degradation, I prepared whole cell lysates of RPE cells treated with A-769662, AICAR, and Compound C (AMPK inhibitor) for 60 minutes, and subjected these to immunoblotting with anti- $\beta 1$-integrin and anti-actin antibodies (loading control). No difference was seen in total $\beta 1$-integrin in all three conditions compared to control, confirming that the reduction of cell surface $\beta 1$-integrin is due to internalization into cellular compartments and not merely reflecting a reduction in whole cell $\beta 1$-integrin (Fig 6).

To ensure that the difference seen in cell surface $\beta 1$-integrin was due to changes in abundance and not changes in cell area, I measured the cell area in control and A-769662 treated cells. There was no apparent difference in cell size in the A-769962 treated condition compared to the control (Fig 7), highlighting that the changes in cell surface $\beta 1$ integrin was indeed due to a difference in $\beta 1$-integrin cell surface abundance. 


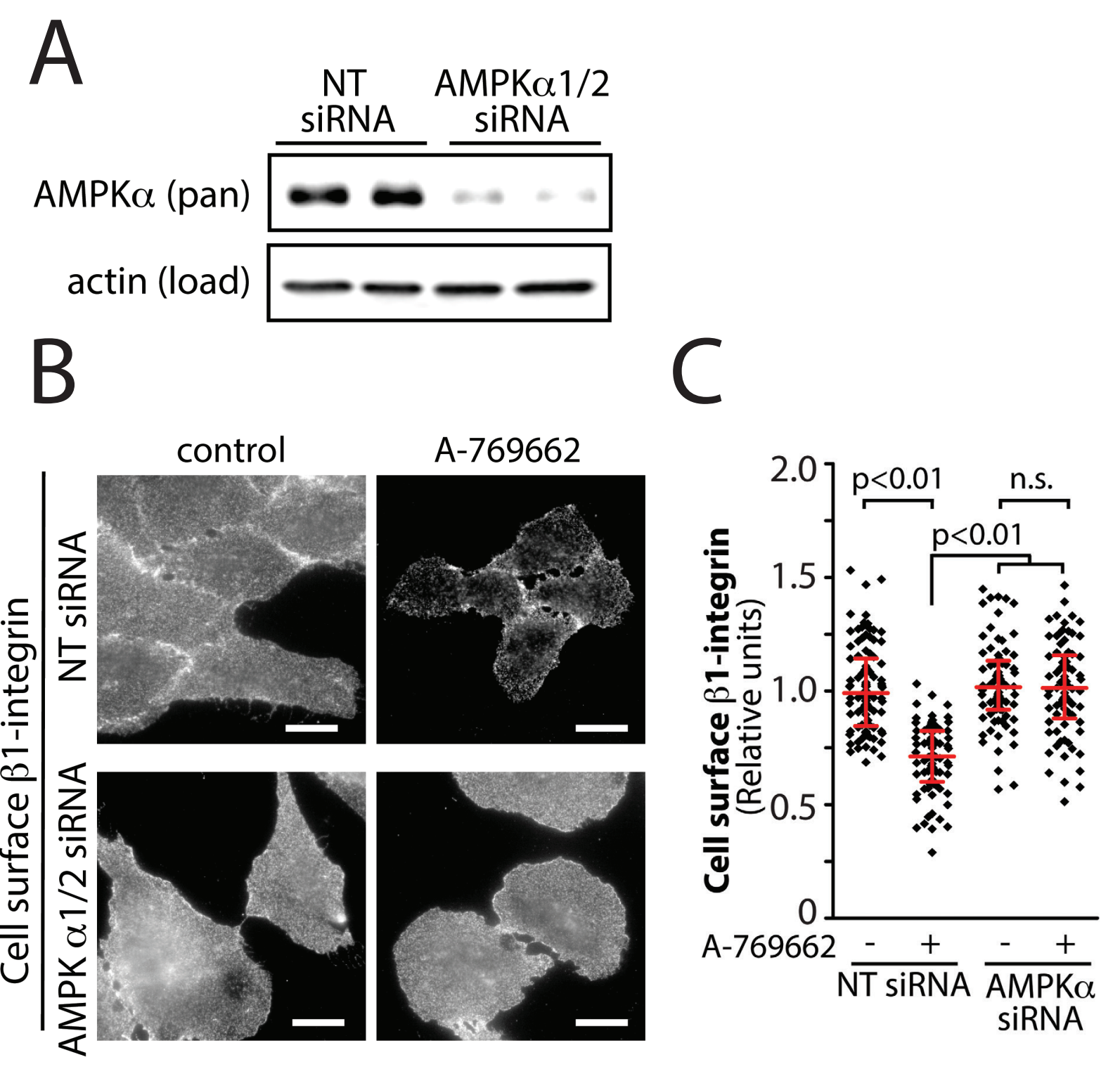

Fig 5. Inhibition of AMPK by siRNA gene silencing prevents the reduction in cell surface $\beta 1$-integrin elicited by A-769662 treatment.

(A-C) RPE cells were transfected with siRNA targeting AMPK $\alpha 1 / 2$ or non-targeting (NT, control) siRNA. (A) Whole cell lysates were prepared and resolved by immunoblotting and probed with anti-AMPK $\alpha 1 / 2$ or anti-actin antibodies. Shown are immunoblots representative of at least 3 independent experiments. (B) Following siRNA transfection, cells were treated with $100 \mu \mathrm{M} \mathrm{A}-769662$ for $60 \mathrm{~min}$ as indicated. Intact cells were labeled with an antibody specific for an exofacial epitope on $\beta 1$-integrin. Shown are representative fluorescence micrographs depicting cell surface $\beta 1$-integrin fluorescence. Scale $=5 \mu \mathrm{m}$ (C) Cell surface $\beta$ 1 -integrin levels obtained by fluorescence microscopy were quantified. Shown are the cell surface $\beta 1$-integrin measurements in individual cells (diamonds) as well as the median \pm interquartile range of these values in each treatment condition $(n=3$ independent experiments) 


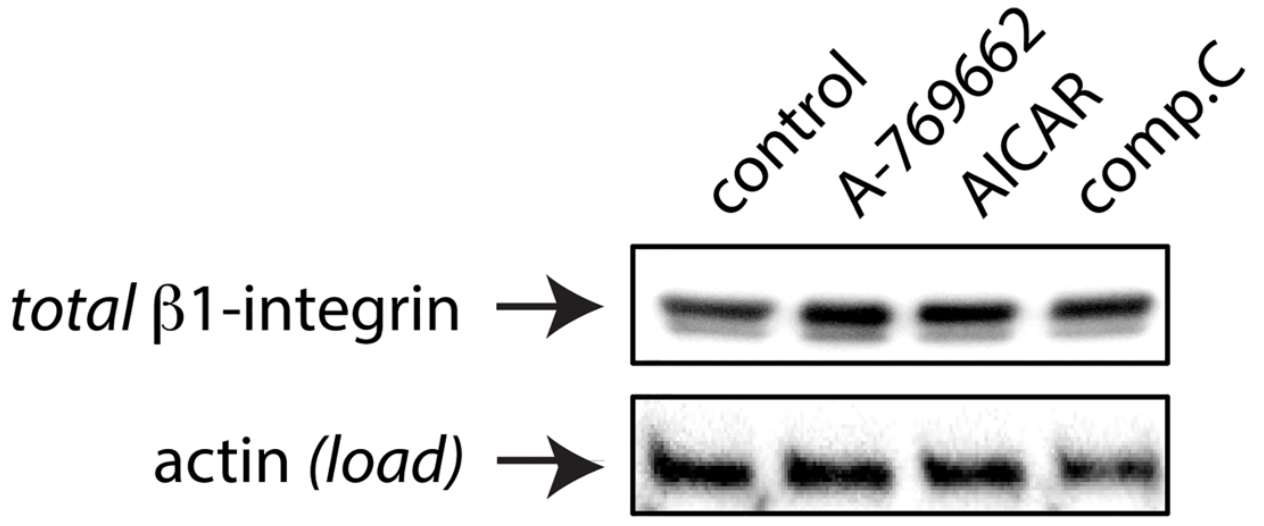

Fig 6. Activation or inhibition of AMPK does not lead to $\beta 1$-integrin degradation.

RPE cells were treated with A-769662 \& AICAR to activate AMPK, and Compound C to inhibit AMPK. Whole cell lysates were prepared and resolved by immunoblotting and probed with anti$\beta 1$-integrin or anti-actin antibodies. Shown are immunoblots for total $\beta 1$-integrin.

\section{AMPK activation by A-769662 hinders migration of RPE-WT cells}

Next, I examined whether there are cell physiological consequences of the regulation of $\beta 1$-integrin by AMPK. Cell migration requires constitutive, directed membrane cycling of $\beta 1$-integrin, from the back of the cell to the front. To determine whether A-769662 treatment affected cell migration, I employed a wound scratching assay, which allows measurement of the rate of cell migration to close a gap formed in a cell monolayer. RPE cells were grown to confluence on $35 \mathrm{~mm}$ plates with a grid and wounded with a single pass of p10 pipette tip. The cells were subjected to A-769662 or the untreated condition. Cell migration was quantified by percent of wound area covered in 24 hours (Fig 8A). Cells in the control condition covered $80 \%$ of the wound after 24 hours, whereas A769662 treated cells only covered $17 \%$ of the wound after the same amount of time (Fig 8B). 

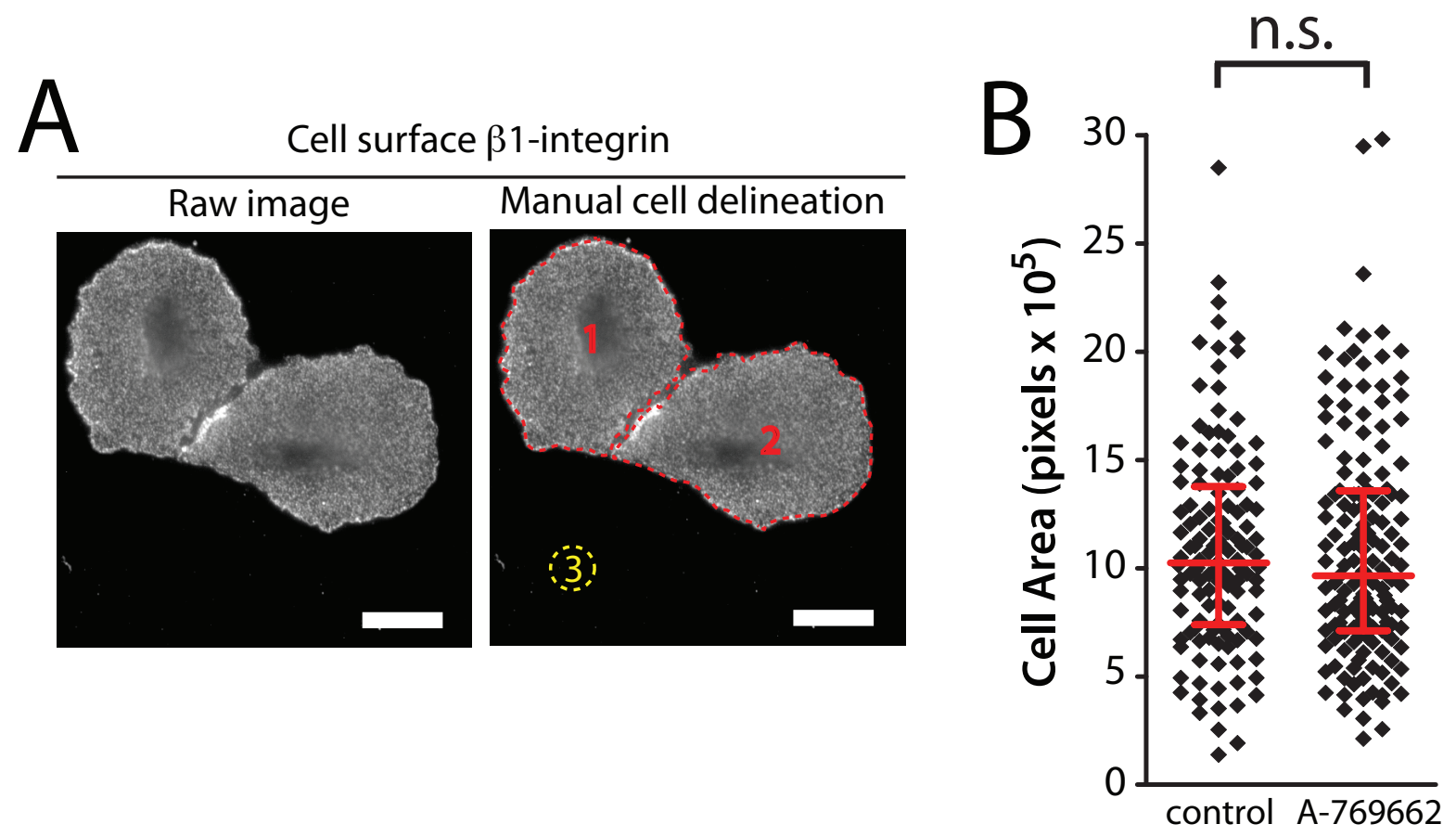

Fig 7. A-769662 treatment does not affect cell area

Manual cell delineation is shown in (A), which involves subtracting the cell fluorescence intensity (1) by the background fluorescence intensity (3) Scale $=5 \mu \mathrm{m}$ (B) The area of cells quantified for cell surface $\beta 1$-integrin experiments is shown. In both control and A-769662, there is no difference in cell size which shows that the decrease $\beta 1$ integrin on the cell surface is not due to a change in cell size, but due to abundance. 
A
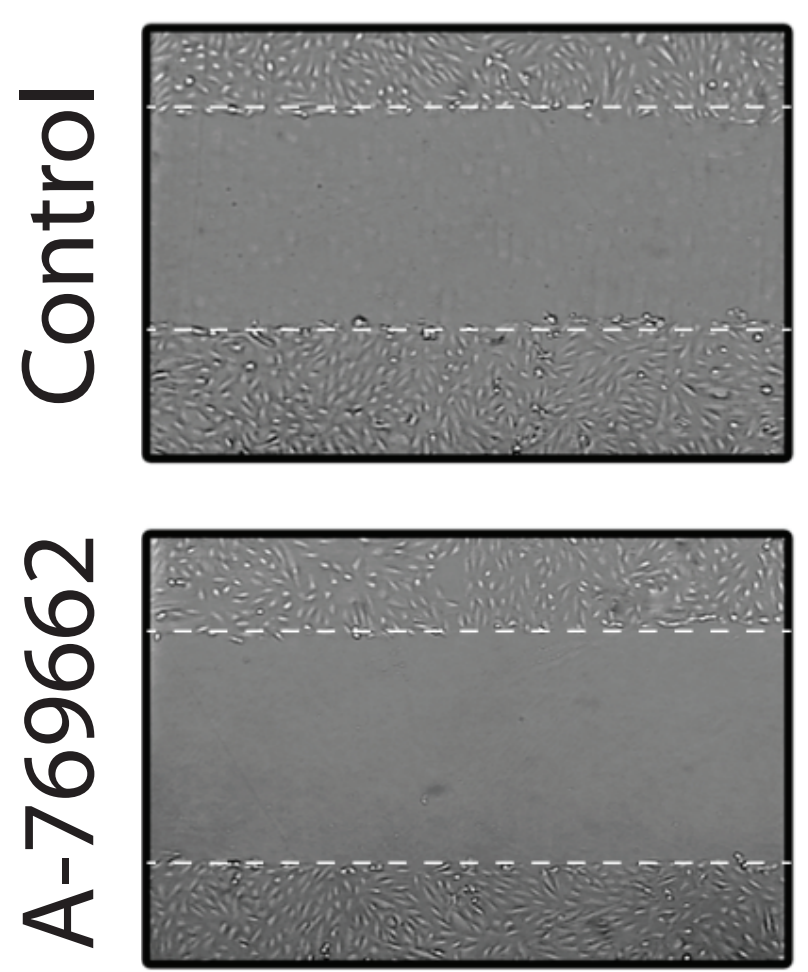

\section{$24 \mathrm{H}$}
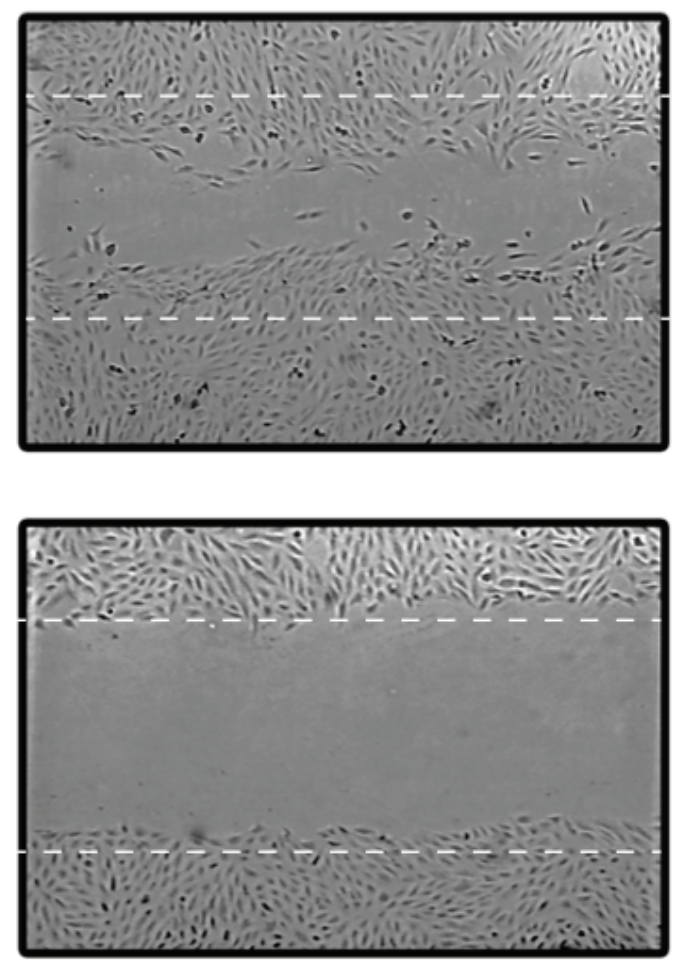

B

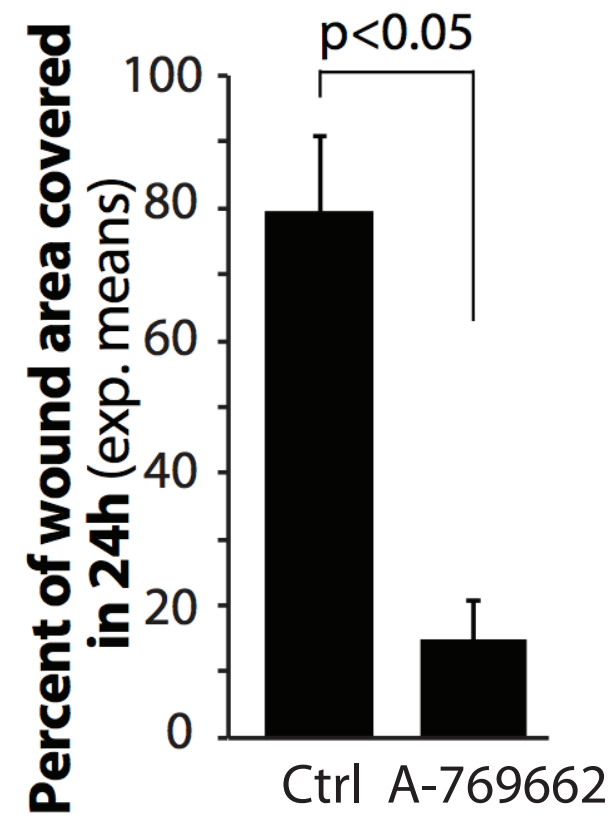

Fig 8. Treatment with A-769662 reduces cell migration

RPE cells were subjected to an epithelial wounding cell migration assay, either under conditions of continuous stimulation with 100 $\mu \mathrm{M}$ A-769662 or unstimulated (control) (A) Shown are representative micrographs of cells immediately after wounding ( $0 \mathrm{~h}$ ) or $24 \mathrm{~h}$ after wounding, as indicated, with the region of the wound indicated by dashed white lines. (B) The coverage of the wounded area by cells 24 hours after wounding was quantified; shown are the means \pm SE of the percent of wounded area covered by migrating cells in $24 \mathrm{~h}$ in control and A-769662 treated cells ( $\mathrm{n}=3, \mathrm{p}<$ 0.05). 


\section{Long term AMPK activation by A-769662 does not affect cell viability}

To ensure that the reduction of cell migration in cells treated with A-769662 for 24 hours was a consequence of signals activated as a result of AMPK activation, and not the result of decreased cell viability, I performed a viability assay with propidium iodide (PI) staining. PI fluorescently labels for nucleic acids in dead cells, but is unable to do so in living cells with an intact plasma membrane, as such, living cells are impermeable to PI (Yeh et al. 1981). I grew RPE cells to confluence in and subjected them to the same conditions used for the cell migration assay: untreated (control) and A-769662 treatment for 24 hours. To obtain a positive control for PI staining, I examined a separate condition in which I permeabilized untreated cells and stained with PI; this mimics the PI staining observed upon cell death. A-769662 treated cells remained intact, as evinced by the lack of PI labeling of A-769662 treated cells (Fig 9). Hence, A-769662 treatment for 24 hours does not cause cell death, and the reduction in cell migration is a consequence of AMPK signaling within viable cells. 
permeabilized

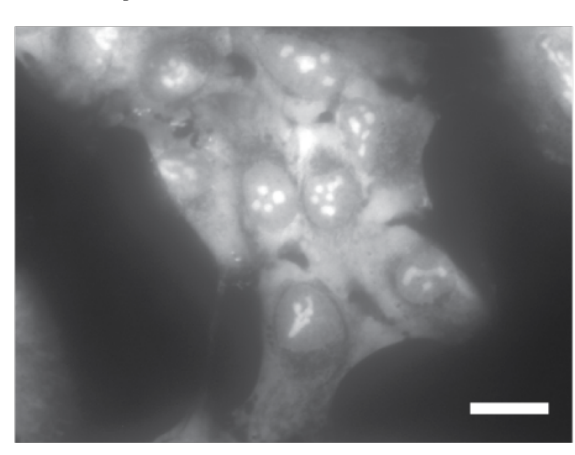

non-permeabilized,

$0.1 \%$ FBS + $100 \mu \mathrm{m} \mathrm{A-769662} \mathrm{(24h)}$

Fig 9. Treatment with AMPK activators does not alter cell viability yet regulates cell surface $\beta 1$-integrin levels.

RPE cells were treated using identical conditions as used for the cell migration assay (Fig 8, $0.1 \%$ FBS in DMEM with $100 \mu \mathrm{M}$ A-769662). Following this treatment, intact cells were subjected to staining using propidium iodide (PI); cells prepared in parallel that were first fixed and permeabilized prior to treatment with PI provide an effective positive control for PI staining to detect permeabilized (non-viable) cells. pixel intensity display range is different between the left panel and the right two panels. In the right two panels, the fluorescence labeling with PI does not produce a signal within cells above the background outside of cells. Scale $=5 \mu \mathrm{m}$.

\section{Results Part II: AMPK activation controls specific stages of $\beta 1$-integrin membrane traffic}

\section{Acute AMPK activation does not appreciably alter the rate of $\beta 1$-integrin endocytosis}

To determine which component of cell surface $\beta 1$-integrin traffic is subject to regulation by AMPK activation, I first examined the rate of $\beta 1$-integrin endocytosis. I performed an endocytic assay to measure endocytosis of $\beta 1$-integrin in cells treated with A-769662 and in control cells. This assay involves labelling all cell surface $\beta 1$-integrin in intact cells with an anti- $\beta 1$-integrin primary antibody at $4^{\circ} \mathrm{C}$, a temperature at which cell surface membrane traffic is reversibly arrested. Following washing to remove excess 
antibody, the cells were then rapidly returned to $37^{\circ} \mathrm{C}$ to allow membrane traffic (including endocytosis) for 15 minutes, and then immediately returned to ice and labelled with secondary antibody. Of note, the secondary antibody may only access the $\beta 1$-integrin antibody remaining at the cell surface, but not the antibody internalized during the $15 \mathrm{~min}$ incubation at $37^{\circ} \mathrm{C}$. As such, comparing the fluorescence intensity of $\beta 1$-integrin remaining at the cell surface (as a function of initial cell surface $\beta 1$-integrin labeling at $4^{\circ} \mathrm{C}$ ) allows measurement of the rate of $\beta 1$-integrin internalization.

The key comparison in this experiment is that of the fraction of cell surface $\beta 1$ integrin remaining at the cell surface after 15-minute internalization in control vs A769662-treated cells. Importantly, these experiments reveal that there is no difference in the amount of $\beta 1$-integrin internalized in untreated and A-769662 conditions (Fig 10). However, there are two key experimental limitations here: 1) that the A-769662 cannot be added prior to the $4^{\circ} \mathrm{C}$ labeling stage, as cooling temperatures alter certain signal transduction pathways (Al-Fageeh \& Smales 2006) and 2) the measurement of $\beta 1$-integrin internalization, and thus A-769662 treatment, is limited to 15 minutes. Any longer timepoints allow the recycling of $\beta 1$-integrin back to the plasma membrane following internalization, which then includes recycled $\beta 1$-integrin and convolutes the parameters being measured (Teckchandani et al. 2009). Hence, that I did not observe an effect A769662 treatment on $\beta 1$-integrin endocytosis may reflect that AMPK does not regulate $\beta 1$ integrin endocytosis, or may instead be the result of the fact that the experimental assay does not allow sufficient time for activation of AMPK and regulation of internalization in 
the 15 minutes of the assay.

\section{$\beta 1$-integrin recycling is regulated by $A M P K$ activation}

Next, I looked at $\beta 1$-integrin recycling to see if A-769662 treatment effected this portion of trafficking. For this, I performed a recycling assay which requires incubating cells at $37^{\circ} \mathrm{C}$ with the anti- $\beta 1$-integrin antibody present in the cellular media (DMEM F12). Cells are incubated for 15,30 and 60 minutes with the antibody solution to label the $\beta 1$ integrin recycling through the plasma membrane. After this stage and subsequent fixation and permeabilization, the $\beta 1$-integrin which bound anti- $\beta 1$-integrin antibodies are probed with fluorescently-conjugated secondary antibodies. The percentage of $\beta 1$-integrin recycling through the cell surface in each condition and time point is determined by (recycling- $\beta 1$-integrin/total- $\beta 1$-integrin). The conditions I tested were untreated and A769662 treated for the three time points: 15,30 and 60 minutes. There is a significant difference in $\beta 1$-integrin recycling in A-769662 treated conditions (Fig 11). Hence, activation of AMPK significantly reduces $\beta 1$-integrin recycling through the plasma membrane. The difference in recycling is present, but modest, at the 30-minute time point (Fig 11). At 60 minutes, the full extent of $\beta 1$-integrin recycling reduction due to A-769662 treatment is evident. There is a 40\% reduction in recycling in A-769662 treated cells compared to control. Hence, upon AMPK activation by A-769662, $\beta 1$-integrin recycling is reduced. This result is consistent with the reduction of cell surface $\beta 1$-integrin in cells treated with A-769662. 


\section{Transferrin receptor recycling is not regulated by AMPK activation}

Notably, the effect of A-769662 on $\beta 1$-integrin was at least partly specific, as this treatment had no effect on the cell surface levels of another constitutively internalizing and recycling membrane protein, transferrin receptor (TfR) (Fig 12). To determine if AMPK activation by A-769662 treatment controls TfR recycling, I measured TfR recycling with an analogous protocol described above using antibodies that recognize an exofacial epitope on TfR. Strikingly, I found that much like what was observed when measuring cell surface TfR, A-769662 treatment does not affect the rate of TfR recycling. Hence, although both $\beta 1$ integrin and TfR both traffic through partly overlapping early and recycling endosomes, the activation of AMPK triggers an underlying signaling mechanism which hinders $\beta 1$-integrin recycling but leaves that of TfR unaffected.

Overall, A-769662 specifically regulates $\beta 1$-integrin recycling ( $>40$ minute of A769662 treatment), but it does not appreciably alter $\beta 1$-integrin endocytosis when AMPK is activated for 15 minutes. As described above, it is important to note the limitation of the endocytic assay with respect to A-769662 treatment and time. $\beta 1$-integrin internalization measurement was limited to 15 minutes, as after this time-point the assay detection becomes convoluted by the measurement of recycling of $\beta 1$-integrin as well. Therefore, I can conclude that A-769662 treatment selectively regulates $\beta 1$-integrin recycling but not that of TfR, and that AMPK may also regulate certain aspects of endocytosis as well.

How might AMPK control the recycling of $\beta 1$-integrin as well as possibly control $\beta 1$ integrin endocytosis? The mechanism that encompasses this could potentially involve Arf6 
GTPases. Arf6 is a known regulator of $\beta 1$-integrin recycling, $\beta 1$-integrin endocytosis and Arfs regulate clathrin mediated endocytosis. 


\section{A Cell surface $\beta 1$-integrin}
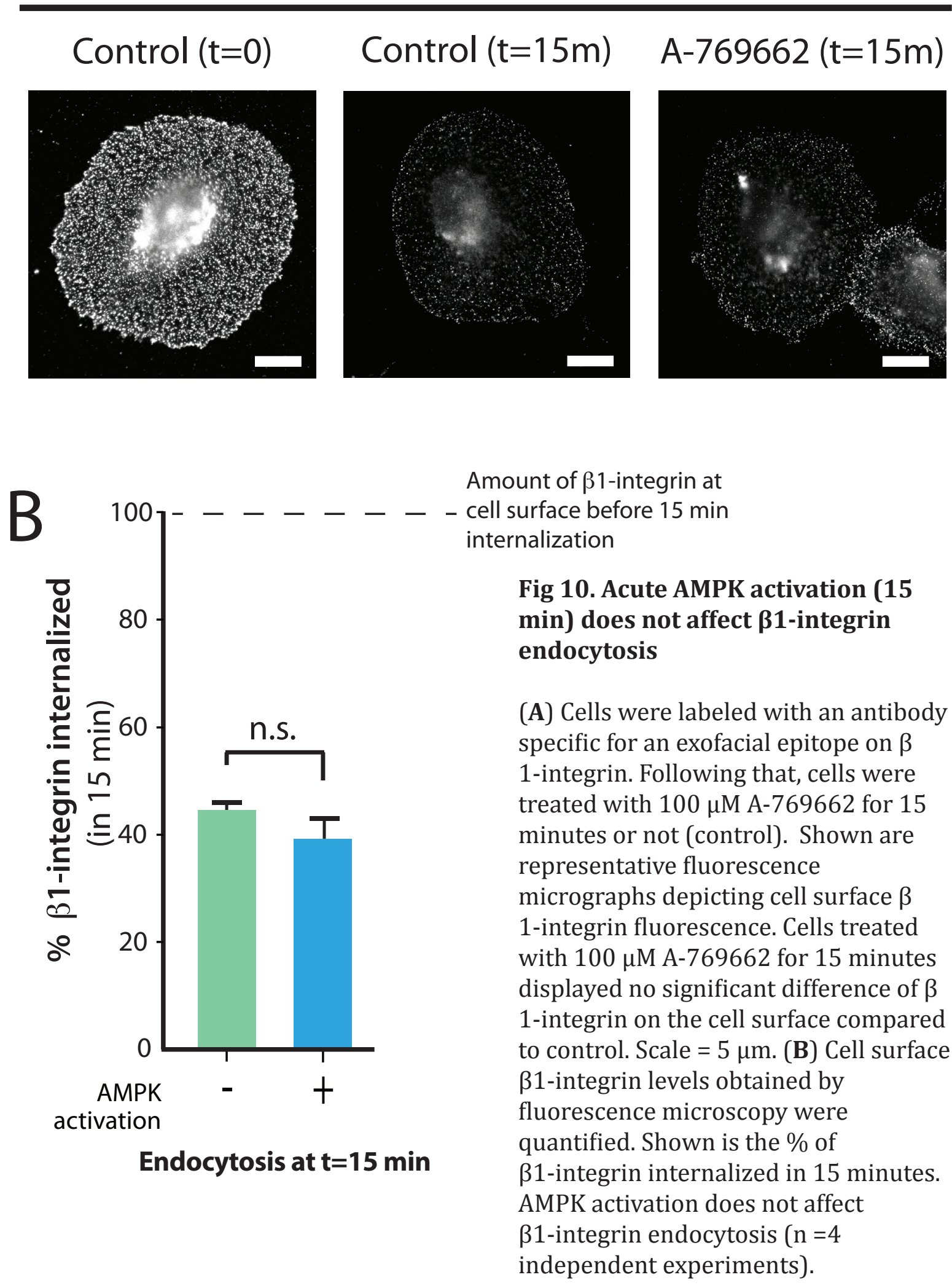

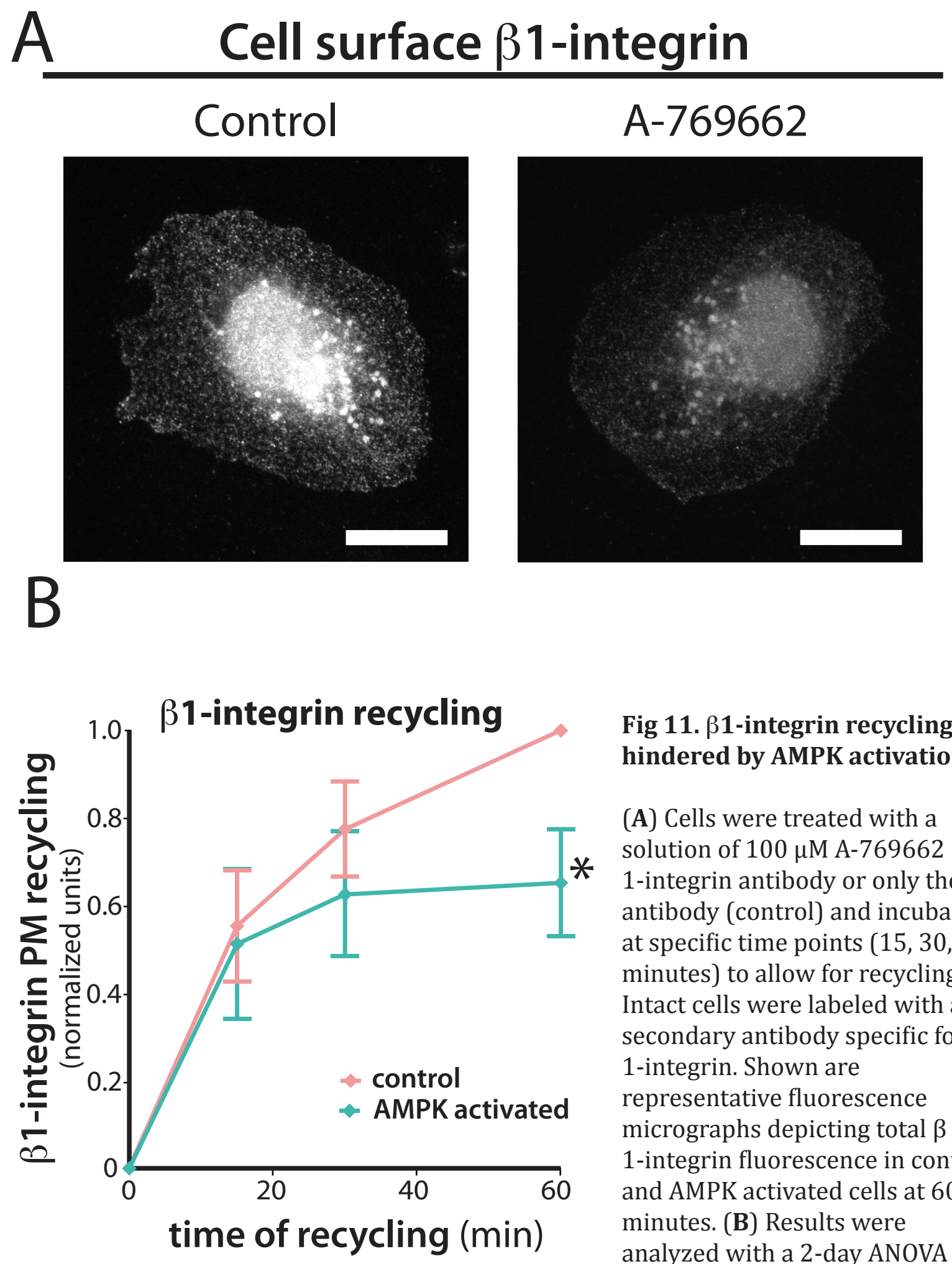

Fig 11. $\beta 1$-integrin recycling is hindered by AMPK activation

(A) Cells were treated with a solution of $100 \mu \mathrm{M}$ A-769662 + $\beta$ 1 -integrin antibody or only the antibody (control) and incubated at specific time points $(15,30,60$ minutes) to allow for recycling. Intact cells were labeled with a secondary antibody specific for $\beta$ 1-integrin. Shown are representative fluorescence micrographs depicting total $\beta$ 1 -integrin fluorescence in control and AMPK activated cells at 60 minutes. (B) Results were analyzed with a 2-day ANOVA followed by a Bonferroni post-test $\left({ }^{*} \mathrm{p}<0.05\right)$. Scale $=5 \mu \mathrm{m}$ ( $n=3$ independent experiments). 


\section{A Cell surface Transferrin receptor \\ Control \\ A-769662}

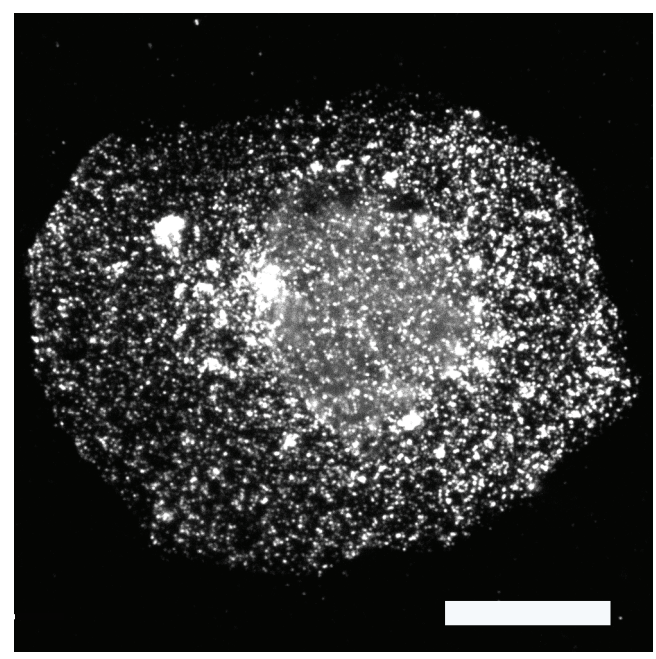

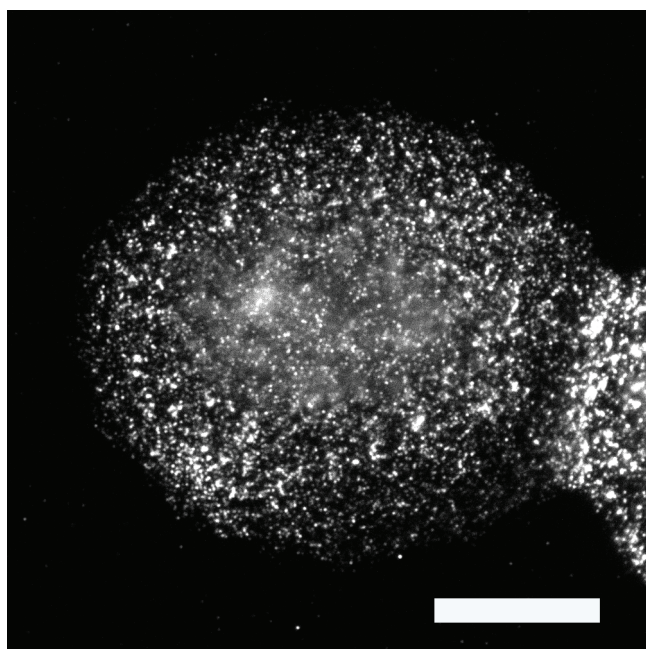

B

Transferrin receptor recycling

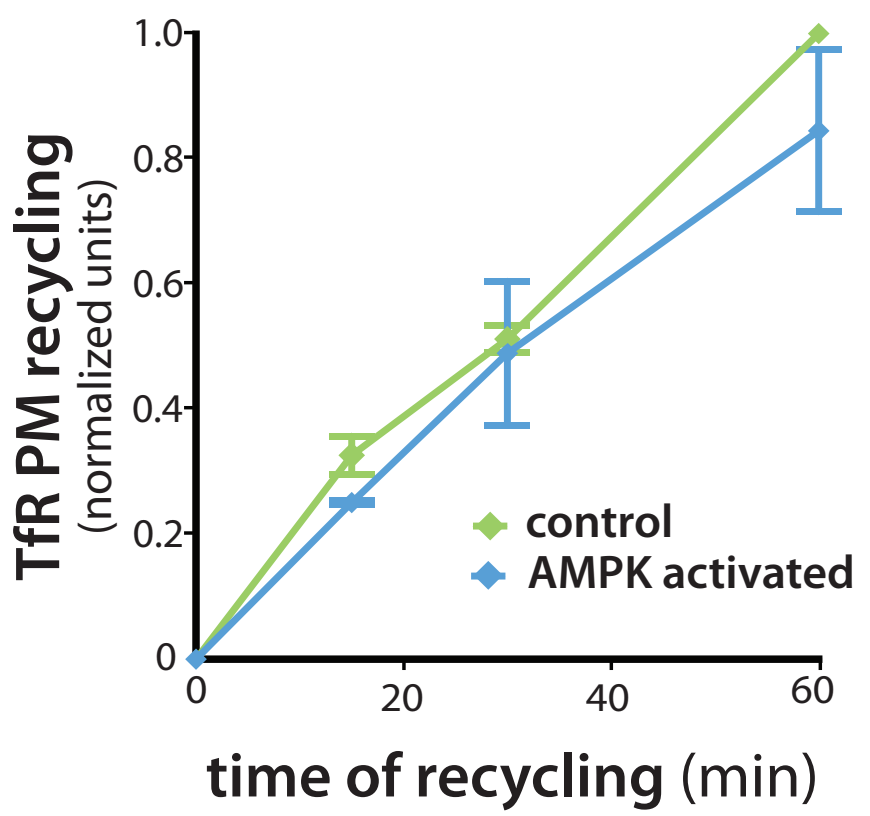

Fig 12. Transferrin receptor recycling is unaffected by AMPK activation

(A) Cells were treated with a solution of $100 \mu \mathrm{M} \mathrm{A}-769662+$ TfR antibody or only the antibody (control) and incubated at specific time points $(15,30,60$ minutes) to allow for recycling. Intact cells were labeled with a secondary antibody specific for TfR. Shown are representative fluorescence micrographs depicting total TfR fluorescence in control and AMPK activated cells at 60 minutes. Scale $=5 \mu \mathrm{m}(\mathrm{n}=3$ independent experiments). (B) Graph depicts the three time-points measured. 


\section{Results part III: Regulation of Arf6 GTPase by AMPK}

With $\beta 1$-integrin recycling specifically affected, the next step was to determine which trafficking protein regulates this process with AMPK. As mentioned, Arf6 proteins have a role in both recycling and endocytosis of $\beta 1$-integrin and regulate clathrin-mediated endocytosis. What is also notable is that we observed that AMPK activation by treatment with A-769662 resulted in the depletion of specific ArfGAPs from the cell surface fraction, as determined by the mass spectrometry screen (Ross et al. 2015). The ArfGAPs that exhibit reduced cell surface abundance upon AMPK activation, as detected by mass spectrometry, are listed in Table 1. Interestingly, analysis of the sequence of these ArfGAPs reveals a number of predicted AMPK phosphorylation sites, as determined by matching to the AMPK consensus phosphorylation motif using ProSite (ProSite match, 2016) (Table 1).

Table 1 - ArfGAPs removed from the cell surface upon treatment with A-769662. Possible AMPK phosphorylation sites as predicted by ProSite. Sequence blasted: [MLIFV]-[RKH]-[RKH]-X-X-[ST] (ProSite match, 2016).

\section{Gene Symbol Protein Description AMPK phosphorylation sit}

ASAP1 ArfGAP with SH3 domain, ankyrin

S733, T1074,

repeat and $\mathrm{PH}$ domain 1

AGAP5 ArfGAP with GTPase domain, ankyrin

T408, S533

repeat and PH domain 5

ARAP2 ArfGAP with RhoGAP domain, S360, T1350

ankyrin repeat and PH domain 2

\section{ARFGAP3}

ADP-ribosylation factor GTPase

S18

activating protein 3 


\section{A-769662 regulates Arf6 GTP binding and subsequently its cellular localization}

With evidence that A-769662 treatment, and thus AMPK, may regulate Arf6 ArfGAPs

(Table 1), and given the important role of Arf6 in controlling $\beta 1$-integrin membrane traffic (Dunphy et al. 2006; Powelka et al. 2004; Oh \& Santy 2010), I sought to test whether A769662 controls Arf6 localization and function. RPE cells were transfected with either wild type Arf6-GFP plasmid (GFP-Arf6-WT henceforth) or an Arf6 mutant that is constitutively bound to GTP ("GFP-Arf6-GTP-locked" henceforth), as it unable to undergo GTP hydrolysis (referred to in the literature as constitutively active Arf6-Q67L, or "GTP-locked"). Based on the observation that "GTP-locked" Arf6 exhibits a mostly uniform localization throughout the plasma membrane and that a mutant of Arf6 that can only bind to GDP exhibits punctate localization, it has been proposed that Arf6 localization to punctate membrane structures vs. uniform membrane distribution may reflect Arf6 GTP/GDP binding status (Pasqualato et al. 2001; Schweitzer \& D’Souza-Schorey 2002; Hattula et al. 2006).

Following transfection with various Arf6-GFP constructs, cells were treated with A769662 to activate AMPK, or left untreated (basal), samples were fixed, processed for fluorescence microscopy and imaged using a spinning disc confocal microscope (Fig 13). Using an automated software as in Aguet et al. (2013) specialised for detection and analysis of diffraction-limited structures within cells (e.g. CCPs), but modified for detection of Arf6 punctae, we revealed a significant increase of Arf6 punctae in the GFP-Arf6-WT cells treated with A-769662 (Fig 13). This consistent with A-769662 treatment eliciting a change from a predominantly uniform plasma membrane Arf6 localization (and thus GTP- 
bound Arf6) to GDP-bound Arf6 (which is said to be localized to punctate structures, such as on intracellular membrane compartments). This suggests that A-769662 treatment regulates Arf6 GTP binding or nucleotide cycling. Furthering this idea, cells expressing GFPArf6-GTP-locked do not exhibit an increase in Arf6 punctae structure upon treatment with A-769662 (Fig 13). Given that A-769662 treatment alters Arf6 localization in a manner that requires GTP hydrolysis of Arf6, it is possible that A-769662 treatment, and thus AMPK, may be regulating membrane traffic processes (e.g. $\beta 1$-integrin recycling and endocytosis) through regulation of Arf6. Consistent with this interpretation, Arf6 is a known regulator of $\beta 1$-integrin trafficking and specifically endocytosis (Oh \& Santy 2010).

\section{Acute perturbation of Arf6 GTP/GDP cycling regulates $\beta 1$-integrin endocytosis}

While it was not straightforward to measure how A-769662 treatment may control $\beta 1$-integrin endocytosis, I nonetheless revisited the idea that A-769662 could regulate $\beta 1$ integrin endocytosis, via Arf6, with the knowledge that A-769662 regulates Arf6-GTP loading. This time, I decided to acutely perturb Arf6 using QS11, because it is more acute than other methods, such as expression of Arf6 mutants or siRNA gene silencing of Arf6 or Arf6 regulators. QS11 is an ArfGAP inhibitor with broad specificity for a number of ArfGAPs, such that treatment of cells with QS11 will elicit an increase in Arf6 GTP levels. First, I examined the effect of QS11 on cell surface levels of $\beta 1$-integrin, by using similar methods as detailed above (Fig 5). This was done in cells treated with QS11 or untreated cells (control). The resulting micrographs revealed an observable decrease in cell surface $\beta 1$-integrin in the QS11 treated cells compared to control, which was confirmed by 
quantification of cell surface $\beta 1$-integrin levels (Fig 14). This suggests that inhibition of ArfGAPs by QS11 has a similar effect on cell surface $\beta 1$-integrin levels as A-769662 treatment.

Next, I revisited the effect of QS11 on $\beta 1$-integrin endocytosis, to compare the effect of QS11 to that of A-769662 treatment, using the $\beta 1$-integrin endocytosis as previously described (Fig 10), with the only difference being a 30-minute pre-incubation of QS11 before $\beta 1$-integrin labelling on ice. This time, the endocytic assay revealed a virtually complete blockage of $\beta 1$-integrin internalization in QS11 treated cells compared to control cells (Fig 15). This shows that Arf6-GTP/GDP cycling is an important aspect of $\beta 1$-integrin trafficking.

Thus, collectively these experiments reveal that AMPK activation regulates both recycling of $\beta 1$-integrin and cycling of Arf6-GTP/GDP (Fig 11; Fig 13). Therefore, the effect of inhibiting ArfGAPs with QS11 phenocopies the effect of A-769662 treatment on $\beta 1$ integrin traffic. This is also consistent with the idea of A-769662 treatment acts via regulation of ArfGAPs to control this mechanism. If A-769662 controls Arf6 or ArfGAPs to control endocytosis, and given the observation in previous studies that ArfGAPs and Arf6 control assembly of clathrin-coated pits (CCPs), I hypothesize that AMPK may control Arf6 within CCPs and thus CCP assembly.

\section{A-769662 regulates Arf6 recruitment to clathrin coated pits}

My work suggests a functional link between AMPK and Arf6 in $\beta 1$-integrin 
membrane traffic. I next sought to determine if AMPK may regulate Arf6 or ArfGAPs to control clathrin-coated pit assembly. To do so, I transfected in GFP-Arf6-WT or GFP-Arf6GTP-locked plasmid into RPE cells stably expressing RFP-clathrin light chain (CLC) (RPERFP henceforth). Using total internal reflection fluorescence microscopy to selectively image the cell surface (and thus CCPs), I examined Arf6 recruitment in CCPs in cells treated with A-769662 to activate AMPK for 15 minutes, or untreated (control).

The micrographs were analyzed using software designed to automatically detect diffraction-limited CCPs (Aguet et al. 2013), which I previously used to quantify Arf6 punctae (Fig 13). This software uses a 2-D Gaussian model approach as an approximation of the PSF. The amplitude of the Gaussian model of the PSF is proportional to the amount of clathrin or Arf6 within each structure, such that the higher the point-source intensity, the more of the specific protein is present within that specific structure.

This analysis revealed that A-769662 alters GFP-Arf6-WT recruitment to CCPs (Fig 16). Specifically, in the control condition, Arf6 localization within CCPs is higher than that of the A-769662 treated condition. However, in the GFP-Arf6-GTP-locked cells, A-769662 treatment does not decrease Arf6 recruitment compared to the control (Fig 17). Overall, Arf6 recruitment is much higher in GFP-Arf6-GTP-locked cells than GFP-Arf6-WT cells. This is consistent with the idea that GTP-locking Arf6 hinders its movement between compartments and causes it to be bound on the plasma membrane. In this model, cells expressing Arf6-locked to the plasma membrane will be found in CCPs in much higher abundance than Arf6 that is able to cycle its GTP/GDP, and therefore its localization. 


\section{Control \\ A-769662}
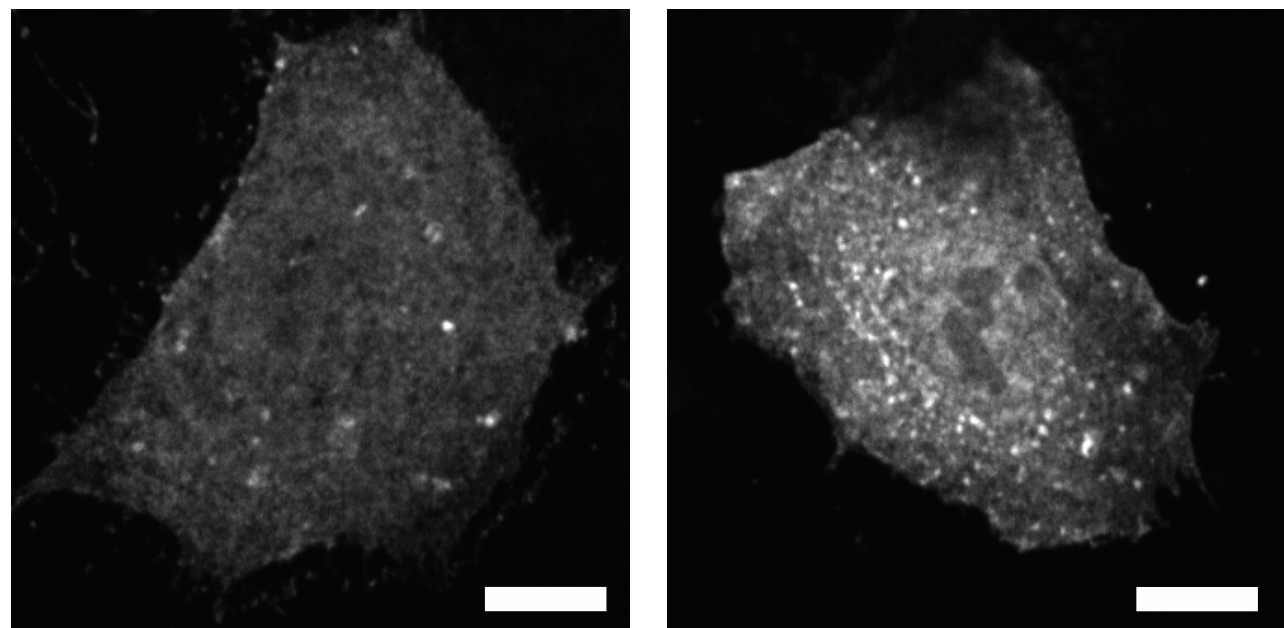

B

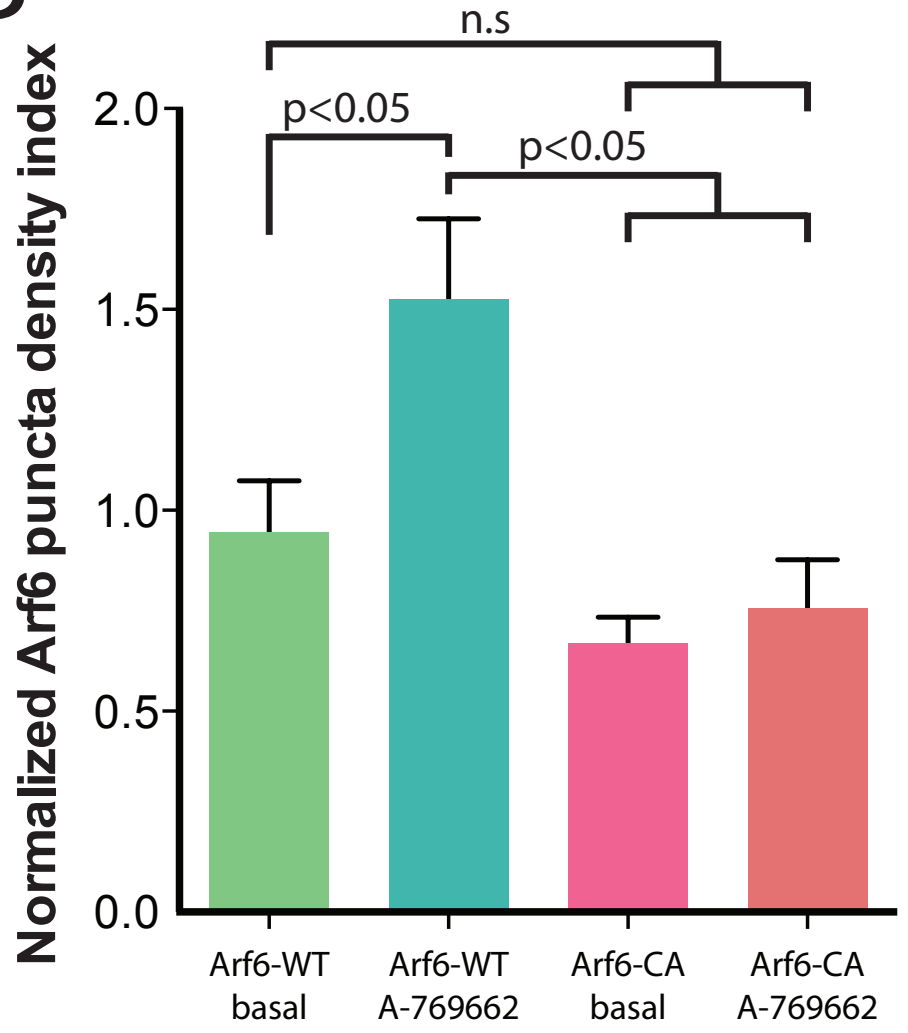

Fig 13. AMPK activation by A-769662 regulates Arf6 GTP binding

(A) Cells expressing GFP-Arf6-WT and GFP-Arf6-GTP locked were stimulated with A-769662 for 60 min (AMPK activated) or $0.1 \%$ FBS (control). AMPK activation alters GFP-Arf6 from a uniform distribution to punctate structures, consistent with a reduction in GTP-bound Arf6 at the cell surface. Scale $=10 \mu \mathrm{m}$. (B) Quantification of Arf6 punctae using an automated detection software modified for Arf6 punctae structures were detected and quantified; shown are means \pm SEM. ( $n=3$ independent experiments) 


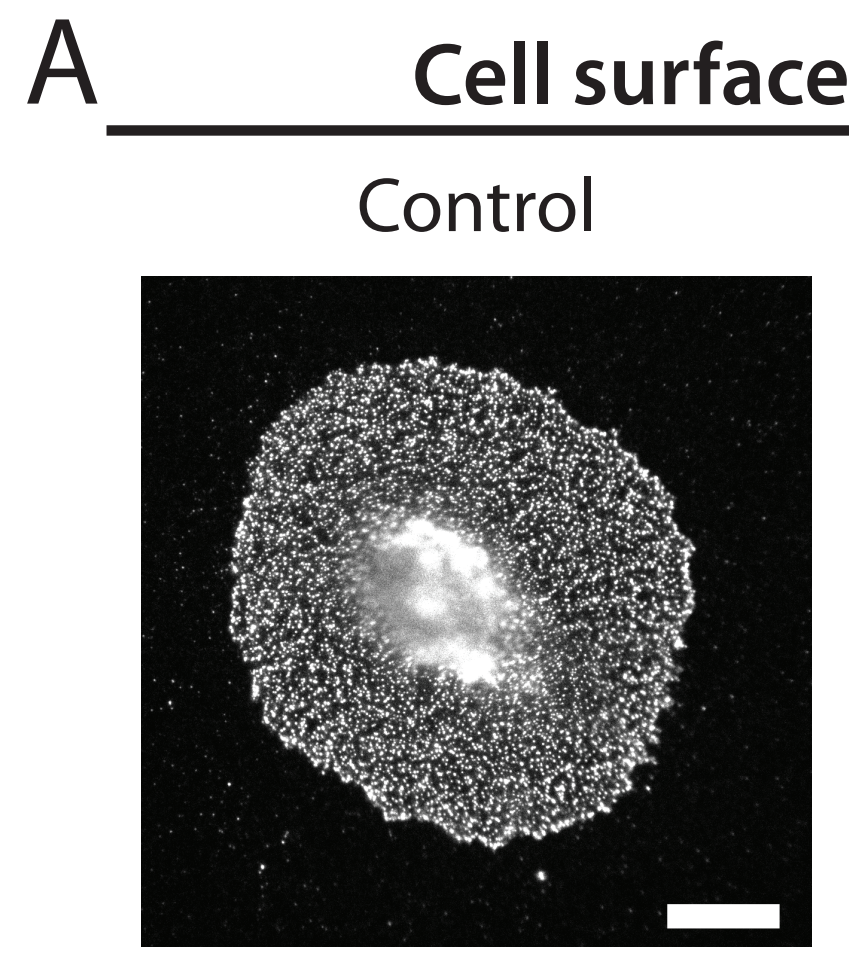

\section{$\beta 1$-integrin}

\section{QS11}
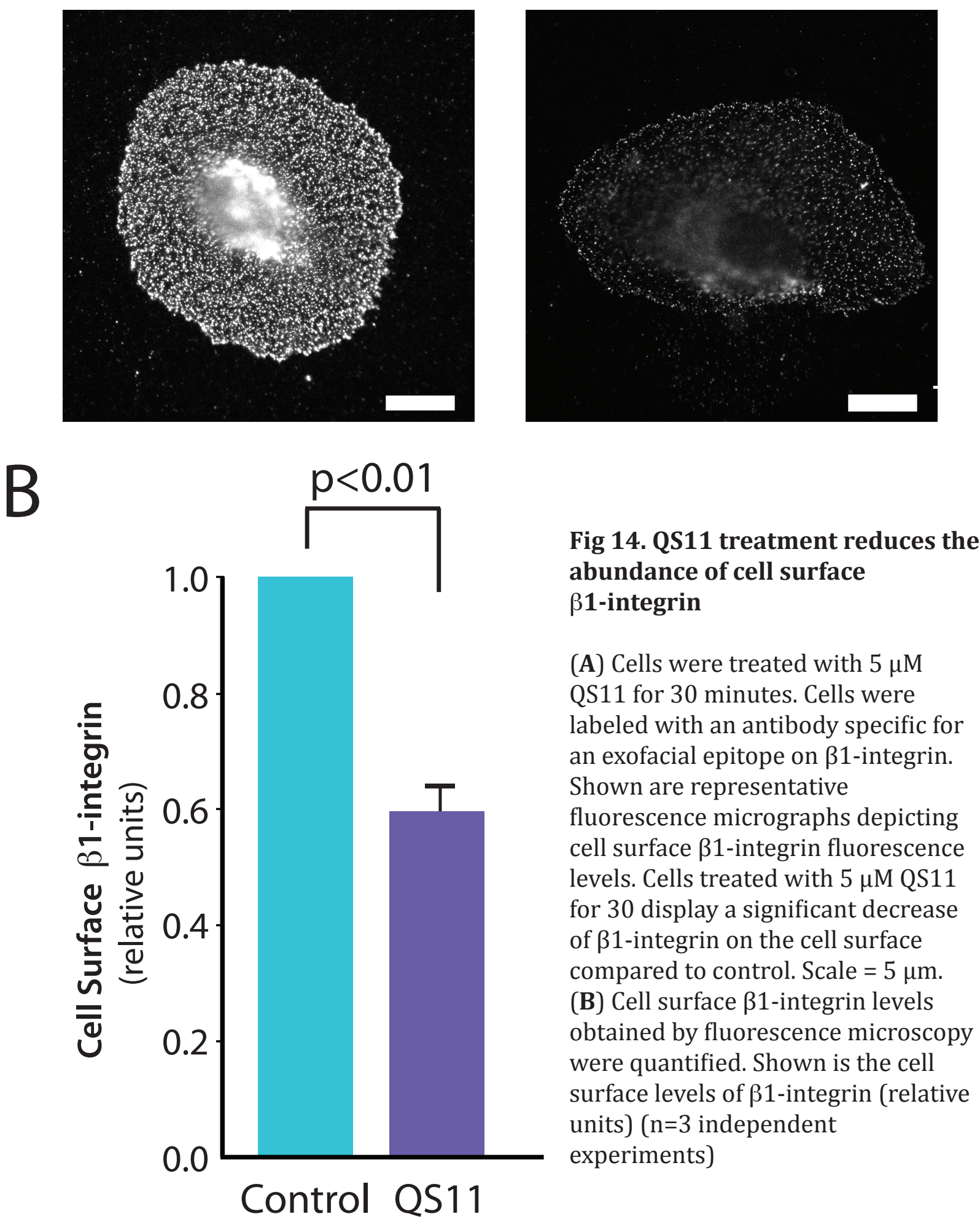


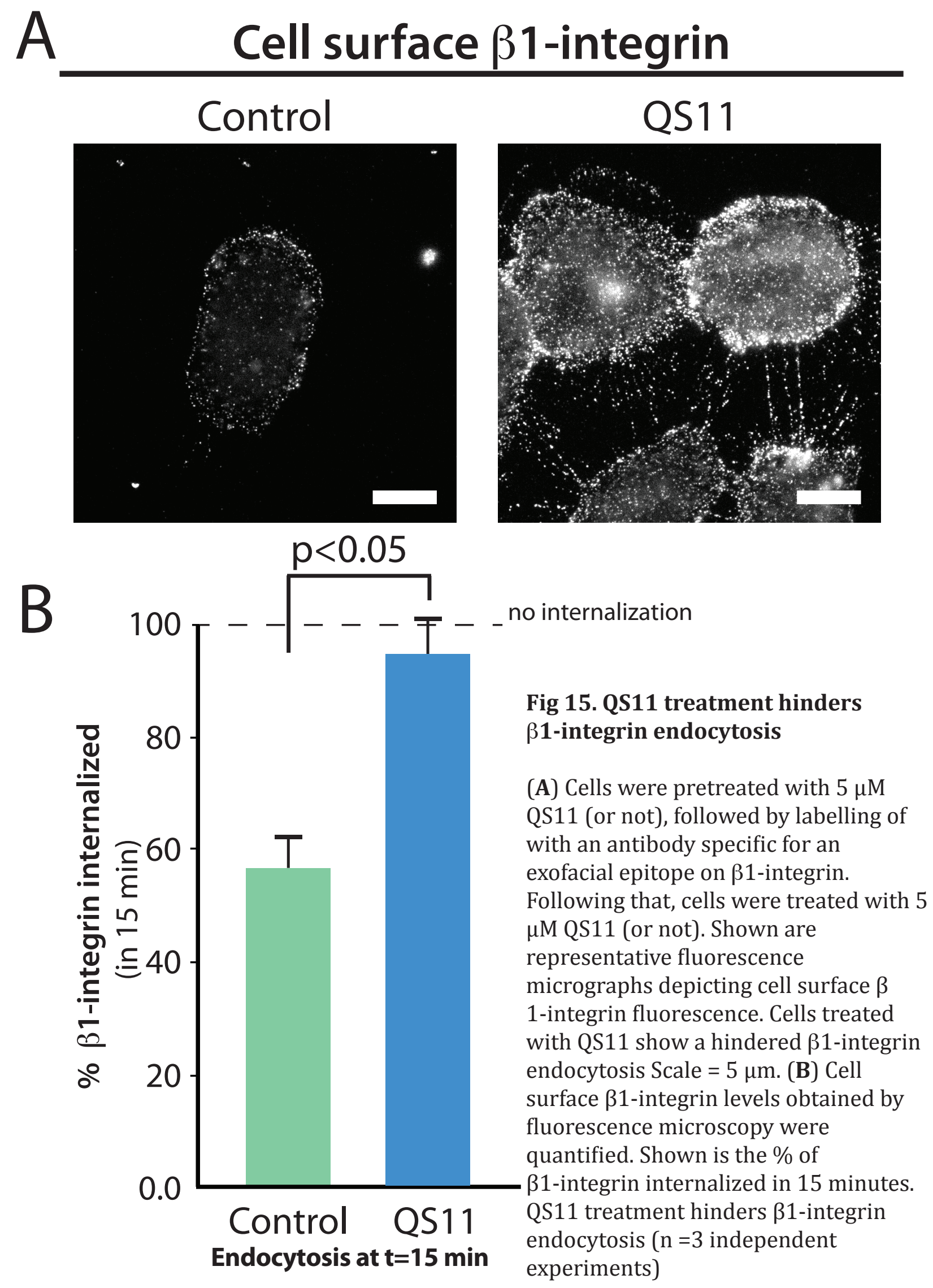



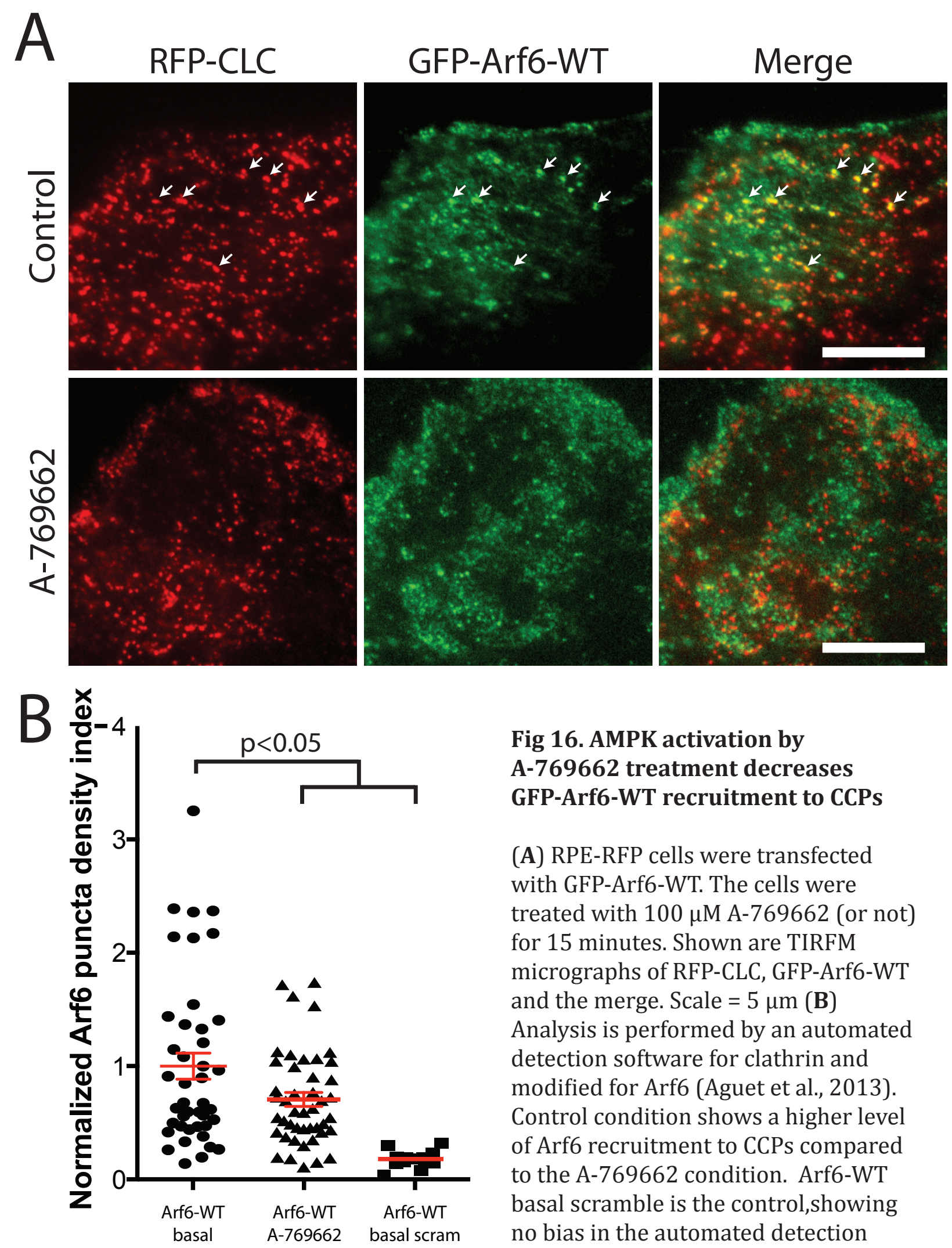

Fig 16. AMPK activation by A-769662 treatment decreases GFP-Arf6-WT recruitment to CCPs

(A) RPE-RFP cells were transfected with GFP-Arf6-WT. The cells were treated with $100 \mu \mathrm{M}$ A-769662 (or not) for 15 minutes. Shown are TIRFM micrographs of RFP-CLC, GFP-Arf6-WT and the merge. Scale $=5 \mu \mathrm{m}$ (B) Analysis is performed by an automated detection software for clathrin and modified for Arf6 (Aguet et al., 2013). Control condition shows a higher level of Arf6 recruitment to CCPs compared to the A-769662 condition. Arf6-WT basal scramble is the control,showing no bias in the automated detection software ( $\mathrm{n}=3$ independent experiments) 

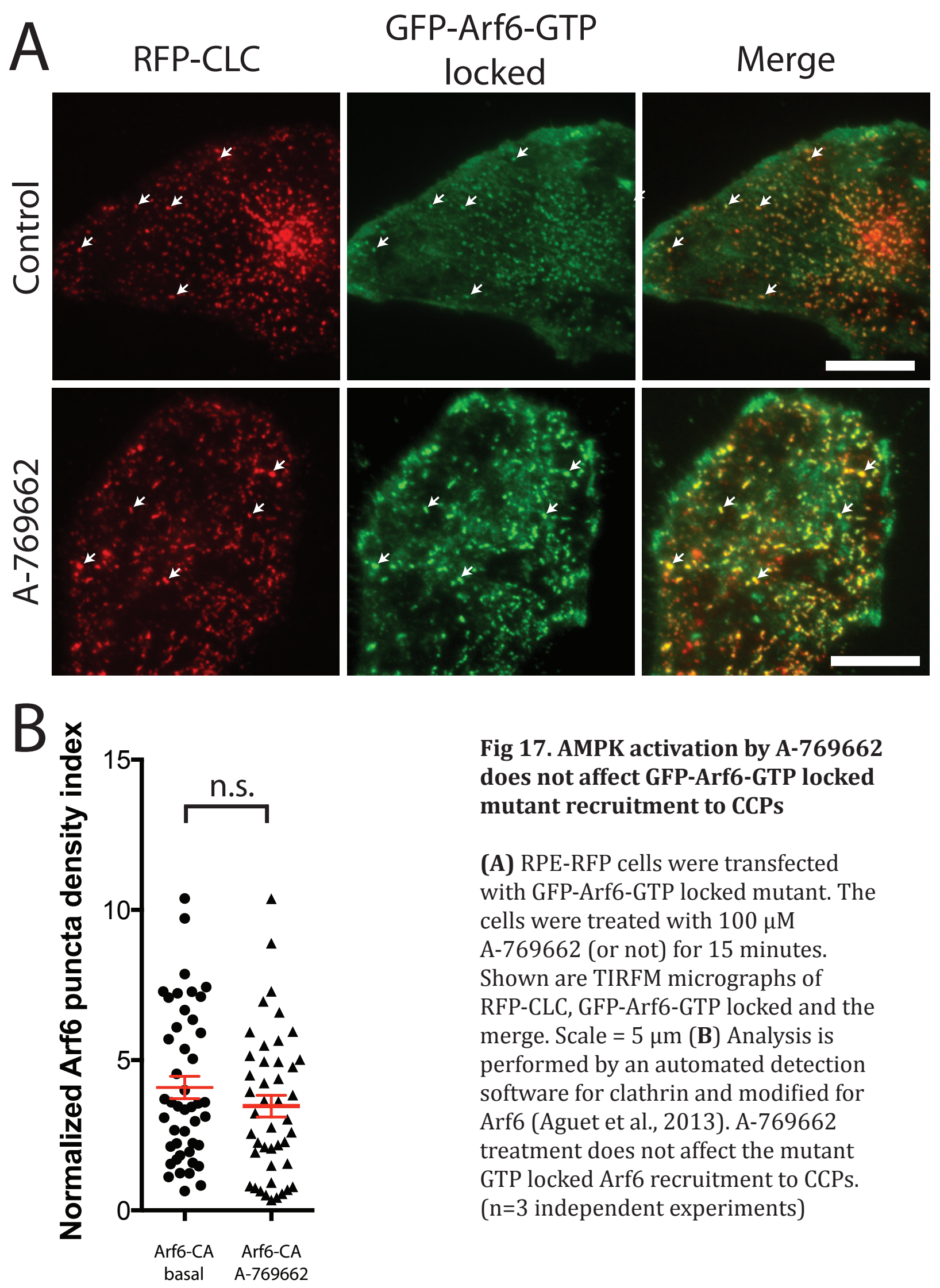

Fig 17. AMPK activation by A-769662 does not affect GFP-Arf6-GTP locked mutant recruitment to CCPs

(A) RPE-RFP cells were transfected with GFP-Arf6-GTP locked mutant. The cells were treated with $100 \mu \mathrm{M}$ A-769662 (or not) for 15 minutes. Shown are TIRFM micrographs of RFP-CLC, GFP-Arf6-GTP locked and the merge. Scale $=5 \mu \mathrm{m}$ (B) Analysis is performed by an automated detection software for clathrin and modified for Arf6 (Aguet et al., 2013). A-769662 treatment does not affect the mutant GTP locked Arf6 recruitment to CCPs. $(\mathrm{n}=3$ independent experiments) 


\section{Arf6 controls clathrin assembly}

Using the automated detection software for clathrin coated pits and Arf6, I looked at how Arf6 expression affects clathrin assembly. CCPs are heterogeneous in many aspects of their properties and function, including in their composition (Mettlen et al. 2010; Banerjee et al. 2012; Loerke et al. 2009; Antonescu et al. 2011). As such, Arf6 may not be localized to all CCPs, and instead, may be controlling the function of a subset of CCPs to which it is recruited. Examining the role of Arf6 in controlling CCP assembly requires methods in which CCPs positive for Arf6 can be analyzed separately from those lacking Arf6. To this end, I sorted the detected CCP objects into CCPs that contain Arf6 and CCPs that lack Arf6. I first examined at the CCPs that lacked Arf6 recruitment (Arf6 negative CCPs). I measured CLC fluorescence intensity: the recruitment of clathrin to CCPs - the higher the fluorescence intensity, the more clathrin that was recruited to the structures in question, and thus the larger size of these diffraction-limited CCPs. I found that in CCPs lacking Arf6 (WT or locked), there was no difference of clathrin recruitment to CCPs across all conditions examined (Fig 18A). Next, I examined all CCPs with Arf6 recruitment (Arf6 positive CCPs) (Fig 18B). A-769662 did not affect clathrin recruitment compared to the control in both GFP-Arf6-WT and GFP-Arf6-GTP-locked conditions. However, there was a significant difference of clathrin recruitment when comparing GFP-Arf6-WT and GFP-Arf6GTP-locked conditions, which suggests that Arf6 enhances the rate or levels of clathrin recruitment to CCPs, and that the GTP-binding by Arf6 further promotes clathrin recruitment.

To determine if the alteration of CCP size by Arf6 occurred only as a result of GTP 
binding by Arf6 (evinced by comparison of the GFP-Arf6-WT and GFP-Arf6-GTP-locked conditions), or whether Arf6 recruitment itself elicited a change in CCP size (relative to CCPs that do not recruit Arf6), I examined the GFP-Arf6-WT cells more closely, looking only at the control condition (i.e. basal, not treated with A-769662). Within the control condition, I focused on Arf6 positive CCPs and Arf6 negative CCPs. This analysis revealed that Arf6 positive CCPs had higher levels of clathrin recruitment than Arf6 negative CCPs (Fig 18C). This is consistent with the previous results (Fig 18A,B) which show that GTPlocking Arf6 on the plasma membrane regulates the formation of CCPs by enhancing the recruitment of clathrin therein. These results demonstrate that not only does GTP binding by Arf6 enhance CCP recruitment of Arf6, but that the subset of CCPs that recruit wild-type Arf6 also exhibit larger size relative to CCPs that do not recruit Arf6. Collectively, these results indicate that Arf6 regulates a subset of CCPs and that control of Arf6 (e.g. by longterm AMPK activation), may regulate the endocytosis of specific cargo receptors (e.g. integrins), but not others (e.g. transferrin receptor).

Therefore, A-769662 treatment does alter certain aspects of CCPs, specifically Arf6 recruitment to CCPs. I've also shown that Arf6 controls clathrin assembly, although the details and mechanisms behind that go beyond the scope of this project. This data is consistent with the model that AMPK regulates ArfGAPs to effect Arf6 regulation, which effects clathrin mediated endocytosis, to regulate $\beta 1$-integrin on the cell surface. 

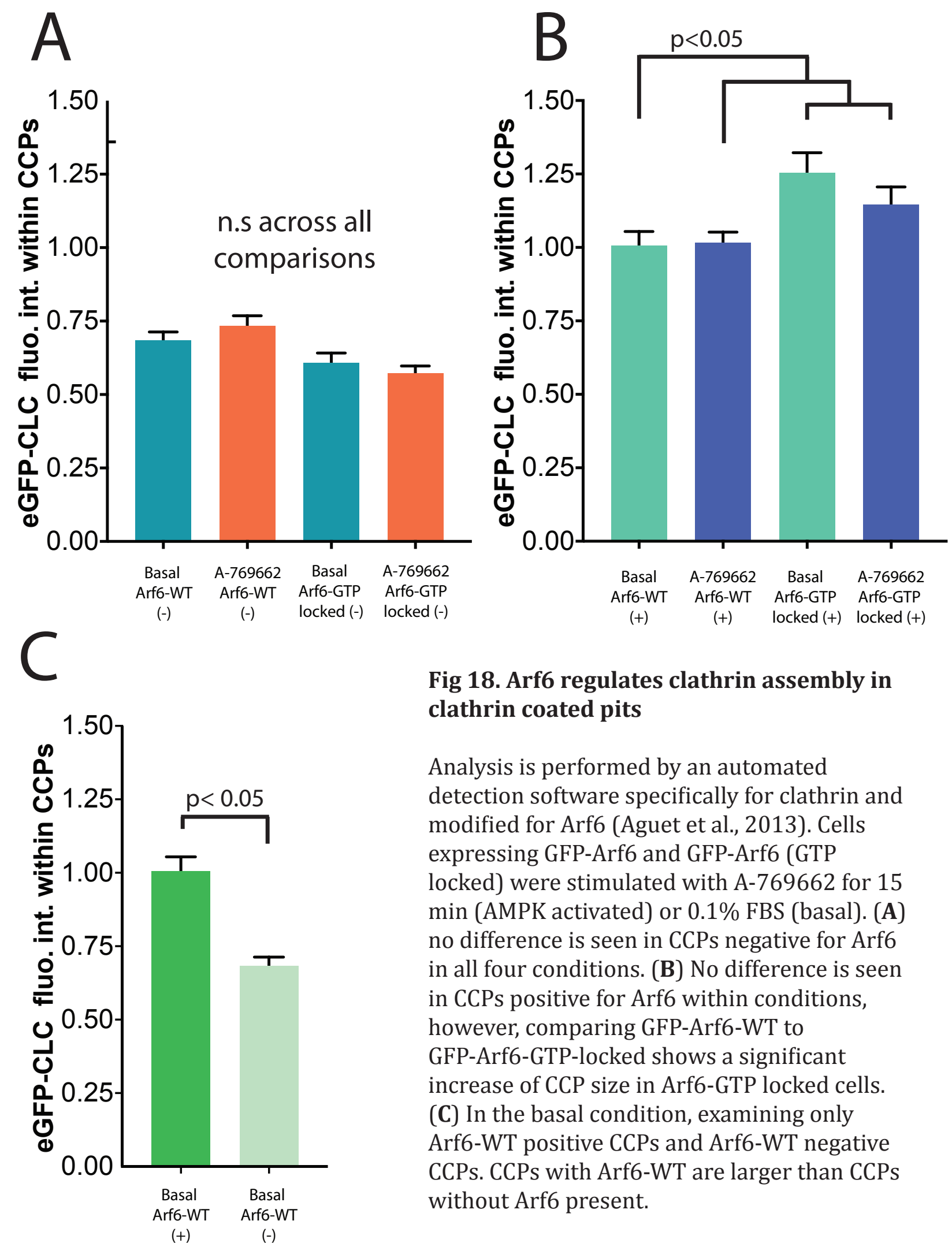

Fig 18. Arf6 regulates clathrin assembly in clathrin coated pits

Analysis is performed by an automated detection software specifically for clathrin and modified for Arf6 (Aguet et al., 2013). Cells expressing GFP-Arf6 and GFP-Arf6 (GTP locked) were stimulated with A-769662 for 15 min (AMPK activated) or $0.1 \%$ FBS (basal). (A) no difference is seen in CCPs negative for Arf6 in all four conditions. (B) No difference is seen in CCPs positive for Arf6 within conditions, however, comparing GFP-Arf6-WT to GFP-Arf6-GTP-locked shows a significant increase of CCP size in Arf6-GTP locked cells. (C) In the basal condition, examining only Arf6-WT positive CCPs and Arf6-WT negative CCPs. CCPs with Arf6-WT are larger than CCPs without Arf6 present. 


\section{Discussion}

To understand how cells are able to adapt to changes in environmental conditions, the influence of the cell surface proteome must be at the forefront of the discussion. It is established that the abundance of certain proteins can be altered from the cell surface upon energetic stress. This includes the facilitative glucose transporters GLUT1 and GLUT4, which exhibit increased abundance on the plasma membrane upon energetic stress (Wu et al. 2013; Chen et al. 2008; Pehmoller et al. 2009), and the NA+/K+ ATPase pump, which exhibits reduced levels at the cell surface upon AMPK activation (Gusarova et al. 2009). AMPK is known as the cell's "energy sensor," as it is the primary responder to energetic shortages and other types of stress. Its activation leads to a cascade of changes that ultimately promotes catabolic pathways and downplays anabolic pathways. Although some foundation has been laid to understand the connection between metabolism and the cell surface proteome, the understanding of how AMPK may regulate and remodel the cell surface proteome is still in its infancy (Ross et al. 2015; Klaus et al. 2012)

A recent publication from our lab has demonstrated a novel method to identify cell surface proteins which exhibit altered abundance at the cell surface upon AMPK activation (Ross et al. 2015). The fraction enriched on the cell surface upon AMPK activation include proteins involved in the immune response (i.e. inflammatory response), proteolytic and wound healing proteins (Ross et al. 2015). Cytoskeletal proteins, cell migration and cell adhesion proteins were among the many that were depleted from the cell surface upon AMPK activation (Ross et al. 2015). This previous work was done by a colleague in the Antonescu lab, Ms. Eden Ross, who focused on cell adhesion proteins due to their roles in 
cell migration, wound healing, but also diseases such as cancer and metastasis of tumours. Specifically, integrins have been shown to be heavily involved in tumour cell metastasis changes in their expression or recycling have impacts on tumour cell metastasis (Desgrosellier \& Cheresh 2010). Integrins $\alpha v \beta 3, \alpha 5 \beta 1$, and $\alpha V \beta 6$ are highly upregulated in some tumours, whereas their normal expression profile is low (Desgrosellier \& Cheresh 2010). In Ms. Ross' study, she studied the relationship between AMPK and $\beta 1$-integrin. She found that using pharmacological activators AICAR and A-769662 decreased $\beta 1$-integrins from the cell surface, but left transferrin receptor unaffected (Ross et al. 2015).

In this present study, I validated the connection between AMPK and $\beta 1$-integrin. I then delved into the mechanism behind this regulatory pathway, asking whether AMPK regulating cell surface $\beta 1$-integrin by regulation of $\beta 1$-integrin endocytosis, decreasing the rate of recycling, or both to reduce the overall levels of cell surface $\beta 1$-integrin. I showed that AMPK activation does not appreciably affect $\beta 1$-integrin endocytosis (albeit that this is within the limitations of the experiment), but has a marketed effect on $\beta 1$-integrin recycling. I followed that by establishing a connection between AMPK and a known regulator of $\beta 1$-integrin trafficking, Arf6. I also demonstrated that AMPK activation correlates with changes in Arf6 localization, and that Arf6 controls aspects of clathrin assembly in CCPs.

\section{Regulation of $\beta 1$-integrin by AMP-activated protein kinase (AMPK)}

As shown in Vincent et al. (2015), off target and AMPK independent effects are 
possible with a variety of AMPK agonists. In fact, A-769662 most closely mimics AMPK activation, as it limits off target and AMPK independent effects, however, with any pharmacological agent, confirming the phenomenon through different means is always beneficial. In our case, it was using siRNA against AMPK $\alpha 1 / 2$ subunit. I achieved $69.6 \pm$ 2.6\% knockdown efficiency, which is comparable to what others report (Fig 5A) (Tangeman et al. 2012). The lack of internalization of $\beta 1$-integrin in the AMPK $\alpha 1 / 2$ deficient cells treated with A-769662 confirms the link between AMPK and $\beta 1$-integrin (Fig 5BC). Importantly, I also show that the reduction of cell surface $\beta 1$-integrin is not due to degradation nor is it due to a change in cell size influencing the analysis, but simply a reduction in $\beta 1$-integrin abundance at the cell surface as it redistributes to intracellular membrane compartments (Fig 6,7). This has some parallels to what others have reported, in that AMPK activation for 24 hours with the benzylisoquinoline alkaloid Berberine reduces $\beta 1$-integrin expression (Tang \& Lee 2015). However, our findings that $\beta 1$-integrin expression is unaffected by AMPK for up to 3 hours shows a very different aspect of regulation of $\beta 1$-integrin by AMPK, such that a reduction in cell surface specific $\beta 1$-integrin occurs initially upon AMPK activation.

I've also demonstrated AMPK activation leads to a severely reduced cell migration. Cell migration is an highly integrated multifaceted process that helps drive morphogenesis, tissue repair, but can also drive disease progression in cancer, and atherosclerosis among others (Ridley et al. 2003). The process itself is very energy intensive, as it requires membrane protrusions at the leading edge with the help of integrins (Ridley et al. 2003). Alongside this is a variety of signaling that occurs through integrins, which are clustered 
together and linked to the actin cytoskeleton to coordinate cell migration. As such, integrins are very intimately involved with cell migration (Ridley et al. 2003). It is clear then, why AMPK activation decreases cell migration (Fig 8)- cell migration cannot occur without proper cycling of integrins, and that is exactly what AMPK activation appears to be affecting, as seen in my $\beta 1$-integrin recycling experiments (Fig 11). Others have looked at other aspects by which AMPK may regulate cell migration. The microtubule plus-end protein, CLIP-170, which binds endocytic vesicles to microtubules, is involved in this process (Nakano et al. 2010). AMPK phosphorylates CLIP-170 on Ser113 to control directional cell migration and speed of microtubule polymerization (Nakano et al. 2010). Interestingly, AMPK depletion by compound C or siRNA resulted in impaired microtubule stabilization, tubulin polymerization and directional cell migration (Nakano et al. 2010). On the opposite spectrum, AMPK activation also inhibits cell migration, which is reflected in the clinical benefits often seen with pharmacological AMPK activators - prevention of atherosclerosis, and cancer metastasis (Yan et al. 2015). In this mechanism, Pdlim5 is phosphorylated by AMPK at Ser177 which inhibits cell migration by supressing the Rac1Arp 2/3 signaling pathway (Yan et al. 2015). It appears both AMPK activation and inhibition can impair cell migration - suggesting that AMPK has a role of fine tuning processes rather than blunt impairment.

To ensure that cell migration reduction was due to AMPK activation, and not cell death due to prolonged AMPK activation (24 hours), I performed a cell viability assay using PI staining (Fig 9). As expected, cell death was not the cause for reduced cell migration, but AMPK activation itself. PI is a useful marker of cell viability, as it is membrane impermeable 
and cannot enter viable cells (Yeh et al. 1981). It will only stain DNA in non-viable cells, as the integrity of their plasma membrane is typically lost upon death (Yeh et al. 1981). Interestingly, in certain conditions AMPK might protect against cell death. AMPK activation by resveratrol can protect against reactive oxidative species, to inhibit the occurrence of cell death (Hwang et al. 2008). However, AMPK appears to have context-specific control of cell physiology, with respect to control of cell viability: in chronic myelogenus leukemia cells, resveratrol promotes cell death by activating AMPK (Puissant et al. 2010).

\section{AMPK regulation of $\beta 1$-integrin endocytosis}

Determining whether AMPK activation regulated endocytosis or recycling of $\beta 1$ integrin was a two-tiered task: measuring endocytic rates with A-769662 treatment and measuring recycling rates with A-769662 treatment. I've shown that endocytosis of $\beta 1$ integrin is not affected in the early time-point of AMPK activation, specifically in the first 15 minutes. I measured that around $44 \%$ of $\beta 1$-integrin undergoes endocytosis in 15 minutes in the control condition and $40 \%$ of $\beta 1$-integrin undergoes undergoes endocytosis in the AMPK activated condition during the same time (Fig 10). These values at the 15-minute time-point are comparable to other reported endocytic rates of $\beta 1$-integrin (Teckchandani et al. 2009). Interestingly, Arjonen et al. (2012) reported distinct endocytic rates for active, inactive and total $\beta 1$-integrins. Their data shows active $\beta 1$-integrin endocytosed at a higher rate when compared to inactive or total $\beta 1$-integrin, at 15 minutes (Arjonen et al. 2012). The endocytic rates reported in their study were around $25-35 \%$ depending on the cell line for total $\beta 1$-integrin - lower than what my data reports (Arjonen et al. 2012). It is 
noteworthy that they used three different cancer cell lines for their measurements (PC-3, MDA-MB-231, and NCI-H460 cells), all three of which yielded different values of endocytosed $\beta 1$-integrin at 15 minutes (Arjonen et al. 2012). The different cell lines could explain the discrepancy, as integrins are often misregulated in cancer cells (Desgrosellier \& Cheresh 2010). Another possible reason is the limitation of the endocytic assay that I used to measure endocytosis. It requires labelling of $\beta 1$-integrin at $4^{\circ} \mathrm{C}$ for one hour, followed by rewarming at $37^{\circ} \mathrm{C}$ with and without $\mathrm{A}-769662$. Due to this, the rewarming period is limited, as using longer time points begins to include $\beta 1$-integrin recycling back to the cell surface, which would be detected as $\beta 1$-integrin that did not undergo endocytosis. It is still possible that AMPK activation affects endocytosis, especially if a longer 30-minute endpoint is used, as it was used in in other studies (Arjonen et al. 2012). In fact, the most striking differences in endocytic rates between various cell lines and between integrin activation states is seen at 30 minutes in Arjonen et al. (2012).

To complement my studies and further study whether and how AMPK activation may control $\beta 1$-integrin endocytosis, other methods may be used. Such methods include the antibody and quenching based assay which can directly measure integrin endocytosis (Arjonen et al. 2012). This method is based on quenching the fluorescent signal of Alexa Fluor 488-conjugated anti- $\beta 1$-integrin antibodies on the plasma membrane using a particular anti-Alexa Fluor 488 antibody. This allows for quenching of all $\beta 1$-integrin labelled on the cell surface, and measuring only the fluorescence of the endocytosed $\beta 1$ integrin (Arjonen et al. 2012). This method has been shown to yield comparable endocytic kinetics of $\beta 1$-integrin (Arjonen et al. 2012), and would allow measurement of 
internalization of $\beta 1$-integrin for longer time-points. Another method to measure $\beta 1$ integrin endocytosis is a biotin-immunoprecipitation based assay or a reversible biotinylation assay (Gabriel et al. 2009), which may also have advantages to measure longer times of $\beta 1$-integrin internalization.

\section{AMPK regulates $\beta 1$-integrin recycling but not Transferrin receptor recycling}

With the data showing that $\beta 1$-integrin endocytosis is not affected by AMPK activation (following 15 minutes AMPK activation and 15 minutes $\beta 1$-integrin internalization), I shifted to measuring $\beta 1$-integrin recycling. I demonstrated that $\beta 1$ integrin recycling is slowed by $40 \%$ with AMPK activation compared to the control, after 1 hour of recycling (Fig 11). With AMPK regulating $\beta 1$-integrin recycling, I questioned whether other receptors are also regulated. Measuring TfR recycling showed no significant difference in control and AMPK activated conditions (Fig 12).

Determining which compartment $\beta 1$-integrin is recycling to is a difficult task as there are many different endosomes involved. Integrin recycling back to the plasma membrane occurs through two spatially and temporally distinct pathways, dubbed the short loop and the long loop pathways (De Franceschi et al. 2015). Recycling through the short loop pathway is a quick delivery back to the plasma membrane, and occurs through the Rab4 endosomes. The long loop pathway involves slower recycling to the plasma membrane, as it connects with the Rab11-positive perinuclear recycling compartments 
(PNRC) before integrins are routed to the cell surface. Integrin activation state must also be taken into consideration, as inactive and active $\beta 1$-integrins are trafficked to different compartments (De Franceschi et al. 2015). Both begin their recycling journey at the early endosomes and the Rab5/Rab21-positive endosomes. From here, active and inactive $\beta 1$ integrins separate - active $\beta 1$-integrins are targeted to Rab11, and inactive $\beta 1$-integrins are recycling to Rab4 endosomes (De Franceschi et al. 2015). Through an F-actin dependent mechanism, inactive $\beta 1$-integrin are trafficked to Arf6-positive protrusions on the plasma membrane (De Franceschi et al. 2015). Inactive integrins are also likely to be found on the plasma membrane and active integrins in the cytoplasm - this builds on the fact that inactive integrins use the short loop and active integrins the long loop (De Franceschi et al. 2015).

Repeating endocytic and recycling assays with antibodies that selectively recognize inactive or active conformations of $\beta 1$-integrin would be an interesting avenue to explore, to determine if the regulation of cell surface $\beta 1$-integrin by AMPK may be selective for a particular activation state of $\beta 1$-integrin. More importance is being placed on integrin activation states and its consequences on their behaviour (Bazzoni et al. 1995; Byron et al. 2009). We've already seen the differences in localization and kinetics of active and inactive integrins (Arjonen et al. 2012; Byron et al. 2009). The possibility that AMPK is regulating a specific population of $\beta 1$-integrins, be it active or inactive, is definitely noteworthy to address moving forward.

Lastly, GTPases are also involved in regulating $\beta 1$-integrin recycling. Arf6 promotes 
$\beta 1$-integrin recycling whereas Rab35 negatively regulates $\beta 1$-integrin recycling. Rab35

does this by inhibiting Arf6 by recruitment of ACAP2 (Dozynkiewicz et al. 2012). ACAP2 is a Arf6 GAP but is also a Rab35 effector. Rab35 recruits ACAP2 to Arf6-positive endosomes where it deactivates Arf6 (Dozynkiewicz et al. 2012). As Arf6 promotes $\beta 1$-integrin recycling, deactivating it leads to a decreased rate of recycling (Dozynkiewicz et al. 2012).

\section{AMPK regulation of Arf6 to control $\beta 1$-integrin trafficking}

Arf6 regulates the endocytosis and recycling of a variety of proteins between the plasma membrane to endosomal systems, including $\beta 1$-integrin (Oh \& Santy 2010). Here, we show that AMPK activation affects Arf6 localization (Fig 13 A,B). A higher number of Arf6 punctate structures are found in AMPK activated cells compared to control. Arf6-GTP is typically found at the cell periphery (i.e. the plasma membrane), whereas Arf6-GDP is found on endosomal compartments (Gaschet \& Hsu 1999). Without directly quantifying levels of Arf6-GTP and Arf6-GDP, it is hard to say whether AMPK activation is favouring one form over the other by and large. However, what can be concluded from these results is that AMPK appears be to regulating Arf6 localization in a manner that requires Arf6 GTP/GDP cycling. In the Arf6-GTP-locked mutant, the number of punctate structures do not increase in the AMPK activated condition in comparison to the control Arf6-GTP-locked condition (Fig 13B). Thus, when Arf6, in conjunction with ArfGAPs cannot hydrolyze GTP to GDP, AMPK activation is not able to influence Arf6 GTP/GDP cycling and also appears to be unable to shift localization of Arf6 to punctate structures. It has been reported that Arf6 binding to structurally distinct GAPs can fine-tune Arf6-dependent integrin trafficking pathways (De Franceschi et al. 2015). A demonstration of this is the ArfGAPs ACAP1 and 
ARAP2 exhibiting differential and opposite effects on focal adhesion morphology, based on their localization to spatially distinct Arf6-positive endosomes (De Franceschi et al. 2015).

To further test the function of Arf6 GTP/GDP cycling, I used an ArfGAP inhibitor QS11. QS11 inhibits a number of ArfGAPs, which increases the levels of Arf6-GTP. I found that cell surface levels of $\beta 1$-integrin decreased after only 30 minutes of QS11 treatment (Fig 14). This mimics the effect of AMPK activation on $\beta 1$-integrin and highlights the importance of Arf6 GTP/GDP cycling on trafficking. As QS11 treatment only needed 30 minutes of activation to elicit a similar effect that A-769662 does in 60 minutes, it is possible that QS11 is acting downstream of AMPK activation, and therefore needs less time to produce an effect. With a limitation of the endocytic assay with respect to A-769662 treatment such that this could be done for only 15 minutes, I revisited the $\beta 1$-integrin internalization assay now with QS11. Importantly, pre-treatment for 30 min with QS11 treatment hinders $\beta 1$-integrin endocytosis significantly compared to the control condition (Fig 15).

As Arf6 is considered "active" in its GTP form, it is established that Arf6 activation enhances $\beta 1$-integrin recycling (Arjonen et al. 2012). I observed that inhibition of ArfGAPs with QS11 (to enhance Arf6-GTP levels) had the same effect as AMPK activation on $\beta 1$ integrin membrane traffic. Typically, small GTPase proteins have been thought as molecular switches that shift been a GTP-bound active state and a GDP-bound inactive state. From this simplistic interpretation arises the notion that a GTP-locked active Arf6 mutant would reproduce or magnify the functions of an active wild-type Arf6. However, in 
this study as well as others that look at $\beta 1$-integrin recycling, this is not the case (Klein et al. 2006; Radhakrishna \& Donaldson 1997; Naslavsky et al. 2003). In fact, completion of the GTP hydrolysis cycle is a necessary component of small GTPases, to elicit the complete biological response. There are some examples of the importance of nucleotide cycling for normal function of Arfs and other GTPases. For Rab and Ran families of small GTPases, completion of the nucleotide cycling is necessary for the transport of vesicles and shifting in and out of the nucleus, respectively (Chavrier \& Goud 1999; Kuersten et al. 2001). Formation of the coat complex protein I also requires nucleotide cycling of Arf1 (Yang et al. 2002). It is then possible that Arf6 nucleotide cycling, and not simply the relative levels of Arf6-GTP or Arf6-GDP, plays a more significant role in regulation of membrane traffic than what was thought before.

The importance of GTP/GDP cycling for Arf6 has been previously demonstrated with major histocompatibility complex class I (MHCI) (Klein et al. 2006). They show that Arf6 regulates its biological functions by cycling through its GTP and GDP bound forms (Klein et al. 2006). For MHCI, GTP hydrolysis of Arf6 is necessary for efficient recycling. Here, ArfGAPs were shown to have a greater role for Arf6 rather than simply an endpoint for deactivating Arf6.

ArfGAPs comprise the largest binding partners of Arf6 (Randazzo \& Hirsch 2004). The ArfGAP ACAP1 is an effector for Arf6, necessary for membrane protrusion formation (Klein et al. 2006). ArfGAPs are also heavily implicated as regulators of the actin cytoskeleton (Inoue \& Randazzo 2007). ArfGAPs are comprised of two main groups 
depending on their structure: ArfGAP1 type, which have an ArfGAP domain at the $\mathrm{N}$ terminal, and AZAP type, ArfGAPs with ANK repeats and a PH domain (Inoue \& Randazzo 2007). Members of ArfGAP1 type include ArfGAP1/3, SMAP1/2, and GIT1/2; members of the AZAP type consist of ASAP1/2/3, ACAP1/2/3, ARAP1/2/3 and AGAP1/2/3 (Inoue \& Randazzo 2007). Our mass spectrometry screen which detailed proteins depleted from the cell surface upon AMPK activation included the ArfGAPs ASAP1, AGAP5, ARAP2 and ArfGAP3 (Table 1). This points to the possibility that AMPK is regulating ArfGAPs which regulate Arf6, to control $\beta 1$-integrin recycling. It is not only the identification of these specific ArfGAPs in our mass spectrometry assay as putative proteins regulated by AMPK that hints at the connection between AMPK and Arf6: these ArfGAPs also have multiple potential AMPK consensus phosphorylation sites (Table 1). I performed this analysis for AMPK consensus phosphorylation motifs using a ProSite feature which searches sequences for specific protein motifs. In this case, ArfGAPs amino acid sequences were used to search for the AMPK consensus phosphorylation site: $\beta \phi \beta X X X S / \operatorname{TXX} \phi$, where hydrophobic $(\varphi)$ $=\mathrm{M}, \mathrm{L}, \mathrm{I}, \mathrm{F}$, or V; basic $(\beta)=\mathrm{R}, \mathrm{K}$, or $\mathrm{H} ; \mathrm{X}=$ any amino acid, and $\mathrm{S} / \mathrm{T}=$ phosphorylation site (Marin et al. 2015). Variability also exists in the sequence that AMPK phosphorylates, as it is able to phosphorylate sites lacking the $-4 /-6$ basic residue (Marin et al. 2015). In some cases, AMPK can also phosphorylate sites with the -5 hydrophobic residue shifted to -4 position (Xu et al. 2014). Several phosphorylation sites were detected on all four ArfGAPs, but this does not necessarily confirm them as targets by AMPK. Further testing needs to be done to determine whether AMPK regulates Arf6 via ArfGAP phosphorylation.

Some of the possible experimental approaches to more directly test the regulation of 
Arf6 by AMPK and Arf6 begins with using an Arf6 pull-down activation assay, which measures the levels of Arf6-GTP and Arf6-GDP in a cell. This involves using covalently conjugated GGA3-PBD beads. The beads utilize a protein binding domain of the Arf6 effector GGA3, which specifically binds the Arf6-GTP bound form (Takatsu et al. 2002; Balasubramanian et al. 2007). Using these beads allows us to pull-down only the Arf6-GTP in a lysate fraction and quantify it via immunoblotting. This would let us see whether AMPK activation changes the ratio of Arf6-GTP and Arf6-GDP. I performed this type of analysis using a commercial kit (Cytoskeleton Inc, Denver, CO), but was unable to observe pulldown of GTP-bound Arf6, even from the positive control fraction provided by the manufacturer. Future experiments with in-house purified GGA3 effector domains of Arf6, to allow scaling up of cellular material from which GTP-bound Arf6 may be precipitated, may allow successful detection of Arf6-GTP levels in control vs AMPK-activated cells. Certainly, the spinning disk confocal images do suggest a role for AMPK in regulating Arf6 cycling, but this would help confirm the phenomenon (Fig 13).

To determine whether AMPK regulates Arf6 cycling to control $\beta 1$-integrin traffic, previous to any experiments looking at specific ArfGAPs found in the mass spectrometry screen, an Arf6 fast-cycling mutant (Arf6-T157N) can be used. This mutant is able to quickly cycle between GTP and GDP states, regardless of any outside signaling input (Klein et al. 2006). For this, cells would be transfected with the GFP-Arf6-T157N, and the cell surface $\beta 1$-integrin measurement would be measured via the immunofluorescence assays used in this thesis, with and without A-769662 treatment. If AMPK activation controls $\beta 1$ integrin traffic by regulating Arf6 nucleotide cycling, then we should see the same level of 
$\beta 1$-integrin cell surface levels in control and AMPK activated conditions in cells expressing the Arf6-T157N. This would very nicely show the importance of Arf6 nucleotide cycling on $\beta 1$-integrin membrane traffic but also confirm if AMPK regulates this process through Arf6.

\section{AMPK and Arfs regulation of CCPs and endocytosis}

Building on the idea that AMPK regulates $\beta 1$-integrin trafficking via Arf6, I have discovered that AMPK activation decreases Arf6 recruitment to CCPs (Fig 16). However, in Arf6-GTP-locked cells, AMPK activation does not influence Arf6 recruitment at all, having similar levels of CCPs as the control condition (Fig 17). The connection between Arf6 and AMPK has been implicated before in a yeast model, in which Snf1p (the yeast homologue of AMPK) acts as a GEF to activate Arf3p (yeast homologue of Arf6) (Hsu et al. 2015). It should be noted that this function of Snf1p as an Arf GEF may be unique to the yeast protein and does not appear to occur in mammalian AMPK (Hsu et al. 2015). Nonetheless, this suggests the existence of evolutionarily conserved requirements for regulation of Arf GTPases by AMPK during metabolic stress, even if this regulation may occur by distinct molecular mechanisms. Further, there have been previous reports of the regulation of clathrin and CCPs by Arf6. Arf6 has been shown to regulate CME from apical and basolateral membranes of polarized MDCK cells (Altschuler et al. 1999; Palacios et al. 2002). Arfs enhance AP-2 binding to membrane clathrin assembly, where using the Arf6-GTP-locked mutant enhanced clathrin and AP-2 recruitment to isolated membrane vesicles, similar to what my data shows with respect to CCP formation at the cell surface in living cells, assayed by TIRF microscopy (Fig 17) (Krauss et al. 2003). ArfGAPs for Arf6 also have the ability to control clathrin mediated endocytosis: SMAP1 binds directly to the clathrin heavy 
chain via a clathrin-box to regulate CME (Tanabe et al. 2005). Lastly, AP-1, the clathrin adaptor complex responsible for sorting cargo between the trans-golgi network and endosomes requires activation by Arf1, which is similar to Arf6 (Ren et al. 2013). Arf1 unlocks the ability for AP-1 to bind cargo, when it is activated by GTP binding. The study demonstrates direct binding of AP-1 by Arf1 at three interaction sites which are important for recruitment, activation, or both (Ren et al. 2013). These authors suggest a model where Arf1 is responsible for the recruitment and activation of AP-1 at membranes (Ren et al. 2013). The last study demonstrates a relationship between Arf1 and AP-1, which could be a similar model with Arf6 and clathrin/AP-2. I propose a model here which involves reciprocal regulation, in which Arf6 regulates CCP assembly and in which some component of CCPs enhances Arf6 binding. As AP-2 is required for the nucleation of clathrin assembly, it is likely that AP-2 is present on the membrane first. AP-2 binding and nucleation then likely recruits Arf6 to the membrane, and presence of Arf6 on the membrane enhances AP2 binding to clathrin (Antonescu et al., 2011), thus making this reciprocal regulation of Arf6 and AP-2/ clathrin one involving positive feedback that promotes CCP formation. As Arf6 is only found in a subset of CCPs, this mechanism appears to function to control the formation of a subset of CCPs, perhaps those harboring $\beta 1$-integrin.

Consistent with this model, I have also demonstrated that presence of Arf6 (WT) or Arf6 (GTP-locked) results in larger clathrin structures compared to structures lacking Arf6 (Fig 18BC). Importantly, the size of CCP with Arf6-WT compared to CCP with Arf6-GTPlocked mutant are significantly smaller. This suggests that Arf6 nucleotide cycling is a part of clathrin assembly. In fact, a previous study has demonstrated the role of completing the 
Arf6 nucleotide cycle in gyrating-clathrin (G-clathrin) regulation (Yi et al. 2013). Briefly, Gclathrin complexes are structurally and functionally distinct, as their complexes do not have AP-1 or AP-2 recruitment (Yi et al. 2013). They are also primarily found below the plasma membrane at sorting endosomes (Yi et al. 2013).

To determine whether Arf6 nucleotide cycling is necessary to regulate clathrin assembly, it is necessary to first use the Arf6-fast cycling mutant as described above. Following that, it is necessary to determine whether one of the ArfGAPs in the mass spectrometry screen (Table 1) may be phosphorylated by AMPK and thus in turn control Arf6 function. For this, a Phosphogel enrichment kit can be used. In short, Phosphogel uses immobilized metal ion chromatography (IMAC) to separate phosphorylated proteins. It involves $\mathrm{Fe}^{3+}$, which binds to phosphorylated proteins much stronger due to the charge interaction (Andersson \& Porath 1986). The kit uses agarose to separate the phosphorylated form of the protein from the non-phosphorylated form. These are then immunoblotted for - a phosphorylated protein will appear to exhibit higher molecular weight due to the impediment caused by the $\mathrm{Fe}^{3+}$-phosphorylation interaction. In conjunction with antibodies that selectively recognize specific ArfGAPs such as ArfGAP3, this method can be applied to identify whether the ArfGAPs in Table $\mathbf{1}$ are phosphorylated by AMPK activation. If this is the case, then point mutations at likely phosphorylation sites would be the next logical step, to see if the knockout reverses the effect of AMPK activation of cell surface $\beta 1$-integrin levels. 


\section{AMPK}

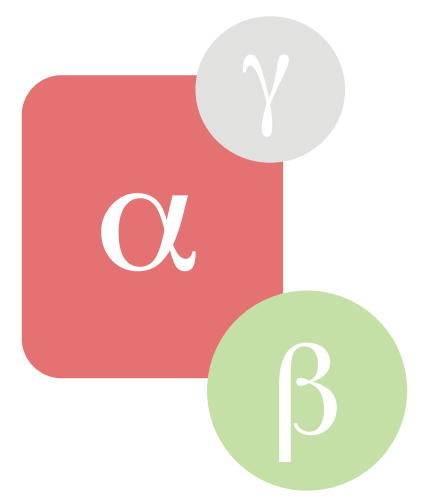

Fig 19. Proposed model for AMPK and Arf6 on $\beta 1$-integrin regulation

The model proposed for AMPK regulation of $\beta 1$-integrin membrane traffic. AMPK affects Arf6 via ArfGAPs, which inturn regulates $\beta 1$-integrin membrane traffic.
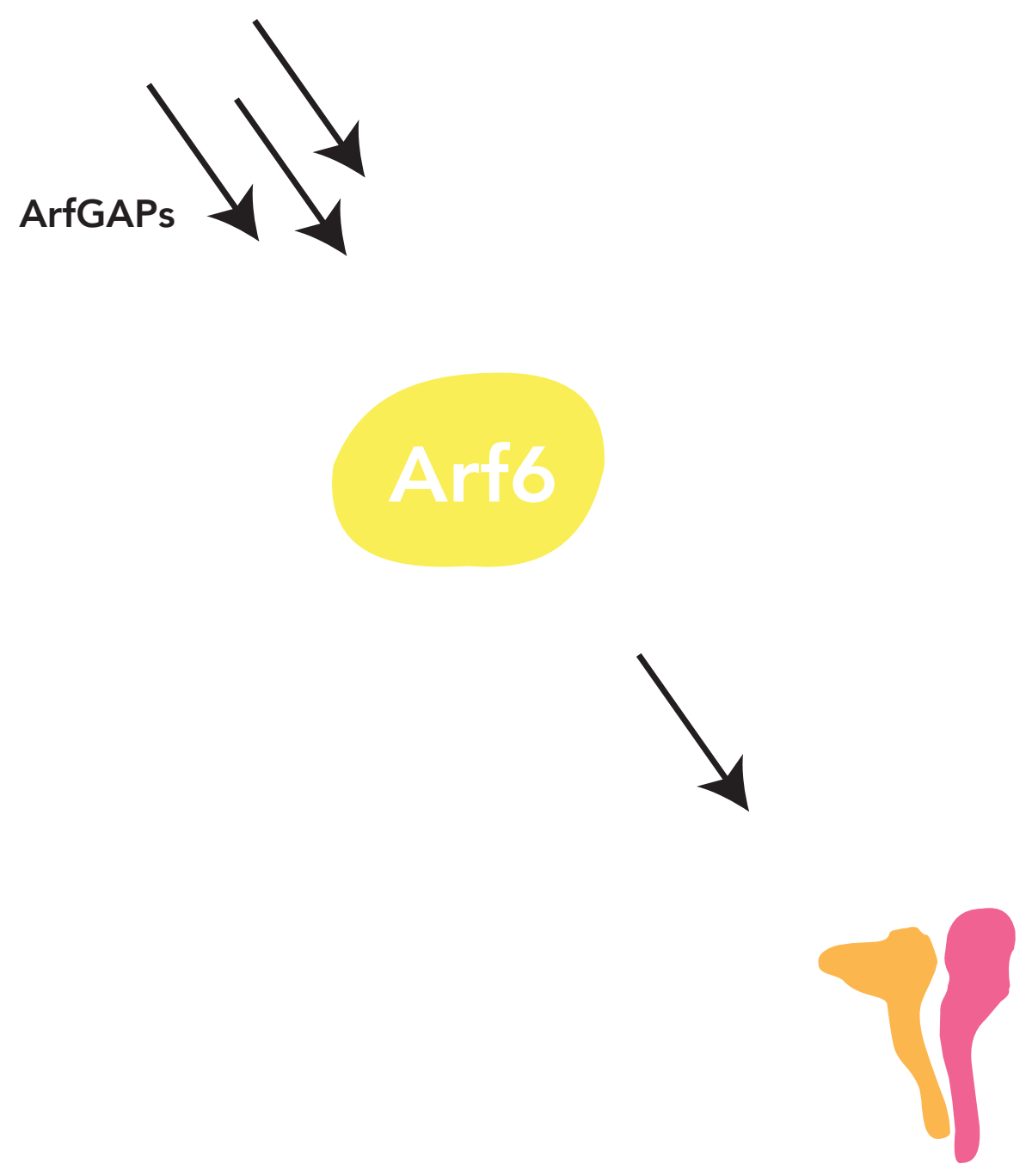

$\beta 1$-integrin membrane traffic 


\section{Conclusion}

In summary, I have established that AMPK activation selectively regulates $\beta 1$ integrin membrane traffic by siRNA knockdown of AMPK $\alpha 1 / 2$. With this, I explored how AMPK activation regulates $\beta 1$-integrin traffic. I have shown that AMPK activation massively reduces RPE cell migration, without affecting the cell viability, possibly due to its regulation of $\beta 1$-integrin. Of interest was whether endocytosis or recycling of $\beta 1$-integrin was affected. I demonstrated that $\beta 1$-integrin endocytosis by AMPK activation was not appreciably affected, although that could potentially be a limitation of the assay used. I followed this by measuring $\beta 1$-integrin and TfR recycling, in which $\beta 1$-integrin but not TfR recycling was affected by AMPK activation. This demonstrated a specific regulation of $\beta 1$-integrin and not TfR by AMPK, which was also seen with cell surface measurements of both receptors (Ross et al., 2015). As data from the mass spectrometry screen suggested, ArfGAPs were depleted from the cell surface upon AMPK activation (Ross et al., 2015).

Due to the established role of Arf6 in $\beta 1$-integrin membrane traffic, I hypothesized AMPK could be acting on some component of Arfs to regulate $\beta 1$-integrin membrane traffic. This was evinced by spinning disk confocal micrographs, depicting an increase of Arf6 punctate structures in AMPK activated cells, but no change in Arf6-GTP-locked mutant cells by AMPK activation. This data hinted at AMPK regulating Arf6 nucleotide cycling; I discovered that ArfGAP inhibition by QS11 treatment mimicked AMPK activation on cell surface $\beta 1$-integrin levels. Revisiting endocytosis with ArfGAP inhibition revealed a reduction of $\beta 1$-integrin internalization. I followed this by measuring clathrin assembly 
dynamics and Arf6, which revealed that AMPK activation reduced colocalization of Arf6WT in CCPs, and that this did not occur in Arf6-GTP locked mutant cells. I also demonstrated that CCPs are larger in structures that contain Arf6-WT, and that presence of Arf6-GTP-locked mutant in CCP increases their size compared to Arf-WT CCPs. This data reveals that AMPK regulates Arf6 localization to CCPs. It also suggests a reciprocal regulation of Arf6 on CCP assembly, and demonstrates that control of Arf6 nucleotide cycling may be part of a mechanism by which AMPK can regulate clathrin/CCP assembly. Discovering which component of Arf6 is regulated by AMPK is the next step in a broader study to understand how AMPK controls cell surface membrane traffic and the cell surface proteome. Whether AMPK acts directly on Arf6 or through an ArfGAP to regulate nucleotide cycling remains to be answered. Understanding this new pathway will lead to better understanding of how AMPK regulates the cell surface proteome, and how selective or broad its control is. Overall, this research may be laying the groundwork for the development of future therapeutic targets, specifically against tumourigenesis and metastasis given the heavy involvement of integrins. 


\section{References}

Abram, C.L. \& Lowell, C.A., 2009. The ins and outs of leukocyte integrin signaling. Annual review of immunology, 27, pp.339-362.

Abu-elheiga, L. et al., 1997. Human Acetyl-CoA Carboxylase 2. J Biol Chem, 272(16), pp.10669-10677.

Abu-Elheiga, L. et al., 1995. Human acetyl-CoA carboxylase: characterization, molecular cloning, and evidence for two isoforms. Proceedings of the National Academy of Sciences of the United States of America, 92(9), pp.4011-5. Available at: http://www.pubmedcentral.nih.gov/articlerender.fcgi?artid=42092\&tool=pmcentrez \&rendertype=abstract.

Abu-Elheiga, L. et al., 2005. Mutant mice lacking acetyl-CoA carboxylase 1 are embryonically lethal. Proceedings of the National Academy of Sciences of the United States of America, 102(34), pp.12011-6. Available at: http://www.pubmedcentral.nih.gov/articlerender.fcgi?artid=1189351\&tool=pmcentr ez\&rendertype=abstract.

Abu-Elheiga, L. et al., 2000. The subcellular localization of acetyl-CoA carboxylase 2. Proceedings of the National Academy of Sciences of the United States of America, 97(4), pp.1444-1449.

Aguet, F. et al., 2013. Advances in analysis of low signal-to-noise images link dynamin and AP2 to the functions of an endocytic checkpoint. Developmental cell, 26(3), pp.279-91. Available at: http://www.cell.com/article/S1534580713003821/fulltext [Accessed May 2, 2015].

Akram, M., 2014. Citric acid cycle and role of its intermediates in metabolism. Cell biochemistry and biophysics, 68(3), pp.475-478.

Al-Fageeh, M.B. \& Smales, C.M., 2006. Control and regulation of the cellular responses to cold shock: the responses in yeast and mammalian systems. The Biochemical journal, 397(2), pp.247-259.

Altschuler, Y. et al., 1999. ADP-ribosylation factor 6 and endocytosis at the apical surface of Madin-Darby canine kidney cells. J Cell Biol, 147(1), pp.7-12. Available at: http://www.ncbi.nlm.nih.gov/entrez/query.fcgi?cmd=Retrieve\&db=PubMed\&dopt=Ci tation\&list_uids=10508850.

Andersson, L. \& Porath, J., 1986. Isolation of phosphoproteins by immobilized metal (Fe3+) affinity chromatography. Analytical biochemistry, 154(1), pp.250-254. 
Andrews, Z.B., 2011. Central mechanisms involved in the orexigenic actions of ghrelin. Peptides, 32(11), pp.2248-2255. Available at:

http://dx.doi.org/10.1016/j.peptides.2011.05.014.

Antonescu, C.N. et al., 2011. Phosphatidylinositol-(4, 5)-bisphosphate regulates clathrincoated pit initiation, stabilization, and size. Molecular biology of the cell, 22(14), pp.2588-2600.

Antonescu, C.N., McGraw, T.E. \& Klip, A., 2014. Reciprocal regulation of endocytosis and metabolism. Cold Spring Harbor perspectives in biology, 6(7), p.a016964. Available at: http://www.ncbi.nlm.nih.gov/pubmed/24984778 [Accessed April 27, 2015].

Antonny, B. et al., 1997. N-terminal hydrophobic residues of the G-protein ADP-ribosylation factor-1 insert into membrane phospholipids upon GDP to GTP exchange. Biochemistry, 36(15), pp.4675-4684.

Aponte, Y., Atasoy, D. \& Sternson, S.M., 2011. AGRP neurons are sufficient to orchestrate feeding behavior rapidly and without training. Nature neuroscience, 14(3), pp.351355. Available at: http://dx.doi.org/10.1038/nn.2739.

Arjonen, A. et al., 2012. Distinct Recycling of Active and Inactive $\beta 1$ Integrins. Traffic, 13(4), pp.610-625. Available at: http://dx.doi.org/10.1111/j.1600-0854.2012.01327.x.

Artavanis-tsakonas, S., Rand, M.D. \& Lake, R.J., 1999. Notch Signaling : Cell Fate Control and Signal Integration in Development. , 284(April), pp.770-777.

Bai, M. et al., 2011. ARFGAP1 promotes endocytosis regulated by AP-2. Nature cell biology, 13(5), pp.559-567. Available at:

http://www.ncbi.nlm.nih.gov/pmc/articles/PMC3087831/.

Balasubramanian, N. et al., 2007. Arf6 and microtubules in adhesion-dependent trafficking of lipid rafts. Nature cell biology, 9(12), pp.1381-1391.

Ballestrem, C. et al., 2000. Actin-dependent lamellipodia formation and microtubuledependent tail retraction control-directed cell migration. Molecular biology of the cell, 11(9), pp.2999-3012.

Banerjee, A., Berezhkovskii, A. \& Nossal, R., 2012. Stochastic Model of Clathrin-Coated Pit Assembly. Biophysical Journal, 102(12), pp.2725-2730. Available at: http://www.ncbi.nlm.nih.gov/pmc/articles/PMC3379625/.

Bazzoni, G. et al., 1995. Monoclonal Antibody 9EG7 Defines a Novel beta 1 Integrin Epitope Induced by Soluble Ligand and Manganese , but Inhibited by Calcium. , 270(43), pp.25570-25577.

Behnia, R. \& Munro, S., 2005. Organelle identity and the signposts for membrane traffic. Nature, 438(7068), pp.597-604. Available at: 
http://www.ncbi.nlm.nih.gov/pubmed/16319879.

Bianchi, A. et al., 1990. Identification of an isozymic form of acetyl-CoA carboxylase. Journal of Biological Chemistry, 265(3), pp.1502-1509.

Blümer, J. et al., 2013. RabGEFs are a major determinant for specific Rab membrane targeting. Journal of Cell Biology, 200(3), pp.287-300.

Bonen, A. et al., 1999. Muscle contractile activity increases fatty acid metabolism and transport and FAT/CD36. Am J Physiol, 276(4 Pt 1), pp.E642-9. Available at: http://www.ncbi.nlm.nih.gov/entrez/query.fcgi?cmd=Retrieve\&db=PubMed\&dopt=Ci tation\&list_uids=10198299.

Browne, G.J., Finn, S.G. \& Proud, C.G., 2004. Stimulation of the AMP-activated Protein Kinase Leads to Activation of Eukaryotic Elongation Factor 2 Kinase and to Its Phosphorylation at a Novel Site, Serine 398. Journal of Biological Chemistry, 279(13), pp.12220-12231.

Byron, A. et al., 2009. Anti-integrin monoclonal antibodies. Journal of cell science, 122(Pt 22), pp.4009-4011.

Caswell, P. \& Norman, J., 2008. Endocytic transport of integrins during cell migration and invasion. Trends in Cell Biology, 18(6), pp.257-263. Available at: http://www.sciencedirect.com/science/article/pii/S0962892408001074.

Caswell, P.T. \& Norman, J.C., 2006. Integrin Trafficking and the Control of Cell Migration. Traffic, 7(1), pp.14-21. Available at: http://dx.doi.org/10.1111/j.16000854.2005.00362.x.

Caswell, P.T., Vadrevu, S. \& Norman, J.C., 2009. Integrins: masters and slaves of endocytic transport. Nature reviews. Molecular cell biology, 10(12), pp.843-53. Available at: http://www.ncbi.nlm.nih.gov/pubmed/19904298 [Accessed January 12, 2015].

Ceresa, B.P., 2006. Regulation of EGFR endocytic trafficking by rab proteins. Histology and Histopathology, 21(7-9), pp.987-993.

Chavrier, P. \& Goud, B., 1999. The role of ARF and Rab GTPases in membrane transport. Current Opinion in Cell Biology, 11(4), pp.466-475.

Chen, S. et al., 2008. Complementary regulation of TBC1D1 and AS160 by growth factors, insulin and AMPK activators. The Biochemical journal, 409(2), pp.449-59. Available at: http://www.ncbi.nlm.nih.gov/pubmed/17995453.

Chidambaram, S., Zimmermann, J. \& von Mollard, G.F., 2008. ENTH domain proteins are cargo adaptors for multiple SNARE proteins at the TGN endosome. Journal of cell science, 121(Pt 3), pp.329-338. 
Claret, M. et al., 2007. AMPK is essential for energy homeostasis regulation and glucose sensing by POMC and AgRP neurons. Journal of Clinical Investigation, 117(8), pp.23252336.

Cocucci, E. et al., 2012. The first five seconds in the life of a clathrin-coated pit. Cell, 150(3), pp.495-507.

Conaway, R.C. \& Conaway, J.W., 1988. ATP activates transcription initiation from promoters by RNA polymerase II in a reversible step prior to RNA synthesis. Journal of Biological Chemistry, 263(6), pp.2962-2968.

Corton, J.M. et al., 1995. 5-aminoimidazole-4-carboxamide ribonucleoside. A specific method for activating AMP-activated protein kinase in intact cells? European journal of biochemistry / FEBS, 229(2), pp.558-565.

Cremona, O. et al., 1999. Essential role of phosphoinositide metabolism in synaptic vesicle recycling. Cell, 99(2), pp.179-188.

Dai, J. et al., 2004. ACAP1 promotes endocytic recycling by recognizing recycling sorting signals. Developmental cell, 7(5), pp.771-6. Available at: http://www.cell.com/article/S1534580704003624/fulltext [Accessed May 2, 2015].

Davies, S.P. et al., 1995. 5'-AMP inhibits dephosphorylation, as well as promoting phosphorylation, of the AMP-activated protein kinase. Studies using bacterially expressed human protein phosphatase-2C?? and native bovine protein phosphatase2Ac. FEBS Letters, 377(3), pp.421-425.

Demetriades, C., Doumpas, N. \& Teleman, A.A., 2014. Regulation of TORC1 in response to amino acid starvation via lysosomal recruitment of TSC2. Cell, 156(4), pp.786-799.

Desgrosellier, J.S. \& Cheresh, D.A., 2010. Integrins in cancer: biological implications and therapeutic opportunities. Nature reviews. Cancer, 10(1), pp.9-22.

Dittman, J.S. \& Kaplan, J.M., 2006. Factors regulating the abundance and localization of synaptobrevin in the plasma membrane. Proceedings of the National Academy of Sciences of the United States of America, 103(30), pp.11399-11404.

Dozynkiewicz, M.A. et al., 2012. Rab25 and CLIC3 Collaborate to Promote Integrin Recycling from Late Endosomes/Lysosomes and Drive Cancer Progression. Developmental Cell, 22(1), pp.131-145. Available at: http://dx.doi.org/10.1016/j.devcel.2011.11.008.

Dunphy, J.L. et al., 2006. The Arf6 GEF GEP100/BRAG2 regulates cell adhesion by controlling endocytosis of beta1 integrins. Current Biology, 16(3), pp.315-320.

Erdmann, K.S. et al., 2007. A role of the Lowe syndrome protein OCRL in early steps of the endocytic pathway. Developmental cell, 13(3), pp.377-390. 
Evans, J.M.M. et al., 2005. Metformin and reduced risk of cancer in diabetic patients. BMJ (Clinical research ed.), 330(7503), pp.1304-1305.

F Cheung, P.C. et al., 2000. Characterization of AMP-activated protein kinase $\gamma$-subunit isoforms and their role in AMP binding. Biochem. J, 346, pp.659-669.

Faubert, B. et al., 2013. AMPK Is a Negative Regulator of the Warburg Effect and Suppresses Tumor Growth In\&\#xa0;Vivo. Cell Metabolism, 17(1), pp.113-124. Available at: http://dx.doi.org/10.1016/j.cmet.2012.12.001.

Faubert, B. et al., 2014. Loss of the tumor suppressor LKB1 promotes metabolic reprogramming of cancer cells via HIF-1alpha. Proceedings of the National Academy of Sciences of the United States of America, 111(7), pp.2554-2559.

Faubert, B. et al., 2015. The AMP-activated protein kinase (AMPK) and cancer : Many faces of a metabolic regulator. Cancer Letters, 356(2), pp.165-170. Available at: http://dx.doi.org/10.1016/j.canlet.2014.01.018.

Ford, M.G. et al., 2001. Simultaneous binding of PtdIns(4,5)P2 and clathrin by AP180 in the nucleation of clathrin lattices on membranes. Science (New York, N.Y.), 291(5506), pp.1051-1055.

Ford, M.G.J. et al., 2002. Curvature of clathrin-coated pits driven by epsin. Nature, 419(6905), pp.361-366.

De Franceschi, N. et al., 2015. Integrin traffic - the update. Journal of cell science, pp.1-14. Available at: http://www.ncbi.nlm.nih.gov/pubmed/25663697 [Accessed February 11, 2015].

Gabriel, L., Stevens, Z. \& Melikian, H., 2009. Measuring plasma membrane protein endocytic rates by reversible biotinylation. Journal of visualized experiments : JoVE, (34), pp.2-5. Available at:

http://www.pubmedcentral.nih.gov/articlerender.fcgi?artid=3152245\&tool=pmcentr ez\&rendertype=abstract.

Gaschet, J. \& Hsu, V.W., 1999. Distribution of ARF6 between membrane and cytosol is regulated by its GTPase cycle. Journal of Biological Chemistry, 274(28), pp.2004020045.

Giugliano, D., Ceriello, A. \& Esposito, K., 2008. Glucose metabolism and hyperglycemia. In American Journal of Clinical Nutrition. pp. 217-222.

Grant, B.D. \& Donaldson, J.G., 2009. Pathways and mechanisms of endocytotic recycling. Molecular Cell Biology, 10(9), pp.597-604.

Gusarova, G.A. et al., 2009. Alpha1-AMP-activated protein kinase regulates hypoxia-induced $\mathrm{Na}, \mathrm{K}-\mathrm{ATP}$ ase endocytosis via direct phosphorylation of protein kinase $\mathrm{C}$ zeta. 
Molecular and cellular biology, 29(13), pp.3455-64. Available at:

http://www.pubmedcentral.nih.gov/articlerender.fcgi?artid=2698765\&tool=pmcentr ez\&rendertype=abstract.

Gwinn, D.M. et al., 2008. AMPK Phosphorylation of Raptor Mediates a Metabolic Checkpoint. Molecular Cell, 30(2), pp.214-226.

ter Haar, E. et al., 1998. Atomic Structure of Clathrin: A $\beta$ Propeller Terminal Domain Joins an $\alpha$ Zigzag Linker. Cell, 95(4), pp.563-573. Available at: http://www.ncbi.nlm.nih.gov/pmc/articles/PMC4428171/.

ter Haar, E., Harrison, S.C. \& Kirchhausen, T., 2000. Peptide-in-groove interactions link target proteins to the beta-propeller of clathrin. Proceedings of the National Academy of Sciences of the United States of America, 97(3), pp.1096-100. Available at: http://www.pubmedcentral.nih.gov/articlerender.fcgi?artid=15533\&tool=pmcentrez \&rendertype $=$ abstract.

Hardie, D.G., Ross, F. a. \& Hawley, S. a., 2012. AMPK: a nutrient and energy sensor that maintains energy homeostasis. Nature Reviews Molecular Cell Biology, 13(4), pp.251262. Available at: http://dx.doi.org/10.1038/nrm3311.

Harms, U. et al., 2014. EIF4B, eIF4G and RNA regulate eIF4A activity in translation initiation by modulating the eIF4A conformational cycle. Nucleic Acids Research, 42(12), pp.7911-7922.

Hattula, K. et al., 2006. Characterization of the Rab8-specific membrane traffic route linked to protrusion formation. Journal of cell science, 119(Pt 23), pp.4866-77. Available at: http://jcs.biologists.org/content/119/23/4866.short\nhttp://www.ncbi.nlm.nih.gov/ pubmed/17105768.

Hawley, S. a et al., 2003. Complexes between the LKB1 tumor suppressor, STRAD alpha/beta and M025 alpha/beta are upstream kinases in the AMP-activated protein kinase cascade. Journal of biology, 2(4), p.28.

Hawley, S. a. et al., 1995. 5 `-AMP Activates the AMP-activated Protein Kinase Cascade, and $\mathrm{Ca}+2 /$ Calmodulin Activates the Calmodulin-dependent Protein Kinase I Cascade, via Three Independent Mechanisms. Journal of Biological Chemistry, 270(45), pp.2718627191.

Hawley, S. a. et al., 2005. Calmodulin-dependent protein kinase kinase-beta is an alternative upstream kinase for AMP-activated protein kinase. Cell Metabolism, 2(1), pp.9-19.

Vander Heiden, M.G., Cantley, L.C. \& Thompson, C.B., 2009. Understanding the Warburg effect: the metabolic requirements of cell proliferation. Science (New York, N.Y.), 324(5930), pp.1029-1033.

Honing, S. et al., 2005. Phosphatidylinositol-(4,5)-bisphosphate regulates sorting signal 
recognition by the clathrin-associated adaptor complex AP2. Molecular Cell, 18(5), pp.519-531.

Hoppe, S. et al., 2009. AMP-activated protein kinase adapts rRNA synthesis to cellular energy supply. Proceedings of the National Academy of Sciences of the United States of America, 106(42), pp.17781-17786.

Houten, S.M. \& Wanders, R.J.A., 2010. A general introduction to the biochemistry of mitochondrial fatty acid $\beta$-oxidation. Journal of Inherited Metabolic Disease, 33(5), pp.469-477.

Hsu, J., Chen, K. \& Lee, F.S., 2015. Snf1/AMP-activated protein kinase activates Arf3p to promote invasive yeast growth via a non-canonical GEF domain. Nature Communications, 6, p.7840. Available at: http://www.nature.com/doifinder/10.1038/ncomms8840.

Huang, X. et al., 2008. Important role of the LKB1-AMPK pathway in suppressing tumorigenesis in PTEN-deficient mice. The Biochemical journal, 412(2), pp.211-221.

Hurley, R.L. et al., 2005. The Ca2+/calmodulin-dependent protein kinase kinases are AMPactivated protein kinase kinases. The Journal of biological chemistry, 280(32), pp.29060-29066.

Huttenlocher, A. \& Horwitz, A.R., 2011. Integrins in Cell Migration. Available at: http://linkinghub.elsevier.com/retrieve/pii/S0076687907260033.

Huveneers, S. \& Danen, E.H.J., 2009. Adhesion signaling - crosstalk between integrins, Src and Rho. Journal of cell science, 122(Pt 8), pp.1059-1069.

Hwang, J.T. et al., 2008. Resveratrol protects ROS-induced cell death by activating AMPK in H9c2 cardiac muscle cells. Genes and Nutrition, 2(4), pp.323-326.

Hyman, T., Shmuel, M. \& Altschuler, Y., 2006. Actin Is Required for Endocytosis at the Apical Surface of Madin-Darby Canine Kidney Cells where ARF6 and Clathrin Regulate the Actin Cytoskeleton. Molecular Biology of the Cell.

Hynes, R.O., 2002. Integrins Bidirectional, Allosteric Signaling Machines. Cell, 110(6), pp.673-687. Available at: http://www.cell.com/article/S0092867402009716/fulltext [Accessed February 6, 2015].

Imamura, K. et al., 2001. Cell cycle regulation via p53 phosphorylation by a 5'-AMP activated protein kinase activator, 5-aminoimidazole- 4-carboxamide-1-beta-Dribofuranoside, in a human hepatocellular carcinoma cell line. Biochemical and biophysical research communications, 287(2), pp.562-567.

Inoki, K., Zhu, T. \& Guan, K.-L., 2003. TSC2 mediates cellular energy response to control cell growth and survival. Cell, 115(5), pp.577-590. 
Inoue, H. \& Randazzo, P.A., 2007. Arf GAPs and their interacting proteins. Traffic, 8(11), pp.1465-1475.

Iverson, A.J. et al., 1990. Immunological analysis of acetyl-CoA carboxylase mass, tissue distribution and subunit composition. The Biochemical journal, 269(2), pp.365-71. Available at: http://www.pubmedcentral.nih.gov/articlerender.fcgi?artid=1131586\&tool=pmcentr ez\&rendertype=abstract.

Jackson, L.P. et al., 2010. A large-scale conformational change couples membrane recruitment to cargo binding in the AP2 clathrin adaptor complex. Cell, 141(7), pp.1220-1229.

Jimenez-Soto, L.F. et al., 2009. Helicobacter pylori type IV secretion apparatus exploits beta 1 integrin in a novel RGD-independent manner. PLoS Pathogens, 5(12).

Jones, M.C., Caswell, P.T. \& Norman, J.C., 2006. Endocytic recycling pathways: emerging regulators of cell migration. Current Opinion in Cell Biology, 18(5), pp.549-557. Available at: http://www.sciencedirect.com/science/article/pii/S095506740600113X.

Jones, R.G. et al., 2005. AMP-activated protein kinase induces a p53-dependent metabolic checkpoint. Molecular Cell, 18(3), pp.283-293.

Kanno, E. et al., 2010. Comprehensive screening for novel rab-binding proteins by GST pulldown assay using 60 different mammalian Rabs. Traffic (Copenhagen, Denmark), 11(4), pp.491-507.

Kelly, B.T. et al., 2014. Clathrin adaptors. AP2 controls clathrin polymerization with a membrane-activated switch. Science (New York, N.Y.), 345(6195), pp.459-463.

Kiens, B., 2006. Skeletal Muscle Lipid Metabolism in Exercise and Insulin Resistance. Physiol Rev, pp.205-243.

Kim, E., 2009. Mechanisms of amino acid sensing in mTOR signaling pathway. Nutrition research and practice, 3(1), pp.64-71.

Kim, J. et al., 2016. AMPK activators: mechanisms of action and physiological activities. Experimental \& Molecular Medicine, 48(4), p.e224. Available at: http://dx.doi.org/10.1038/emm.2016.16.

Kirchhausen, T., Owen, D. \& Harrison, S.C., 2014. Molecular structure, function, and dynamics of clathrin-mediated membrane traffic. Cold Spring Harbor Perspectives in Biology, 6(5).

Klaus, A. et al., 2012. A two-dimensional screen for AMPK substrates identifies tumor suppressor fumarate hydratase as a preferential AMPK $\alpha 2$ substrate. Journal of 
Proteomics, 75(11), pp.3304-3313. Available at:

http://dx.doi.org/10.1016/j.jprot.2012.03.040.

Klein, S. et al., 2006. Role of the Arf6 GDP/GTP cycle and Arf6 GTPase-activating proteins in actin remodeling and intracellular transport. Journal of Biological Chemistry, 281(18), pp.12352-12361.

Koronakis, V. et al., 2011. WAVE regulatory complex activation by cooperating GTPases Arf and Rac1. Proceedings of the National Academy of Sciences of the United States of America, 108(35), pp.14449-54. Available at:

http://www.pubmedcentral.nih.gov/articlerender.fcgi?artid=3167530\&tool=pmcentr ez\&rendertype=abstract.

Krauss, M. et al., 2003. ARF6 stimulates clathrin/AP-2 recruitment to synaptic membranes by activating phosphatidylinositol phosphate kinase type Iy. Journal of Cell Biology, 162(1), pp.113-124.

Kuersten, S., Ohno, M. \& Mattaj, I.W., 2001. Nucleocytoplasmic transport: Ran, beta and beyond. Trends in cell biology, 11(12), pp.497-503.

Li, X.-B., Gu, J.-D. \& Zhou, Q.-H., 2015. Review of aerobic glycolysis and its key enzymes new targets for lung cancer therapy. Thoracic cancer, 6(1), pp.17-24. Available at: http://www.pubmedcentral.nih.gov/articlerender.fcgi?artid=4448463\&tool=pmcentr ez\&rendertype=abstract.

Lim, C.J. et al., 2008. Integrin-mediated Protein Kinase A Activation at the Leading Edge of Migrating Cells J. E. Schwarzbauer, ed. Molecular Biology of the Cell, 19(11), pp.49304941. Available at: http://www.ncbi.nlm.nih.gov/pmc/articles/PMC2575143/.

Loerke, D. et al., 2009. Cargo and Dynamin Regulate Clathrin-Coated Pit Maturation F. Hughson, ed. PLoS Biology, 7(3), p.e1000057. Available at: http://www.ncbi.nlm.nih.gov/pmc/articles/PMC2656549/.

Luiken, J.J.F.P. et al., 2003. Translocation in Rat Cardiac Myocytes Is Mediated Through AMP-Activated Protein Kinase Signaling. Diabetes, 52, pp.1627-1634.

Mai, A. et al., 2011. Competitive binding of Rab21 and p120RasGAP to integrins regulates receptor traffic and migration. The Journal of cell biology, 194(2), pp.291-306. Available at: http://www.pubmedcentral.nih.gov/articlerender.fcgi?artid=3144408\&tool=pmcentr ez\&rendertype=abstract [Accessed April 27, 2015].

Marin, T.L. et al., 2015. Identification of AMP-activated protein kinase targets by a consensus sequence search of the proteome. BMC Systems Biology, 9(1), pp.1-12. Available at: http://www.biomedcentral.com/1752-0509/9/13.

Mcmahon, H.T. \& Boucrot, E., 2011. Molecular mechanism and physiological functions of 
clathrin-mediated endocytosis. Nature Publishing Group, 12(8), pp.517-533. Available at: http://dx.doi.org/10.1038/nrm3151.

Mettlen, M. et al., 2010. Cargo- and adaptor-specific mechanisms regulate clathrinmediated endocytosis. Journal of Cell Biology, 188(6), pp.919-933.

Miaczynska, M. et al., 2004. APPL proteins link Rab5 to nuclear signal transduction via an endosomal compartment. Cell, 116(3), pp.445-456.

Mim, C. \& Unger, V.M., 2012. Membrane curvature and its generation by BAR proteins. Trends in biochemical sciences, 37(12), pp.526-533. Available at: http://www.ncbi.nlm.nih.gov/pmc/articles/PMC3508348/.

Munday, M.R., 2002. Regulation of mammalian acetyl-CoA carboxylase. Biochemical Society transactions, 30(Pt 6), pp.1059-1064.

Nakano, A. et al., 2010. AMPK controls the speed of microtubule polymerization and directional cell migration through CLIP-170 phosphorylation. Nature cell biology, 12(6), pp.583-590. Available at: http://dx.doi.org/10.1038/ncb2060.

Naslavsky, N., Weigert, R. \& Donaldson, J.G., 2003. Convergence of non-clathrin- and clathrin-derived endosomes involves Arf6 inactivation and changes in phosphoinositides. Molecular biology of the cell, 14(2), pp.417-431.

Newsholme, E.A., Crabtree, B. \& Ardawi, M.S., 1985. The role of high rates of glycolysis and glutamine utilization in rapidly dividing cells. Bioscience reports, 5(5), pp.393-400.

Oakhill, J.S. et al., 2011. AMPK Is a Direct Adenylate Charge-Regulated Protein Kinase. Science, 332(6036), pp.1433-1435. Available at: http://science.sciencemag.org/content/332/6036/1433.abstract.

Oh, S.J. \& Santy, L.C., 2010. Differential effects of cytohesins 2 and 3 on beta1 integrin recycling. The Journal of biological chemistry, 285(19), pp.14610-6. Available at: http://www.pubmedcentral.nih.gov/articlerender.fcgi?artid=2863229\&tool=pmcentr ez\&rendertype $=$ abstract.

Palacios, F. et al., 2002. ARF6-GTP recruits Nm23-H1 to facilitate dynamin-mediated endocytosis during adherens junctions disassembly. Nature cell biology, 4(12), pp.929-936.

Partridge, A.W. et al., 2005. Transmembrane domain helix packing stabilizes integrin $\alpha \operatorname{IIb} \beta 3$ in the low affinity state. Journal of Biological Chemistry, 280(8), pp.7294-7300.

Pasqualato, S. et al., 2001. The structural GDP / GTP cycle of human Arf6. Molecular Biology, 2(3), pp.234-238.

Pasqualato, S., Renault, L. \& Cherfils, J., 2002. Arf, Arl, Arp and Sar proteins: a family of GTP- 
binding proteins with a structural device for "front-back" communication. EMBO reports, 3(11), pp.1035-1041.

Pehmoller, C. et al., 2009. Genetic disruption of AMPK signaling abolishes both contractionand insulin-stimulated TBC1D1 phosphorylation and 14-3-3 binding in mouse skeletal muscle. Am J Physiol Endocrinol Metab, 297(3), pp.E665-75. Available at: http://www.ncbi.nlm.nih.gov/pubmed/19531644\nhttp://ajpendo.physiology.org/co ntent/ajpendo/297/3/E665.full.pdf.

Pellinen, T., 2006. Small GTPase Rab21 regulates cell adhesion and controls endosomal traffic of 1-integrins. The Journal of Cell Biology, 173(5), pp.767-780. Available at: http://www.jcb.org/cgi/doi/10.1083/jcb.200509019 [Accessed March 14, 2015].

Pellinen, T. \& Ivaska, J., 2006. Integrin traffic. Journal of cell science, 119(Pt 18), pp.37233731.

Pinter, K. et al., 2013. Localisation of AMPK $\gamma$ subunits in cardiac and skeletal muscles. Journal of Muscle Research and Cell Motility, 34(5-6), pp.369-378.

Powelka, A.M. et al., 2004. Stimulation-Dependent Recycling of Integrin b1 Regulated by ARF6 and Rab11. , pp.1-18.

Puissant, A. et al., 2010. Resveratrol promotes autophagic cell death in chronic myelogenous leukemia cells via JNK-mediated p62/SQSTM1 expression and AMPK activation. Cancer Research, 70(3), pp.1042-1052.

Radhakrishna, H. \& Donaldson, J.G., 1997. ADP-ribosylation factor 6 regulates a novel plasma membrane recycling pathway. The Journal of cell biology, 139(1), pp.49-61.

Randazzo, P.A. \& Hirsch, D.S., 2004. Arf GAPs: multifunctional proteins that regulate membrane traffic and actin remodelling. Cellular signalling, 16(4), pp.401-413.

Rapoport, I. et al., 2008. A motif in the clathrin heavy chain required for the Hsc70/auxilin uncoating reaction. Molecular biology of the cell, 19(1), pp.405-413.

Regen, C.M. \& Horwitz, A.F., 1992. Dynamics of beta 1 integrin-mediated adhesive contacts in motile fibroblasts. The Journal of cell biology, 119(5), pp.1347-1359.

Ren, X. et al., 2013. Structural basis for recruitment and activation of the AP-1 clathrin adaptor complex by Arf1. Cell, 152(4), pp.755-767.

Ridley, A.J. et al., 2003. Cell migration: integrating signals from front to back. Science (New York, N.Y.), 302(5651), pp.1704-9. Available at: http://classic.sciencemag.org/content/302/5651/1704.full.

Ross, E. et al., 2015. AMP-activated protein kinase regulates the cell surface proteome and integrin membrane traffic. PloS one. 
Sakamoto, K. et al., 2006. Deficiency of LKB1 in heart prevents ischemia-mediated activation of AMPK $\alpha 2$ but not AMPK $\alpha 1$. American journal of physiology. Endocrinology and metabolism, 290(5), pp.E780-E788. Available at: http://www.ncbi.nlm.nih.gov/pmc/articles/PMC2128705/.

Sakamoto, K. et al., 2005. Deficiency of LKB1 in skeletal muscle prevents AMPK activation and glucose uptake during contraction. The EMBO journal, 24(10), pp.1810-1820.

Sakamoto, K. \& Holman, G.D., 2008. Emerging role for AS160/TBC1D4 and TBC1D1 in the regulation of GLUT4 traffic. American journal of physiology. Endocrinology and metabolism, 295(1), pp.E29-37. Available at:

http://ajpendo.physiology.org/content/295/1/E29.long \nhttp://www.ncbi.nlm.nih.g ov/pubmed/18477703\nhttp://www.pubmedcentral.nih.gov/articlerender.fcgi?artid $=$ PMC2493596.

Sakurai, A. et al., 2011. Phosphatidylinositol-4-phosphate 5-kinase and GEP100/Brag2 protein mediate antiangiogenic signaling by semaphorin 3E-plexin-D1 through Arf6 protein. The Journal of biological chemistry, 286(39), pp.34335-45. Available at: http://www.jbc.org/cgi/content/long/286/39/34335 [Accessed May 2, 2015].

Salt, I. et al., 1998. AMP-activated protein kinase: greater AMP dependence, and preferential nuclear localization, of complexes containing the alpha2 isoform. The Biochemical journal, 334 ( Pt 1, pp.177-87. Available at: http://www.pubmedcentral.nih.gov/articlerender.fcgi?artid=1219677\&tool=pmcentr ez\&rendertype=abstract.

Samovski, D. et al., 2012. Insulin and AMPK regulate FA translocase/CD36 plasma membrane recruitment in cardiomyocytes via Rab GAP AS160 and Rab8a Rab GTPase. Journal of lipid research, 53(4), pp.709-717.

Sazanov, L.A., 2015. A giant molecular proton pump: structure and mechanism of respiratory complex I. Nat Rev Mol Cell Biol, 16(6), pp.375-388. Available at: http://dx.doi.org/10.1038/nrm3997.

Schweitzer, J.K. \& D’Souza-Schorey, C., 2002. Localization and activation of the ARF6 GTPase during cleavage furrow ingression and cytokinesis. Journal of Biological Chemistry, 277(30), pp.27210-27216.

Scott, J.W. et al., 2004. CBS domains form energy-sensing modules whose binding of adenosine ligands is disrupted by disease mutations. Journal of Clinical Investigation, 113(2), pp.274-284.

Shattil, S., Kim, C. \& Ginsberg, M., 2010. The final steps of integrin activation: the end game.

Shaw, R.J. et al., 2016. The LKB1 tumor suppressor negatively regulates mTOR signaling. Cancer Cell, 6(1), pp.91-99. Available at: http://dx.doi.org/10.1016/j.ccr.2004.06.007. 
Shaw, R.J. et al., 2004. The tumor suppressor LKB1 kinase directly activates AMP-activated kinase and regulates apoptosis in response to energy stress. Proceedings of the National Academy of Sciences of the United States of America, 101(10), pp.3329-3335.

Shearer, J. et al., 2004. AMP Kinase-Induced Skeletal Muscle Glucose But Not Long-Chain Fatty Acid Uptake Is Dependent on Nitric Oxide. Diabetes, 53(6), pp.1429-1435.

Shearer, J. et al., 2005. Heart-type fatty acid-binding protein reciprocally regulates glucose and fatty acid utilization during exercise. American journal of physiology. Endocrinology and metabolism, 288(2), pp.E292-E297.

Smilenov, L.B. et al., 1999. Focal adhesion motility revealed in stationary fibroblasts. Science (New York, N.Y.), 286(5442), pp.1172-1174.

Steinberg, G.R. et al., 2004. AMP-activated protein kinase is not down-regulated in human skeletal muscle of obese females. Journal of Clinical Endocrinology and Metabolism, 89(9), pp.4575-4580.

Steinberg, G.R. \& Kemp, B.E., 2009. AMPK in Health and Disease. Physiological reviews, 89(3), pp.1025-1078.

Steven, a C. et al., 1983. Mass distributions of coated vesicles isolated from liver and brain: analysis by scanning transmission electron microscopy. The Journal of cell biology, 97(6), pp.1714-23. Available at: http://www.pubmedcentral.nih.gov/articlerender.fcgi?artid=2112720\&tool=pmcentr ez\&rendertype=abstract.

Suter, M. et al., 2006. Dissecting the role of 5'-AMP for allosteric stimulation, activation, and deactivation of AMP-activated protein kinase. Journal of Biological Chemistry, 281(43), pp.32207-32216.

Swiatecka-Urban, A., 2013. Membrane trafficking in podocyte health and disease. Pediatric Nephrology (Berlin, Germany), 28(9), pp.1723-1737. Available at: http://www.ncbi.nlm.nih.gov/pmc/articles/PMC3578983/.

Takatsu, H. et al., 2002. GGA proteins associate with Golgi membranes through interaction between their GGAH domains and ADP-ribosylation factors. Biochem J, 365(Pt 2), pp.369-378. Available at: http://www.ncbi.nlm.nih.gov/pubmed/11950392.

Tanabe, K. et al., 2005. A novel GTPase-activating protein for ARF6 directly interacts with clathrin and regulates clathrin-dependent endocytosis. Molecular biology of the cell, 16(4), pp.1617-28. Available at:

http://www.pubmedcentral.nih.gov/articlerender.fcgi?artid=1073646\&tool=pmcentr ez\&rendertype=abstract.

Tang, W. \& Lee, K., 2015. Inhibitory effects of Berberine on the migratory and invasive abilities of cancer cells. , pp.8-11. 
Tangeman, L., Wyatt, C.N. \& Brown, T.L., 2012. Knockdown of AMP-activated protein kinase alpha 1 and alpha 2 catalytic subunits. Journal of RNAi and gene silencing : an international journal of RNA and gene targeting research, 8, pp.470-8. Available at: http://www.pubmedcentral.nih.gov/articlerender.fcgi?artid=3542724\&tool=pmcentr ez\&rendertype=abstract.

Teckchandani, A. et al., 2009. Quantitative proteomics identifies a Dab2/integrin module regulating cell migration. , 186(1), pp.99-111.

Toker, A., 1998. The synthesis and cellular roles of phosphatidylinositol 4,5-bisphosphate. Current Opinion in Cell Biology, 10(2), pp.254-261.

Traub, L.M., 2009. Tickets to ride: selecting cargo for clathrin-regulated internalization. Nature reviews. Molecular cell biology, 10(9), pp.583-96. Available at: http://www.ncbi.nlm.nih.gov/pubmed/19696796.

Uni, T., 1981. ATP Requirement HeLa for the Processes Cell Nuclei1 of DNA Replication in Isolated The ATP requirement for two steps of DNA replication, the synthesis and subse quent joining of Okazaki fragments, was investigated by using isolated HeLa cell nuclei . Am. , 89(3), pp.801-807.

Urbanska, A. et al., 2011. Biochemical characterization of APPL Endosomes: The role of annexin A2 in APPL membrane recruitment. Traffic, 12(9), pp.1227-1241.

Vincent, E.E. et al., 2014. Differential effects of AMPK agonists on cell growth and metabolism. Oncogene, (January), pp.1-13. Available at: http://www.nature.com/doifinder/10.1038/onc.2014.301 [Accessed March 17, 2015].

Viollet, B. et al., 2006. Activation of AMP-activated protein kinase in the liver: a new strategy for the management of metabolic hepatic disorders. The Journal of physiology, 574(Pt 1), pp.41-53. Available at:

http://www.ncbi.nlm.nih.gov/pubmed/16644802\nhttp://www.pubmedcentral.nih.g ov/articlerender.fcgi?artid=PMC1817784.

Warburg, O., 1956. On the origin of cancer cells. Science (New York, N.Y.), 123(3191), pp.309-314.

Webb, D.J. et al., 2004. FAK-Src signalling through paxillin, ERK and MLCK regulates adhesion disassembly. Nature cell biology, 6(2), pp.154-161.

Woods, A. et al., 2005. Ca2+/calmodulin-dependent protein kinase kinase-beta acts upstream of AMP-activated protein kinase in mammalian cells. Cell metabolism, 2(1), pp.21-33.

Woods, A. et al., 2003. LKB1 Is the Upstream Kinase in the AMP-Activated Protein Kinase Cascade. Current Biology, 13(22), pp.2004-2008. 
Wraith, D.C. \& Chesterton, C.J., 1982. Cell-surface remodelling during mammalian erythropoiesis. Biochem J, 208(1), pp.239-242. Available at: http://www.ncbi.nlm.nih.gov/pubmed/7159394.

Wu, N. et al., 2013. AMPK-Dependent Degradation of TXNIP upon Energy Stress Leads to Enhanced Glucose Uptake via GLUT1. Molecular Cell, 49(6), pp.1167-1175. Available at: http://dx.doi.org/10.1016/j.molcel.2013.01.035.

Xiao, B. et al., 2011. Structure of mammalian AMPK and its regulation by ADP. Nature, 472(7342), pp.230-3. Available at: http://dx.doi.org/10.1038/nature09932.

Xing, Y. et al., 2010. Structure of clathrin coat with bound Hsc70 and auxilin: mechanism of Hsc70-facilitated disassembly. The EMBO journal, 29(3), pp.655-665.

$\mathrm{Xu}, \mathrm{Q}$. et al., 2014. AMPK regulates histone H2B O-GlcNAcylation. Nucleic acids research, 42(9), pp.5594-5604.

Yan, D. et al., 2010. The cell-surface proteins Dally-like and Ihog differentially regulate Hedgehog signaling strength and range during development. Development (Cambridge, England), 137, pp.2033-2044.

Yan, Y. et al., 2015. Augmented AMPK activity inhibits cell migration by phosphorylating the novel substrate Pdlim5. Nature communications, 6, p.6137. Available at: http://www.pubmedcentral.nih.gov/articlerender.fcgi?artid=4317497\&tool=pmcentr ez\&rendertype=abstract [Accessed March 17, 2015].

Yang, J.-S. et al., 2002. ARFGAP1 promotes the formation of COPI vesicles, suggesting function as a component of the coat. The Journal of cell biology, 159(1), pp.69-78.

Yang, Y. et al., 2011. Hunger states switch a flip-flop memory circuit via a synaptic AMPKdependent positive feedback loop. Cell, 146(6), pp.992-1003. Available at: http://dx.doi.org/10.1016/j.cell.2011.07.039.

Yeh, C.J.G., Hsi, B.L. \& Page Faulk, W., 1981. Propidium iodide as a nuclear marker in immunofluorescence. II. Use with cellular identification and viability studies. Journal of Immunological Methods, 43(3), pp.269-275.

Yi, L., Yi, Zhan \& Keen, J.H., 2013. Arf6 Regulation of Gyrating-Clathrin.

Yue, J. et al., 2014. Microtubules regulate focal adhesion dynamics through MAP4K4. Developmental cell, 31(5), pp.572-85. Available at: http://www.cell.com/article/S1534580714006911/fulltext [Accessed May 2, 2015].

Zheng, B. \& Cantley, L.C., 2007. Regulation of epithelial tight junction assembly and disassembly by AMP-activated protein kinase. Proceedings of the National Academy of Sciences of the United States of America, 104(3), pp.819-22. Available at: http://www.pubmedcentral.nih.gov/articlerender.fcgi?artid=1783397\&tool=pmcentr 
ez\&rendertype=abstract.

Zoncu, R. et al., 2009. A phosphoinositide switch controls the maturation and signaling properties of APPL endosomes. Cell, 136(6), pp.1110-1121. 